\title{
Investigation of Relationships among Consumer Perceptions and Brand Preference In Photoshopped and Non-Photoshopped Fashion Advertisements
}

\author{
Kristina A. Smith
}

Follow this and additional works at: https://researchrepository.wvu.edu/etd

\section{Recommended Citation}

Smith, Kristina A., "Investigation of Relationships among Consumer Perceptions and Brand Preference In Photoshopped and Non-Photoshopped Fashion Advertisements" (2016). Graduate Theses, Dissertations, and Problem Reports. 7132.

https://researchrepository.wvu.edu/etd/7132

This Thesis is protected by copyright and/or related rights. It has been brought to you by the The Research Repository @ WVU with permission from the rights-holder(s). You are free to use this Thesis in any way that is permitted by the copyright and related rights legislation that applies to your use. For other uses you must obtain permission from the rights-holder(s) directly, unless additional rights are indicated by a Creative Commons license in the record and/ or on the work itself. This Thesis has been accepted for inclusion in WVU Graduate Theses, Dissertations, and Problem Reports collection by an authorized administrator of The Research Repository @ WVU. For more information, please contact researchrepository@mail.wvu.edu. 
Investigation of Relationships among Consumer Perceptions and Brand Preference In Photoshopped and Non-Photoshopped Fashion Advertisements

Kristina A. Smith

Thesis submitted to the Davis College of Agriculture, Natural Resources and Design at West Virginia University in partial fulfillment of the requirements for the degree of

Master of Science

in

Design and Merchandising

Jung Ha "Jennifer" Yang, Ph. D., Chair

Harry N. Boone, Jr., Ph.D.

Christine Rittenour, Ph.D.

School of Design and Community Development

Morgantown, West Virginia 2016

Keywords: Advertising, Fashion, Digital Alteration, Body Image, Social Comparison Copyright 2016 Kristina Smith 


\begin{abstract}
Investigation of Relationships among Consumer Perceptions and Brand Preference In Photoshopped and Non-Photoshopped Fashion Advertisements
\end{abstract}

\author{
Kristina A. Smith
}

The use of digital alteration software on fashion models in advertising photographs has been used to promote an ideal standard of beauty for women. In an attempt to differentiate the thin ideal, fashion brand Aerie has vowed to not use digital alteration software to alter the physical characteristics of the models in their advertisements, while other companies such as Victoria's Secret continues to utilize digital alteration techniques on their advertisements. This research examined consumer brand preference using Photoshopped Victoria's Secret and nonPhotoshopped Aerie fashion advertisements found from an online source. The purpose of this study was to examine college aged females perceptions of fashion brands Victoria's Secret and Aerie. Through the use of an online survey, this study examined women's brand preference of Victoria's Secret and Aerie based on body image, online visual media literacy, self-esteem, selfcongruence, brand image perception, and image preference. Results indicated that certain dimensions of body image and self-esteem, online visual media literacy, brand image, image preference, and self-congruence each played a key role in determining brand preference. These findings are vital as they can suggest alternative advertising methods for each brand. 


\section{Acknowledgements}

Kristina Smith

I would like to thank the faculty of the Davis College of Agriculture, Natural Resources \& Design. It has been an honor learning from each of you. I would like to thank Dr. Harry Boone and Dr. Christine Rittenour for being on my thesis committee. I would especially like to thank Dr. Jennifer Yang for being the chair of my committee; without your patience, support, motivation, and late night phone calls this thesis would not have happened. I have learned so much from you during this process. Thank you also to Dr. Kerry Odell for advising me through my graduate school experience and for the funding that made this research possible.

A big thank you for my parents for always listening and supporting each of my decisions and for always being a phone call away. Lastly, I would like to thank my husband, David, for inspiring me to start grad school and cheering me on during this process. 
Table of Contents

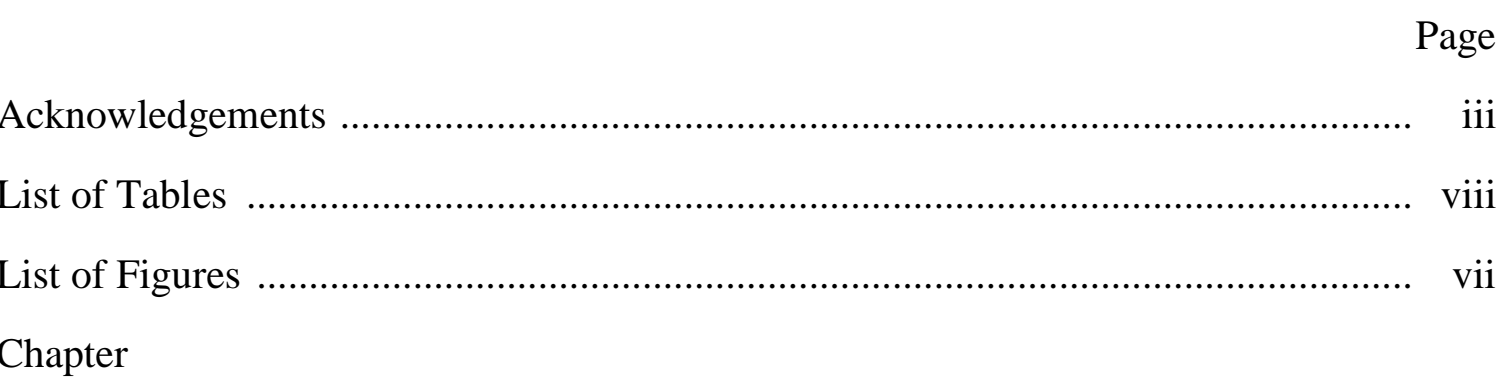

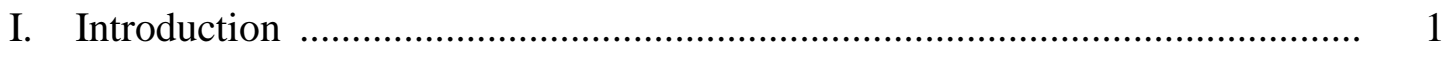

Purpose of the study .......................................................................... 6

Definitions of concepts used in the study ............................................ 8

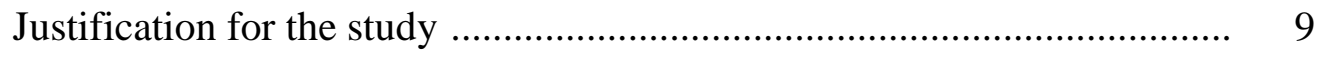

II. Literature Review ............................................................................... 11

Influence of Advertisements on Consumers ..................................... 11

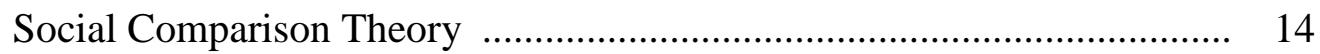

Upward Comparison ............................................................ 15

Self-Motivating/Non-Competitor .......................................... 16

Avoidance ............................................................................ 17

Downward Comparison ......................................................... 18

Body Image ........................................................................... 19

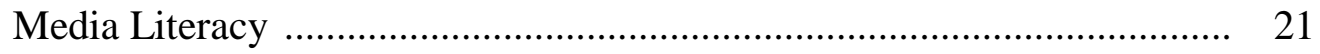

Visual Literacy .......................................................................... 23

Online Visual Media Literacy .......................................................... 25

Brand Image ......................................................................... 26

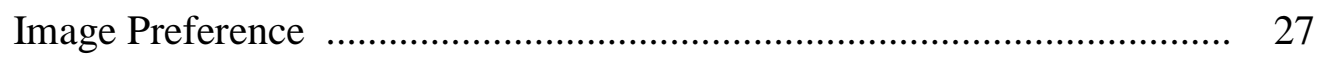

Self-Esteem ......................................................................... 28

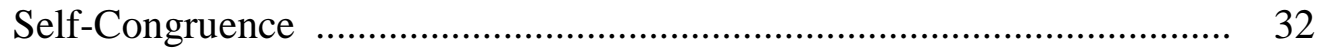

Brand Preference ......................................................................... 33 


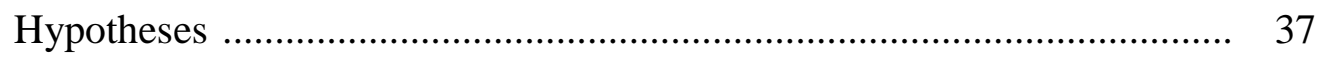

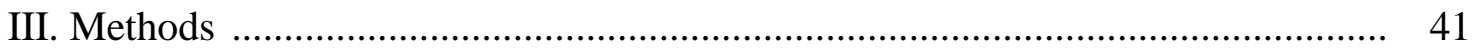

Questionnaire Development ................................................................. 41

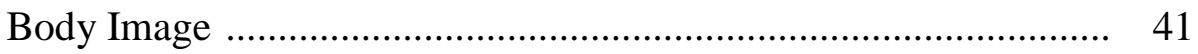

Online Visual Media Literacy ....................................................... 46

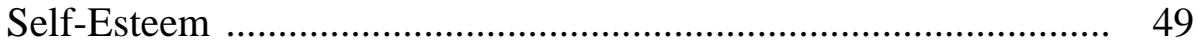

Self-Congruence …………………………………………...... 51

Image Preference ………………………………………....... 53

Brand Image ………………………………………………... 55

Brand Preference ………………………………………....... 58

Data Collection Procedure _........................................................................ 61

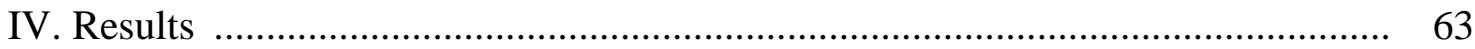

Profile of the Respondents .................................................................... 63

Preliminary Data Analyses ................................................................... 65

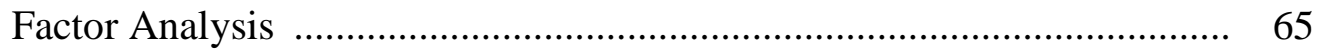

Results of Statistical Analysis to Test Hypotheses .................................. 68

Testing the Proposed Framework ……………………………...... 69

Relationship between Body Image and Self-Respect and Body Image and Self-Worth (Hypothesis 1) ................. 71

Relationship between Online Visual Media Literacy and Self-Respect and Online Visual Media Literacy and Self-Worth (Hypothesis 2) ........................................... 75

Relationship between Victoria's Secret Brand Image and Self-Congruence, and Aerie Brand Image and Self-Congruence (Hypothesis 3) .................................. 78 Relationship between Victoria's Secret Image Preference and Self-Congruence and Aerie Image Preference and Self-Congruence (Hypothesis 4) 
Relationship between Victoria's Secret Brand Preference, Self-Respect and Self-Worth and Aerie Brand Preference, Self-Respect, and Self-Worth (Hypothesis 5) ................... 84

Brand Preference and Self-Congruence and Aerie Brand Preference (Hypothesis 6) .................... 88

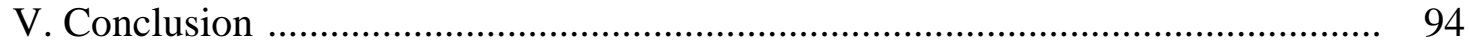

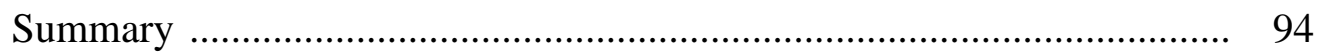

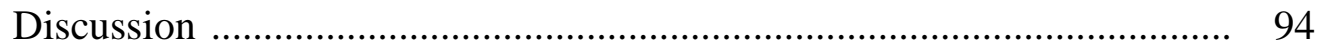

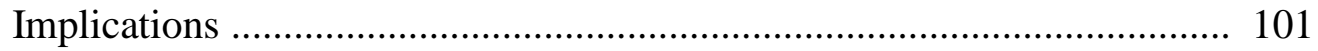

Limitations …........................................................................... 104

Conclusions ............................................................................... 104

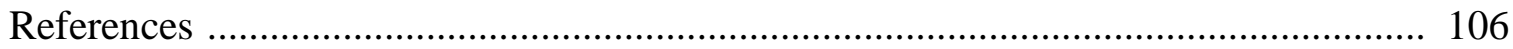

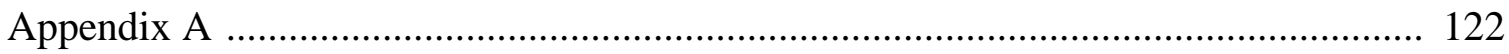

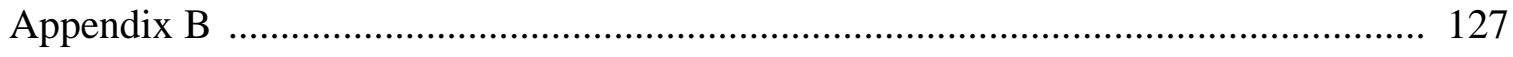




\section{LIST OF TABLES}

Table

Page

3.1. Body Cathexis Scale

3.2 Body-Esteem Scale for Adolescents and Adults

3.3 Perceived Reality of Magazine Images of Women Scale

48

3.4 Rosenberg Self-Esteem Scale 50

3.5 Self-Image Congruence Scale

3.6 Perceived Reality of Magazine Images of Women Scale.

3.7 Fashion Brand Image Scale 56

3.8 Self-Image Congruence Scale for Brand Preference

4.1 Demographic Characteristics of the Survey Respondents

4.2 Cronbach's Alpha of One-Factor Variables

65

4.3 Factor Analysis for Body Image

4.4 Factor Analysis for Self-Esteem

68

4.5 Relationship between Body Image and Self-Respect

72

4.6 Relationship between Body Image and Self-Worth 74

4.7 Relationship between Online Visual Media Literacy and Self-Respect 76 
4.8 Relationship between Online Visual Media Literacy and Self-Worth

4.9 Relationship between Victoria's Secret Brand Image and Self-Congruence .. 79

4.10 Relationship between Aerie Brand Image and Self-Congruence

80

4.11 Relationship between Victoria's Secret Image Preference

and Self-Congruence.

82

4.12 Relationship between Aerie Image Preference and Self-Congruence 83

4.13 Relationship between Self-Respect, Self-Worth, and Victoria's Secret Brand Preference 85

4.14 Relationship between Self-Respect, Self-Worth, and Aerie Brand Preference

4.15 Relationship between Self-Congruence and Victoria's Secret

4.16 Relationship between Self-Congruence and Aerie 90

4.17 Hypothesized Relationships and Summary of Results 91 


\section{LIST OF FIGURES}

Figure Page

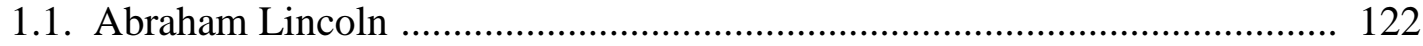

1.2. German Chancellor.................................................................................. 123

1.3. Julia Roberts in Lancôme advertisement....................................................124

1.4. Christy Turlington in Maybelline advertisement ......................................125

1.5. Perfect Body advertisement by Victoria's Secret ........................................126

2.1. Conceptual Framework ..................................................................... 36

4.1. Relationship between Body Image and Self-Respect ............................ 73

4.2. Relationship between Body Image and Self-Worth ............................... 75

4.3. Relationship between Online Visual Media Literacy and Self-Respect ...... 76

4.4. Relationship between Online Visual Media Literacy and Self-Worth ........ 78

4.5. Relationship between Victoria's Secret Brand Image and Self-Congruence 79

4.6. Relationship between Aerie Brand Image and Self-Congruence ................ 81

4.7. Relationship between Victoria's Secret Image Preference and Self- Congruence .............................................................. 82

4.8. Relationship between Aerie Image Preference and Self-Congruence ......... 84

4.9. Relationship between Self-Worth and Victoria's Secret Brand Preference . 86

4.10. Relationship between Self-Worth and Aerie Brand Preference ............... 87

4.11. Relationship between Self-Congruence and

Victoria's Secret Brand Preference .................................................... 89

4.12. Relationship between Self-Congruence and Aerie Brand Preference ........ 90 


\section{Chapter One}

\section{Introduction}

The digital alteration of photographs has been used since the early 1900s. Historic photos have used various techniques, such as the face swapping of John Calhoun and Abraham Lincoln (see Figure 1.1) and the removal of individuals or objects (see Figure 1.2), in the photograph of Willy Brandt and the disappearing beer bottles. These editing techniques using photographic film have evolved over the years and now digital photography has allowed users to manipulate their photographs using computer software. Photoshop, a computer software program created in 1990 by brothers Thomas and John Knoll, has now become a verb (i.e. Photoshopped), synonymous for digitally retouched, altered, enhanced, or manipulated. Often, when audiences are exposed to the term 'Photoshopped,' they may think of advertisements. Photoshop and other digital enhancement software have expansive capabilities. Using the software, photo retouchers are able to distort physical features by increasing or decreasing the size of limbs and by airbrushing the skin, removing veins, freckles, moles, wrinkles, or hair (Odell, 2012). Advertisements within image-driven industries, such as the cosmetic and fashion industry, are especially associated or described as Photoshopped, as they attempt to sell an image of a glamorous lifestyle.

As digital alteration computer software continues to evolve, art directors have become inspired by a heightened reality and are creating images comparable to those achieved through computer-generated effects in movies, presenting models with unattainable elongated and slender physical characteristics (Wilson, 2009). Often, models in fashion advertisements are

digitally manipulated to be longer and leaner. Kahle and Homer (1985) found that consumers 
believe a thinner model to be more attractive than a plus sized model, and therefore, more trustworthy. Consumers have associated plus sized models with negative labels such as less popular, less outgoing, lazy, and less intelligent (Molloy \& Herzberger, 1998; Stephens, Hill, \& Hamon, 1994).

However, according to Poulter (2011) audiences see advertisements and they may be critical, if the photograph appears too unrealistic. For example, in 2011, the Advertising Standards Authority (ASA) banned a Lancôme ad featuring Julia Roberts (see Figure 1.3) and a L'Oreal ad featuring Christy Turlington (see Figure 1.4). The banned ads were claimed by the ASA to be deceptive in nature and promoting unrealistic beauty standards as both women's complexions were airbrushed to smooth finish. In addition to the above-mentioned bans from an authority, consumers have placed negative publicity on companies that excessively promoted unrealistic body images. For example, known for their thin lingerie models otherwise called 'Angels,' a fashion retailer, Victoria's Secret, has also gained public attention as online communities reported the Photoshop mistakes made in their advertisement photos. From reshaping the model's thighs to enlarging the breasts, Victoria's Secret has digitally manipulated the models in their advertisements. In November 2014, Victoria's Secret released its Perfect 'Body' campaign, which featured ten Victoria's Secret models, each with very similar body shapes and sizes (see Figure 1.5). Shoppers were put off by the campaign's title as they believed it enforced a stereotype against body diversity and angered at the company for their dishonesty regarding the digital alteration of the models in the campaign (Bahadur, 2014). The above phenomena are consistent with the findings from previous research. Many consumers felt that the excessive use of digital alteration software to enhance advertisements was misleading and it 
created unrealistic beauty standards (Knobloch-Westerwick \& Romero 2011; Reaves, Hitchon, Park \& Yun, 2004a; Thompson \& Heinberg, 1999).

Counter to the prevalent usage of Photoshop in the fashion industry and considering the uncomfortable reactions exhibited by consumers to these unrepresentative images, in January 2014, American Eagle Outfitters released an original campaign for its lingerie brand, Aerie. The name of the campaign was The Real You with a tagline that read: <Think Real. Get Real. No Supermodels. No Retouching. The Real You Is Sexy.> (American Eagle, 2014). The purpose of the campaign was to challenge beauty standards within the fashion and marketing industries by avoiding any retouching to the models in the campaign. Audiences were pleased to see physical characteristics such as freckles, moles, tattoos, and natural creases on various models whose size ranged from lightweight to the lighter end of plus sized (Broderick, 2014). Along with the tagline that was stamped onto each photo was a note from Aerie that read the following:

\section{DEAR AERIE GIRLS,}

We think it's time for a change. We think it's time to GET REAL and THINK REAL. We want every girl to feel good about who they are and what they look like, inside and out. This means

NO MORE RETOUCHING OUR GIRLS AND NO MORE SUPERMODELS.

Why? Because there is no reason to retouch beauty. We think

THE REAL YOU IS SEXY

Xoxo, 
Aerie

Aerie's senior director of marketing Dana Seguin said,

We're not altering the girls in any way. Nothing is covered up--tattoos, stretch marks, scars, freckles--what you see is what you get. We're not altering their bodies in any way. The product fits them as shown and no alteration to them at all. (Beer, 2014, para 5)

Since Aerie released The Real You campaign, their profits have increased by $6 \%$, or ten million dollars, between 2014 and 2015 (American Eagle, 2015). Other companies are realizing the impact that body positivity through lack of digital alteration can have on consumers. Magazines such as Verily, Seventeen, and Glamour have recently made strong statements due to their change in the Photoshop policies. While each magazine's stance differs ranging from Verily's stance on no Photoshop used whatsoever to Glamour's avoidance of digitally manipulating the appearance of celebrities, and Seventeen's promise not to digitally alter the appearance of real girls used in their articles, each has taken into consideration of what could better fit the desires of their consumers. As photo-editing technology has become more mainstream and accessible, consumers are becoming more aware of the photo editing process and are speaking out against the excessive use of Photoshop in advertisements. The consumers are voicing their opinions and have emphasized a need for change within the fashion industry, thus attracting support from other organizations founded on positive body image, such as the Brave Girls Alliance, Spark Movement, and Beauty Redefined (Brave Girls Alliance, 2014).

In addition to Aerie and Verily, Seventeen, and Glamour pioneering changing the beauty norms in advertising, the online retailer ModCloth became the first retail organization to sign the 
"Heroes Pledge for Advertisers" in August 2014. The pledge promises not to "change the shape, size, proportion, color, and/or remove/enhance physical features" of the models in advertisements post-production (Brave Girls Alliance, 2014). Modcloth Chief Marketing Officer, Nancy Ramamurthi stated: "It's easy for us to sign on to something celebrating real people". She added, "When you see in the public this kind of change in attitude of embracing a company that does what's right, companies will make the shift" (Adamczyk, 2014). Consistent with Ramamurthi's statement, an anonymous Modcloth representative, elaborated on their pledge saying:

We do still use Photoshop, and frequently (all retailers do). Photoshop as a tool is something that helps us keep our images looking sharp. I like to think of our approach as fine-tuning things that the photographers may have missed on the set. Since then, we've continued with our "less is more" approach and correct only minor color issues. We will continue to use Photoshop as a retouching tool, but very conservatively. We don't smooth skin bumps or rolls, and we don't remove natural freckles. We refuse to enhance or diminish bust, thighs, arms or buttocks. We don't do 'airbrushing' with the paint tool, and we avoid over-using the stamp tool. On the other hand, we want the models to look their best! So we do remove blemishes and stray hairs, lighten under-eye circles, and even skin tones or tan lines. We also have to consider copyright issues with some tattoos or do some work to preserve the model's modesty, particularly with sheer products or intimates. At the end of the day, it's the product that's on sale, and we want our models to feel respected while looking realistic. When it comes to our intimates, however, the same goes. You'll see real bodies with curves, you'll see slim bodies with no curves, you'll see bust-lines fit a bra just how it will fit on any other gal out there. We'll continue with the 
philosophy we've always upheld: Show real girls (with real bodies) and the rest falls into place. (E. Seibel, personal communication, November 21, 2014)

Clothing companies such as Aerie and ModCloth are continuing to pay attention to the concerns of their consumers and are choosing to take a stance against photo alteration in order to promote realism in the advertising field. Through the continuous digital and traditional communication, consumers are voicing their thoughts and opinions based on the advertisements they are exposed to. Businesses have the opportunity to listen to the voice of the consumer and create appealing advertisements through their choice to use digital manipulation software less in advertising photos, thus changing the way consumers view advertisements and strengthening their relationship with the brand.

\section{Purposes of the Study}

As mentioned in the previous section, there is a discrepancy between consumers' reactions to Photoshopped images. Previous studies have found consumers' preference for thin models in advertisements (Kahle \& Homer, 1985). However, there were reports of consumers' negative reactions to Photoshopped images of models in advertisements. Provided that Photoshop technology is commonly used in the fashion industry, it is important to understand consumer perceptions of fashion advertisements because it will play a crucial role in brand image and brand relationships with the customers.

Previous literature has investigated consumer perceptions of digitally altered fashion advertisements in magazines (Posavac, Posavac, \& Posavac, 1998; Romero, 2011; Shelden, 2010; Thompson \& Heinberg, 1999; Yu, 2014; Wasilenko, Kulik, \& Wanic, 2007). One of the most distinguished common findings of the above studies was that participants make appearance comparisons between the models in the advertisements and themselves. When participants were 
informed of the digital alteration procedures performed on each advertising image, their selfesteem was enhanced knowing that the comparisons made were unrealistic. Considering the above common results, the current research analyzes consumer perceptions of online fashion advertisements.

Investigating consumer opinions on digital alteration would be meaningful in an online advertisement context, because consumers are spending more time online than using magazines and are, therefore, exposed to more online advertisements. For example, online spending for consumer products during the holidays has increased by $13 \%$ during the past two years (Comscore, 2015). Examining the use of magazines and advertising in today's culture may be seen as less current as Rideout, Foehr, and Roberts (2010) reported that print media is consumed an average of 38 minutes a day, compared to internet usage averaging to 6.09 hours a day (Mander, 2012).

This study examines the differences in consumer perceptions on online fashion advertisements of two competing brands. Previous research (Bissell 2004; Bissell 2006; Reaves, Bush-Hitchon, Park, \& Yun, 2004a; Reaves, Bush-Hitchon, Park, \& Yun, 2004b; Reaves, 2011) examined consumer's preference between manipulated fashion advertising images, but not competing brands where one brand uses digital enhancement and the other does not.

Expanding off of the previous literature, the research questions for this study are as follows:

- $\mathrm{RQ}_{1}$ : How do consumers' perceptions of themselves play a role in evaluating the images used in online fashion advertisements? 
- $\mathrm{RQ}_{2}$ : What are consumer perceptions of Photoshopped and non-Photoshopped images used in online fashion advertisements?

- $\mathrm{RQ}_{3}$ : How do consumer characteristics affect brand preference in the context of online fashion advertisements?

The purpose of this research is to examine how consumer traits such as body image, selfesteem, self-congruence, online visual media literacy, brand image, and image preference play a role in determining brand preference between two competing brands. One brand's advertisements do not use digital alteration software to change the physical traits of their models, while the other brand does use digital enhancement within its advertisements.

Using the following operational definitions, this study investigated Photoshopped advertising images versus the lack thereof in order to predict consumers' brand preference.

\section{Definitions of concepts used in the study.}

- Body Image: The mental picture we have in our minds of the size, shape and form of our bodies and our feelings concerning these characteristics and one's body parts (Greene, 2011)

- Online Visual Media Literacy: The knowledge of digital manipulation of a fashion advertising photograph and the ability to analyze the media's usage in an online environment (Bissel, 2006; Buckingham, 2003).

- Self-Esteem: “A favorable or unfavorable attitude toward the self” (Rosenberg 1965, p. 15).

- Self-congruence: The match/mismatch between the brand user image and the consumer actual self-image, ideal self-image, social self-image, and/or ideal social self-image (Johar \& Sirgy 1991). 
- Brand Image: Consumers' perception of a brand (Keller, 1993).

- Image Preference: A greater liking for one image over another (Oxford Dictionaries, n.d.).

- Brand Preference: "The extent to which a customer favors particular offering in relation to an offering by another provider" (Hellier, Geursen, Carr, \& Rickard, 2003, p. 1765).

\section{Justification for the Study}

The subject of body image and self-esteem play a significant role in determining ethical advertising (Tsai, 2013) as women often compare themselves to the models shown in advertisements (Festinger, 1954). While many studies (Botta, 1999; Henderson-King \& Henderson-King, 1997; Myers \& Biocca, 1992; Yu, 2014) examined the roles of traditional advertisements and women's body image perceptions, there are limited studies focusing on digital and social media marketing campaigns. For example, despite previous study results indicating the correlation of viewing fashion advertisements in magazines and negative body image (Posavac, Posavac, \& Posavac, 1998; Shelden, 2010; Thompson \& Heinberg, 1999; Yu, 2014), there is a gap in the current literature addressing digital advertisements. Consumers are accessing digital advertisements in a similar manner in which they would access a traditional print advertisement in a fashion magazine. A consumer may visit a website where they are exposed to a digital advertisement in the form of a banner, side panel, or a pop-up window within the web browser, as well as subscribe to a fashion magazine. Previous studies have shown the significance of how digitally altering an advertisement can mislead consumers about the advertised product leading to decreased levels of self-esteem and body image (Bissell, 2004; Coleman, 2008; Knobloch-Westerwick \& Romero, 2011). 
To combat self-esteem issues brought on by media influences, media literacy and visual literacy programs strive to educate audiences about the messages the media portrays. These messages may be sexual in nature or promote unhealthy body image (Lin, 2008). Understanding the media's messages is important so audiences understand the purpose of the advertisement and how the message is enforced. When consumers possess visual media literacy, the comparisons they may make between themselves and a model in the advertisement will be less harmful to their self-esteem (Bissell, 2004). As self-esteem plays an integral role in the relationship consumers share with a brand (Malär, Krohmer, Hoyer, \& Nyffenegger, 2011).

Based on the current phenomenon and related previous studies mentioned above, this study aims to explore brand preference in relation to various consumer characteristics, in the domain of online fashion advertisements. The current study may fill the gaps in the literature by addressing the importance of examining online visual media literacy while analyzing the level of body image satisfaction to predict self-esteem, and furthermore, self-congruence, brand image, and brand preference. 


\section{Chapter Two}

\section{Literature Review}

The following section includes the literature review of the concepts introduced in the previous chapter and the theory adopted for the study. The literature review addresses the factors of digital marketing, body image, and social comparison.

\section{Influence of Advertisements on Consumers}

According to Media Dynamics Incorporated (2014), a typical adult has potential daily exposure to about 360 advertisements in any form. Two hundred and seventy-two of these exposures come from the major traditional media (e.g., TV, radio, magazines, and newspapers). While traditional media continues to play a large role in advertising, newer technological advancements of the Internet and immersion of mobile devices have allowed for advertising techniques to expand. With the increase of Internet speed and wireless Internet locations, more people are connecting to the Internet (Mander, 2012). In a study conducted by Global Web Index (Mander, 2012), it was found that globally, Internet users now spend a daily average of 6.09 hours - up from 5.5 hours in 2012 - on online media and that $30 \%$ of the time spent on online media is accessed from a mobile device - a rise from $22 \%$ in 2012 . These numbers are even higher for female consumers, with eight hours and 37 minutes on the PC and nine hours and 43 minutes on a mobile device while print media is much less consumed averaging out to 38 minutes a day, including only three minutes with a newspaper (Rideout et al., 2010). As technology advances, marketers are searching for creative ways to reach out to consumers and with the common use of the Internet, marketers have found a way to stay in 
touch with broad audience for their marketing communications. While the tracking of daily advertisement exposure through traditional media is essential to determine effectiveness, marketers are aware of an increase in the popularity of social networking sites (e.g., Facebook, Pinterest, Instagram), opening up an entire new industry: digital marketing.

Wertime and Fenwick (2008) defined digital marketing as "the future evolution of marketing that happens when the majority, or totality, of a company's marketing uses digital channels" (p. 30). The Global Web Index estimated that Internet users spend 28\% of their time online using social networking sites, which equates to about 1.69 hours per day. Globally, Internet users now spend a daily average of 6.09 hours on online media, up from 5.55 hours in 2012 (Mander, 2012). Based on the above findings, the amount of time consumers spend with media is on its increase. Subsequently, this increased usage of media can lead to frequent exposures to advertisements (Elmore, 2013). The more ads consumers view, the more accepting they become of the repetitive enforced message. Elmore (2013) has found that repeated exposure to an advertising campaign increased the likelihood of changing consumer awareness and attitudes towards a brand. These repetitive messages have allowed for studies to illustrate that seeing these altered images can affect the brain in determining acceptance and attractiveness of the image in the advertisement.

The ideal body is often projected in today's media and with the increase of ad exposures, many females feel a pressure to strive toward the media photos (Stephen \& Perera, 2014). A content analysis of 10 women's magazines by Wasylkiw, Emms, Meuse, and Poirier (2009) showed that $95 \%$ of the models in fashion magazines were lean; in fitness magazines, $55 \%$ were lean and $36 \%$ were muscular - only $6 \%$ of the models in both magazine types had a soft and 
round body type. Viewing these repetitive messages in the media has given women a clear definition of beauty standards from Western culture.

Beauty standards today are forming at a more rapid rate. Rather than taking long amounts of time to formulate a beauty preference, women's perceptions of attractiveness changed depending on their exposure type after only sixty seconds of exposure to photos of either lightweight or plus-size models (Stephen \& Perera, 2014). In Stephen and Perera's study (2014), when a group of men and women examined a series of five pictures of the same female model whose body had been digitally altered to five degrees of heaviness or thinness, each group was asked to pick the most attractive of the five after being primed with a specific category of photos. When viewing the highly attractive lightweight models, female participants rated images with an average Body Mass Index (BMI) of slightly less than 17 as most attractive. Those who viewed the attractive plus-sized models, leaned toward a BMI of 18.5 as most attractive. These results show that viewing the light weight models may have greater impact than plus size models and may influence women's judgments to a greater extent as they internalize media's message of the ideal body more strongly.

Additional factors besides BMI that may distinguish beauty standards include facial characteristics, ethnicity, and body shape. Though the Stephen and Perera's study (2014) examined body image perception among Asian females, Powell and Kahn (1995) found that African-American women have less of a desire for a thin body shape than Caucasian women and identify heavier body shapes as ideal. This idea illustrates that female consumers each have their own idea of beauty standards, whether the standards are set by culture, upbringing, media exposure, or other unexplored factors. Powell and Kahn (1995) postulated that the key difference in the body image between African-American and Caucasian women is that Caucasian 
women have experienced greater social pressure to be thin compared to the experiences of African-American women. They also indicated that African American women were able to ignore the predominantly Caucasian media message that thinness is essential for a successful life. Supporting the results from Powell and Kahn's study, Grogan (1999) determined that body image dissatisfaction is the highest among American Caucasian women and less frequent with other groups, including Asians, Hispanics and African-Americans. In order to explain why Caucasian women are most affected by the thin ideal, Orbach (1993) and Grogan (1999) suggested that the promotion of femininity is more common with Caucasian women than it is with women of other ethnicities, relating the drive for thinness to cultural traditions and upbringing. Therefore, consumers from different ethnic background (e.g., Caucasian, African American, Asian, Hispanic) exhibited various opinions on body image. While previous studies focus on explaining the respondents' thoughts, feelings, and beliefs (Powell \& Kahn, 1995; Orbach, 1993; Grogan, 1999; Tsai, 2013, Thomspon \& Heinberg, 1999; Richins, 1991; Myers \& Biocca, 1992; Cash, Cash \& Butters, 1983), consumers' reactions to advertisement images presumed that they compare themselves with the image in the advertisement. This presumption leads to the adoption of Social Comparison Theory. The following section explains the Social Comparison Theory which is adopted as the theoretical background of the current study.

\section{Social Comparison Theory}

The Social Comparison Theory was developed to aid in understanding how and why individuals evaluate themselves against others (Festinger, 1954). James (1890), Cooley (1902), and Mead (1934) argued that people's self-concept is dependent on how others view and react to them. The Social Comparison Theory further suggests that people make automatic comparisons 
as a result of seeing these images without even self-recognizing the act of comparison. Wills (1981) suggested that people utilize social comparison either for self-evaluation or self- enhancement.

Several studies reported that the individuals who were dissatisfied with their body were more likely to engage in social comparisons with ideal body images, which induced further negative consequences on self-perceptions (Bessenoff, 2006; Trampe, Stapel, \& Siero, 2007). In most advertisements, the goal is to seduce consumers with idealized versions of life (Tsai, 2013). The process in which consumers compare their lives to the more glamorous ideas illustrated in advertisements is known as upward comparison (Bissell, 2006). Often, consumers' comparison with advertising images is that of an upward comparison, resulting in inferior evaluations of their own self-worth. As women read a fashion magazine, they compare their looks to the appearances of models in editorial content and in advertisements. When they perceive a discrepancy between the two, they desire to narrow the gap between their own image and the idealized ones of the models (Bissell, 2004). As such, Social Comparison Theory further explains this consumer behavior of comparing oneself with others portrayed in various advertisements.

Social comparisons can be divided into either an upward comparison or a downward comparison. Studying each form of social comparison (i.e., upward, downward) and the possible reaction of upward social comparison (i.e., self-motivating, and avoidance) can be advantageous in determining appropriateness of advertising and segmenting a specific type of consumer. The following is the detailed explanation of the dimensions included in the theory.

Upward comparison. Since the nature of digitally-altered advertisements focuses on fantasy, upward social comparisons are considered to be common in image-driven advertisements. An upward comparison occurs when models in an advertisement are viewed 
as superior in comparison to the readers. Major, Testa, and Bylsma (1991) have found that when upward social comparisons are made, the later effects are often associated with increases in emotional upset and decreases in self-esteem. Upward social comparisons are generally regarded as ego-deflating, yet people often compare themselves with those whose abilities and attributes are better than their own (Collins, 1996). Heinberg and Thompson (1992) demonstrated an example of upward social comparison by surveying 189 female undergraduate students. They found that celebrity comparisons were significantly linked to increased body dissatisfaction, increased drive for thinness, and increased bulimic behaviors. Similar to Heinberg and Thompson's findings, Dittmar and Howard (2004) examined the relation of women's internalization of the thin ideal and their tendency to make upward social comparisons with media models. They found that $75 \%$ of women exhibited one of two combinations: 1) low levels of social comparison with high thinness internalization or 2) high comparison rates with low levels of thinness internalization. Both studies illustrate that comparisons to idealized media images raises comparison standards for attractiveness and lowers satisfaction with one's own attractiveness (Richins, 1991).

Collins (1996) found that upward comparison only sometimes results in more negative self-evaluations and that it can also be self-enhancing, thus, people may make upward comparisons in hopes of enhancing their self-assessments.

Self-motivating/non-competitor. Knobloch-Westerwick and Romero (2011) stated that an individual who was satisfied with his or her body shape may still view an advertising model's body shape as more attractive, resulting in upward comparison. Previous research (Collins, 1996; Mazur, 1986; Stapel \& Siero, 2007; Wills, 1981) exhibited that when a subject uses selfevaluation when comparing their body image against the idealized beauty models, lowered body 
image and self-esteem were likely to occur. However, if the target of the comparison is seen as a non-competitor, an upward comparison driven by self-improvement was likely to be inspiring, rather than threatening to one's self-perception. Research by Knobloch-Westerwick and Romero (2011) shows that upward comparisons are more likely to be sought out if the performance seems attainable and the social comparisons are likely to inspire self-improvement. The authors found that after exposing male and female participants to 20 advertisement images and 20 magazine articles on fitness, the female and male magazine readers who were satisfied with their body shape showed no significant impact of editorial context on exposure to ideal body imagery ads. In a study by Richins (1991), it was gathered that when a participant considered a model's appearance was attainable and when the dissatisfactory body part of their choice was viewed as something to be easily improved upon participants expressed optimism and their selfimage was not negatively affected by the comparison of themselves and the model. Similarly, Myers and Biocca (1992), documented that after female college students viewed ads with models of ideal body size, they were motivated by self-improvement because the subjects felt thinner and more attractive than they normally did. This resulted in feelings of self-esteem that are likely to be temporarily enhanced in anticipation of a better future self. In order to protect one's selfesteem, they may demonstrate avoidance to the factor believed to cause stress.

Avoidance. In an attempt to avoid the degradation of one's self-esteem, consumers may disregard the media image by labeling the models as irrelevant, artificial, or unhealthy, and thus, undesirable (Tsai, 2013). To reassert a positive sense of self, the comparers may render the comparison target inappropriate as an object of comparison to reassert a positive sense of self. Wasilenko, Kulik, and Wanic (2007) studied avoidance of social comparison using a naturalistic setting. Females were monitored as they exercised at a facility. When a fit female 
was present, other females who considered themselves to be less fit cut their exercise time short in order to avoid seeing the fit female and avoid an upward comparison of themselves and the fit subject. Similarly, when an unfit subject entered the facility, the respondents exercised for a longer duration because they did not feel threatened. Research by Knobloch-Westerwick and Romero (2011) indicated that when exposed to magazine advertisements and articles, individuals dissatisfied with their body shape allotted less time for exposure of ads displaying an ideal body shape image topics compared to readers who were satisfied with their bodies. The authors proposed that with the use of models with average size body types or displays of regular individuals, avoidance could be lessened for media users who wish to avoid ideal body imagery.

Individuals who consider their appearance to be ideal may compare their own body to a subject they deem unattractive, thus creating a downward comparison (Knobloch-Westerwick \& Romero, 2011). A downward comparison would involve comparing oneself with those who are inferior on certain dimensions of evaluation, such as physical appearance.

Downward Comparison. The theory of downward comparison posits that a person experiencing negative beliefs about themselves can enhance their well-being by comparing themselves to someone they deem less fortunate (Wills, 1981). Downward comparison theory addresses scenarios where obstruction or hardship has been a hindrance to an individual. The individual may believe that in order to cope with their current situation, they can boost their selfesteem by comparing themselves to a less fortunate other (Wills, 1981). Crocker and Schwartz (1985) found that individuals high in self-esteem were more likely to make self-enhancing downward comparisons than those with low self-esteem. They argued that individuals with high self-esteem had positive self-concepts because they engaged in self-enhancing strategies 
(e.g.change in hair style, use of makeup, exercising). Downward comparison can occur during these self-enhancing life choices. For example, while one is exercising in a group, they may boost their own self-esteem by comparing themselves to someone who they deem as less physically fit. In some cases, a downward comparison can arise by actively causing harm to another person, thus putting them in the less fortunate position (Wills, 1981).

The above review of literature related to the Social Comparison Theory provides a theoretical connection among consumer characteristics such as body image, online media visual literacy, brand image, image preference, self-esteem, self-congruence, and brand preference. The following sections provide a review of literature for the above-listed concepts explored in this study.

\section{Body Image}

Body image is defined as "the mental picture we have in our minds of the size, shape and form of our bodies and our feelings concerning these characteristics and one's body parts" (Green, 2011, p. vii). According to Cash and Pruzinsky (2002), body image is not a stable trait, but is also a variable state influenced by contextual events such as upbringing, socialization, culture, and exposure to media images and messages. Posavac, Posavac, and Posavac (1998) suggested that women with low body satisfaction were more vulnerable to effects from ideal body images than those with higher body satisfaction. Mendelson, Mendelson, and White (2001) substantiated that an individuals' feelings about body image can be different for the following segments: weight, general appearance, and comparisons to other's physical traits. With these factors in mind, Mendelson et al. created a scale that consisted of three categories: general feelings about appearance, weight satisfaction and evaluations attributed to others about one's body and appearance. These were constructed in order to measure the body-esteem of adolescents and adults. Using this scale as a questionnaire to 1,344 participants, they found a 
strong connection between global self-esteem and the three categories previously mentioned.

These results indicate that there are several components that influence an individual's body image.

Some previous quantitative studies have linked significant associations between exposure to thin female images in magazines and on television, and certain phenomena such as disordered eating, drive for thinness, and body dissatisfaction (Botta, 1999; Harrison \& Cantor, 1997; Seock \& Merritt, 2013). In a Fijian longitudinal study, the impact of Western ideals of beauty was measured in a three-year period through the introduction of television. After the three years of being exposed to U.S. television programs, $15 \%$ of the teenage female participants developed bulimia (Orbach, 2002). Alternatively, Henderson-King and Henderson-King (1997) found that when women were exposed to media images, those who matched the thin ideal media image had a more positive body image than those who were not close to the thin ideal body image.

The term, body cathexis, is often interchangeable with body satisfaction, and it is defined as the "degree of satisfaction or dissatisfaction with various parts or processes of the body" (Secord \& Jourard, 1953, p. 343). Yu and Damhorst (2015) found that levels of body cathexis shape consumers' enjoyment of an online shopping experience, such as examining an item with a 360 degree tool, zooming in and out, virtually trying the product on, and reading product content information, leading to individual differences in online apparel shopping behaviors. Participants with higher body satisfaction tended to perceive more enjoyment of the virtual product experience in online apparel shopping, which helped them to facilitate more positive attitude toward products and increase online purchase intention. The findings of Park, Nam, Choi, Lee, and Lee (2009) complemented Yu and Damhorst's results, acknowledging that female consumers with slim bodies were likely to show higher body cathexes and, consequently, had 
higher fashion-oriented attitudes in shopping. When surveying two groups of women - those with slim bodies and the others with larger bodies, they found that the females with slim bodies were more interested in the fun aspect of Internet shopping instead of the convenience aspect, whereas those with larger bodies were more concerned with the convenience of Internet shopping. Also within the context of body image and apparel shopping, Shin and Baytar (2013; 2014) investigated whether the bodies of female models displayed on a fashion retail website influence female consumers' level of body satisfaction and found that females were concerned with the fit of the garment if it was displayed on a model that did not match their own size.

The above studies demonstrate the importance of how levels of body image can influence consumer shopping behavior. The following section deals with media literacy and visual literacy, leading to online visual media literacy, which is another consumer characteristic that may affect consumer perceptions on images used in online fashion advertisements.

\section{Media Literacy}

Buckingham (2003) defined media literacy as "the knowledge, skills, and competencies required in order to use and interpret media" (p. 36). Pérez Tornero, and Varis (2010) explained that media literacy concerns all media, including television, film, radio, and recorded music, the press, the Internet, and any other digital communication technology. Irving and Berel (2001) stated that media literacy promotes adaptive behavior by teaching individuals to evaluate media critically and, consequently, to reduce the credibility and persuasive influence of media messages. As today's individuals are met with images and sounds from various media, having the ability to analyze and interpret those messages portrayed by the media plays a central role in the current visual culture. The process of assimilating and using the codes involved in the

contemporary media were broken down into three steps: (a) access, (b) analyze, and (c) evaluate 
(Pérez Tornero \& Varis, 2010). Each of the three components fostered the development of awareness, critical thinking and ability to solve problems. Once an individual completes the three step process, Pérez Tornero and Varis stated that they would then be faced with another three factors, in which the individual may choose to take action: (a) create, (b) communicate, and (c) share information. These processes illustrated that an individual's mind would go through these steps at varying rates of speed with the potential to leave powerful impressions. Depending on the impression left, the individual may choose to share the impression of information in their own manner, thus informing others of the message and exemplifying the urgency of media literacy

Previous literature analyzed the effect media education had on children (Austin \& Johnson, 1997; Voojis \& Van der Voort, 1993). These authors reported that through media literacy programs, children's' positive intentions of alcohol use (Austin \& Johnson, 1997) and acceptance of television violence were reduced (Voojis \& Van der Voort, 1993). Wade, Davidson, and O'Dea (2003) compared the effectiveness of self-esteem training and media literacy education using eighth-grade boys and girls as participants. The participants were administered one of three conditions (i.e., self-esteem training, media literacy education, and control group) and measured three times during a three-month period. Students that participated in the media literacy education group displayed a lower level of concern for body weight compared to the students in the other two groups (i.e., self-esteem training group and control group). Tirlea, Truby, and Haines (2013) devised a program that promoted an active lifestyle, healthy eating habits and media literacy for girls in elementary and middle schools. After participating in the ten week program, both sets of girls demonstrated increased levels of selfesteem. Besides children, women were in need of media literacy education regarding media that 
promotes thinness and dieting to lose weight. Irving and Berel (2001) examined the effectiveness of two different styles of media literacy intervention programs on female college student aged participants. The first program was an externally-oriented intervention that focused on critical thinking and taking action to challenge unhealthy media messages. The second was an internally-oriented intervention which taught women to challenge negative bodyrelated cognitions that arise in response to media. To compare each program's level of effectiveness, a control group which was not given any media education was also examined. The authors found that the two media literacy interventions could promote media skepticism and reduce negative body image among the study participants and concluded that both the external and internal orientation are similar in effectiveness at increasing skepticism about media images that depict a thin ideal of beauty. Choma, Foster, and Radford (2007) also investigated media literacy among female adults. After showing Slim Hopes, a media literacy based film, the participants had higher levels of self-esteem and a better understanding of media

messages. These findings indicate that media education that increases media literacy can make a positive difference in the minds of females and the media's messages. As such, media literacy has established critical thinking about the media's portrayal of women and its messages. To further analyze the media, one must learn of the behind the scenes steps on how the visual images in media are created, thus possessing a certain level of visual literacy.

\section{Visual Literacy}

Based on Bissell (2006), visual literacy is defined as "knowledge of digital manipulation of a fashion photograph" (p.4). In order to assess the visual literacy, Bissell studied female respondents' knowledge of digital manipulation, upon exposure to a fashion and fitness model. Bissell demonstrated that when women were exposed to fashion advertisements that 
included the statement "The image below has been digitally manipulated to enhance the model's appearance" (p. 10), the respondents were informed of the fact that the model's image had been enhanced and manipulated by means of body warping and correcting skin tone, and thus, had less of a desire to look like that model and expressed a more positive personal body image. This finding suggested that if women are educated about how unrealistic some media images actually are, they can distinguish between what is real and what is not, leading them to be more critical when receiving advertisement messages. Bissell $(2004,2006)$ demonstrated that when women become exposed to a media image, most women were uneducated about the photo editing process. In order to educate women of the photo editing process, Reaves (2004a, 2004b) exposed subjects to a before and after digitally altered advertisement, and found that the participants were able to point out the differences and did not agree with the changes made by the photo retouchers. When shown the original, unretouched image and the final digitally-altered image, participants were able to see the changes that had been made to the original photo. Though Reaves' studies illustrate the effect of seeing both the original and finished advertising image, a typical consumer is only exposed to the final edited advertisement. Without seeing the original photo, the consumer may be unaware of the changes made to the original photo. To support the idea of lack of education regarding media images, a survey conducted by One Poll (2013), asked women in the United Kingdom various questions on their knowledge of photo editing and advertising. The results showed that $15 \%$ of the $18-24$ year old women believed that the images of celebrities and models they see in magazines accurately reflected what the models looked like in reality.

In order to educate women about the photo editing process, it must be emphasized that Adobe Photoshop has many capabilities and can transform an ordinary photo into something 
of fantasy. Professional photo retouchers can distort the model's body by slimming down a waist or making legs thinner. The model's skin can be airbrushed removing veins, freckles, moles, and bags under the eyes. Body hair is removed, wrinkles subdued, teeth whitened, and kneecaps and hands are smoothed (Odell, 2012). When a photo is heavily edited for an advertisement using the capabilities listed above, the original photo loses much of its authenticity by erasing several physical traits. These editing capabilities affected women's body image perception because women were comparing themselves to the altered photograph (Bissell, 2002). Bissell's findings (2004) support that of Wade, Davidson, \& O'Dea (2003), exhibiting that children's and women's levels of media literacy and visual literacy played a significant role in determining their levels of body satisfaction. Females with lower levels of visual literacy made greater comparisons of themselves and the models in fashion advertisements. In order to more precisely study media education and visual literacy in a digital field, the term "online visual media literacy" is defined in the following section.

\section{Online Visual Media Literacy}

Online visual media literacy is defined for this study, as the knowledge of digital manipulation of a fashion advertising photograph and the ability to analyze the media's usage in an online environment (Bissel, 2006; Buckingham, 2003). This definition was created based on the definitions of visual literacy and media literacy that were discussed in earlier sections. Both visual literacy and media literacy emphasize the importance of informing consumers of the meaning behind the messages and how the media portrays them using digital manipulation software. Previous literature has used media literacy and visual literacy to test consumers' knowledge of media messages mainly focusing on television (Bissell, 2004; Botta, 1999, 2000; Collins, 1996) and magazines (Coleman, 2008; Cusumano \& Thompson, 1997; Thompson 
\& Heinberg, 1999). As exposure to online media have increased, (Rideout et al., 2010), it is important to understand the meanings of the photos in an online setting as well as other traditional media. By combining informative and instructional elements from visual literacy and media literacy, other factors such as body satisfaction and self-esteem may be better predicted and manipulated. The topics of self-esteem and body image are crucial for this study because previous research has illustrated how the media plays a significant role in negatively affecting both (Bissell, 2006; Botta, 1999 \& 2000; Coleman, 2008; Grogan, 1999; Mazur, 1986).

\section{Brand Image}

Brand image is defined as consumers' perception of a brand (Keller, 1993). Having a distinct brand image is important so that consumers can differentiate products and services from competing brands (Keller, 1998). Sirgy (1986) stated that the greater the match of the brand image, the more positive attitude the consumer would have toward the brand, and vice versa. According to Park et al. (1986), brand image has two dimensions: functional and symbolic. A brand using a functional approach emphasizes the physical aspects of the product and its practical uses which reflect its functional performance. Park, Jaworski, and MacInnis (1986) suggested that the functional image was designed to solve externally-generated consumption needs. Compared to the functional image, symbolic brand image is a more abstract concept as it was used toward creating self-expression and generating prestige for status appeal.

Cho, Fiore and Russell (2015) found through interviews that consumers liked a fashion brand because the brand maintained positive cognitive, sensory, and affective associations. They concluded that subscale elements from Roberts (2005) of mystery, sensuality, and intimacy may directly influence consumers' perceived value, approval, willingness to pay an increased price, recommendation of the brand, and patronage intentions. Kang and Park-Poaps (2011) uncovered 
that, by means of social comparison, when undergraduate students treated shopping as a social activity, they were influenced by their peers as to what brands to buy. These findings indicate that social shopping for fashion are linked to product satisfaction and experience satisfaction.

\section{Image Preference}

In this study, the definition of image preference has been modified from the Oxford dictionary's definition of the term "preference" to be "a greater liking for one image over another" (Oxford Dictionaries, n.d.). The importance of dissecting advertising image preference of a consumer is justified by Mehrabian (1971), as he proposed that, through the immediacy principle, individuals are attracted to other people and things they like, evaluate highly, and prefer. Alternately, people will distance themselves from persons or things they dislike, evaluate negatively, and do not prefer. For instance, Ford, LaTour, and Lundstrom (1991) found that among females, those younger respondents with a higher level of education possessing feminist beliefs are more critical of ad images, and said that they would not buy or would stop buying products related to an offensive ad campaign that showed an inappropriate portrayal of female roles.

Previous research have presented that there are various outlooks about beauty standards focusing on age, race, and facial proportion (Cunningham, Roberts, Barbee, \& Druen, 1995). According to the Source-Valence Model (McGuire, 1985), a consumer assesses a model featured in advertising images based off of familiarity, likeability, similarity, and attractiveness (Ohanian, 1990). Kretz (2011) found that when female college students believed that the models in fashion advertisements were portrayed as relatable women, they identified with the models and held positive attributes toward the brand. Supporting these conclusions, Yu (2014) investigated females' preference for fashion advertising images by showing participants one of two ads. 
Though both ads were the same regarding product and setting, one advertisement featured a digitally altered model wearing size ten to represent a realistic size. The other advertisement featured the same model, digitally altered to be a size zero representing the thin ideal. Yu found that participants exposed to thinner of the two models in the fashion ads showed greater body dissatisfaction and lower positive attitude toward the ads than those participants exposed to average sized models. These findings validate previous studies that support a more positive or favorable advertising effectiveness of realistic or average-sized model images in physical attractiveness and/or body size

However, the findings of Kretz (2011), Ohanian (1990), and Yu (2014) support a fine line between a model representing an average size (size ten) versus a plus size model (size sixteen and up). Kahle and Homer (1985) uncovered an association between attractiveness and source credibility, leading to the conclusion that a thin model is more likely to be a credible source than a plus-size model, because consumers believe her to be more attractive. Kahle and Homer (1985) concluded the reasoning behind the consumers' preference toward thin models was that the models deemed attractive were better liked, thus creating a positive impact on the attitude toward the brand. Women labeled as "overweight" have been associated with negative labels such as less popular, less outgoing, lazy, and less intelligent (Molloy \& Herzberger, 1998; Stephens, Hill, \& Hamon, 1994). Similarly, Joseph (1982) and Simon, Berkowitz, and Moyer (1970) supported that thin women were perceived to be selected more frequently for job hires, friendship, and as a romantic interest.

\section{Self-Esteem}

Self-esteem can be defined in various ways due to its complex nature. Perhaps most widely used, Rosenberg's self-esteem definition is (1965) a favorable or unfavorable attitude 
toward the self (p. 15). This definition of self-esteem leaves room for expansion as Maslow (1954) delves further, explaining self-esteem as "the desire for strength, for achievement, for adequacy, for mastery and competence, and for independent and freedom” (p. 177). Self-esteem is considered one of the strongest psychogenic needs, and people are strongly driven to feel good about themselves (Malär, Krohmer, Hoyer, \& Nyffenegger, 2011). For instance, Solomon (1983) gave the example of adolescent boys and their use of products such as cars, clothing, and cologne deemed "macho" being used to improve their masculine sense of self-esteem.

Malär, Krohmer, Hoyer, and Nyffenegger (2011) hypothesized that self-esteem strengthens the relationship between self-congruence with a brand. Adult male and female business professionals were surveyed to analyze a connection between self-esteem and congruence. Their findings indicated that consumers with high self-esteem are attracted to a retail brand that matches their sense of self. This process is explained through the selfverification process, which boosts consumer's feelings about themselves and creates a stronger brand connection. The participants with low self-esteem found brands that corresponded to their ideal self more appealing because of the self-enhancing opportunity these brands presented. Lastly, the brands that were in line with the actual self were perceived negatively when consumers did harbor good feelings about their current selves.

Guindon (2002) emphasizes that the feelings of worth and acceptance are integral elements of self-esteem. In order to understand the complexity of self-esteem one must consider that there are various types of self-esteem. Global self-esteem is defined as an overall estimate of general-self-worth and the level of respect for one-self (Guindon, 2002). According to Balcetis, Cole, Chelberg, and Alicke (2013), global self-esteem is measured as a part of a hierarchical set of evaluations that form an enduring attitude about the self that is 
relatively resistant to the ups and downs of everyday life. Global self-esteem is associated with long-term and constant qualities of the self, playing a role in predicting mental health including chronic depression and anxiety (Pyszczynski, Greenberg, Solomon, Arndt, \& Schimel, 2004), general happiness (Lucas, Diener, \& Suh, 1996), and trait optimism (Lyubomirsky, Tkach, \& DiMatteo, 2006).

Balcetis et al. (2013) examined the role of awareness of ideal body standards in lowering young women's global self-esteem. In order to test the role of awareness, female participants partook in a computer questionnaire that measured their eye movements between a question on the left side of the computer screen and a statement on the right side. For example, on the left side of the computer screen was question that asked respondents about their satisfaction with their own bra cup size. On the right side was the statement "Ohio University females think the ideal size is a size C". Balcetis et al. tracked changes in self-esteem to propose a connection between awareness of ideal standards and consequential changes in selfesteem. They discovered through the female participants' eye movements that awareness correlated with decreases in self-esteem across the questionnaire as women were concerned with the information describing the thin ideal. This study provided evidence that awareness of ideal standards can adversely affect global self-esteem among women, regardless of their actual body weight and shape. The following section provides insight on another component of selfesteem, selective esteem.

Selective self-esteem is an evaluation of specific traits or qualities within the self at times according to situation (Guindon, 2002). In accordance to the findings of Balcetis et al. (2013), self-esteem can vary within a situation or specified time. Gonzales and Hancock (2011) used social networking website, Facebook.com, to analyze selective self-esteem. 
They reported that the respondents who updated their personal profiles and viewed their own profiles during the testing reported greater self-esteem. Kamysheva, Wertheim, Skouteris, Paxton, and Milgrom, (2009) represented another example of selective self-esteem by surveying pregnant women. Pregnant women easily developed a negative self-esteem and lower levels of body image due to the significant body changes and weight gain that occurred during pregnancy. These findings continue to reinforce the concept of temporary and time appropriate selective self-esteem, because Gonzales and Hancock's study used Facebook as a tool to analyze user's selective self-esteem as they checked their personal profiles, and Sohn and Bye (2015) restricted the participants to negative body image thus low self-esteem during pregnancy. These studies explain the temporary and time-appropriate nature of self-esteem.

Previous literature has supported the connection between self-esteem and body image in women (Hume \& Mills, 2013; Lennon \& Rudd, 1994; Lennon, Rudd, Sload, \& Kim, 1999). For example, Hume and Mills (2013) found that women with a high-perceived self-image and high self-esteem were more likely to purchase lingerie while women with lower perceived self-image purchased underwear for functional use only. Lennon and Rudd (1994) investigated relationships among body image, attitudes toward gender roles, self-esteem, and appearance management behaviors. They established that, among college women, $8 \%$ of the variance in self-esteem was due to body satisfaction. The correlation of body image and self-esteem can also be applied to individuals of various ethnic backgrounds as Lennon, et al. (1999) surveyed Korean, Singaporean, African-American, and Caucasian-American women. They assessed levels of selfesteem, perspective of gender roles, and body image to find that across all ethnic groups the women with high self-esteem associated with positive body image. 
The above-mentioned studies related to self-esteem and body image assumed that individuals compare themselves to the ideal image. For example, a woman who identifies with the model in the advertisements and another woman that sees the differences between the model and herself, compare themselves to the photo of an ideal body portrayed in an advertisement. Similarly, when a brand appeals to a consumer, the consumer experiences selfcongruence.

\section{Self-Congruence}

Self-congruence is described as the match/mismatch between the brand user image and the consumer actual self-image, ideal self-image, social self-image, and/or ideal social self-image (Johar \& Sirgy 1991). The theory of self-congruence is based on the concept that consumers use brands to communicate their self-concepts, and exhibit a tendency to make assumptions about others off of the brands that they notice others using (Sung \& Choi, 2010).

Previous findings within the retail industry indicated that consumers prefer to buy a certain brand over others when they consider their brand of choice to exhibit an image similar to their own self-concept (Dolich, 1969; Mason \& Mayer, 1970; Piacentini \& Mailer, 2004; Rhee \& Johnson, 2012). Dolich's findings concluded that among male and female college students, preferred brands of cigarettes, beer, tooth paste and bar soap similar to the self-concepts of respondents than least preferred product brands. As a result of interviewing 38 male and female teenage students, Piacentini and Mailer established that adolescents purchased and wore certain clothing brands to reflect economic status and to fit in with their social groups. Mason and Mayer (1970) used the concept of self-congruence by interviewing female shoppers. By asking participants to rate local apparel retail establishments as high, medium, or low status, they found that respondents ranked the store they were patronizing as high status much more frequently than 
the other choices. To predict consumer behavior, Sirgy, Grewal, Mangleburg, Park, Chon, Claiborne and Berkman (1997) surveyed twenty participants on their ideas of brand image and self-congruence regarding athletic footwear. Their results indicated that the participants' selfimage coincided with the brand image of their preferred brand. Aagerup (2011) supported Sirgy et al.'s claim as they investigated female consumers and found that the use of thin models led to positive brand perception. If the brand's expectations coincided with the user's self-image, a strong sense of brand preference was established among the female subjects.

Sirgy and Johar (1999) stated that if consumers experience self-congruence with a brand, they would be motivated to purchase that product because the use of the product would satisfy self-esteem, social consistency, and/or social approval needs. When consumers use the product, they would be able to fulfill their needs of self-consistency, social consistency, social approval, and self-esteem.

\section{Brand Preference}

Brand preference is defined as the behavioral tendencies and how consumers will act toward the preferred brand (Zajonc \& Markus, 1982). Choi, Liu, Liu, Mak, and To (2010) studied brand preference in fast fashion companies. They concluded that there were several elements of consumer characteristics that effect brand preference. Those elements were: brand loyalty, involvement, perceived quality, self-image, brand concept consistency, and product feature similarity.

In order to predict fashion brand preference, Mulyanegara and Tsarenko (2009) used the Big Five model (McCrae \& Costa, 1990) consisting of five factors: extraversion, agreeableness, conscientiousness, neuroticism, and openness. For their questionnaire distributed to 250 male and female undergraduate students, they further adapted Aaker's (1997) brand personality 
concept to measure the dimensions of consumer personality, brand congruence, consumer values, and prestige sensitivity. Their findings indicated that the personality variable was not strong enough to be a reliable predictors of fashion brand preferences. However, there was significant findings on the association between consumer personality and personal values with prestige sensitivity playing a mediating role. Based off their results, Mulyanegara and Tsarenko (2009) reason for their finding, "People with a high level of prestige sensitivity are more likely to be affected by their values when it comes to fashion brand preferences" (p. 367).

$\mathrm{Hu}$, Liu, Wang, and Yang (2012) sought to measure brand preference of automobiles by examining the role of functional and symbolic image congruity. They uncovered that brand image and brand preference were linked. Their results concluded that consumers' brand preference resulted in a negative impact when a brand's perceived symbolic image is higher than the consumers' expectations. The findings of Mulyanegara and Tsarenko (2009) coincide with $\mathrm{Hu}$ et al. (2012) as they examined consumer values predicting brand preferences. By relating consumer values to brand preference marketers can focus on creating a brand image that better reflect the values of target consumers.

D’Alessandro and Chitty (2011) specified other elements affecting consumer advertising image preference including source credibility, body shape, and apparent ethnicity. Justifying this claim by use of survey, the authors found that Singaporean female participants who were exposed to clothing brand advertisements featuring a thin model or model with a realistic body shape developed a more favorable attitude toward the brand than the other group of participants who were exposed to a plus-size model. The respondents also exhibited a greater interest in the brand when the advertisements used Chinese models instead of Western models. These findings concluded that if the model in the advertisement is of the same ethnic background and 
representative of realistic body shape, consumers could relate to them. When the consumer focuses on the image illustrated through an advertisement while comparing this image to their own self-concept, a preference for the brand occurs.

In fashion marketing, an indicator of brand preference and the consumer's self-image has been linked toward the physical appearance of the model in the fashion advertisement and the underlying messages of the ad itself, referring to the concept of self-congruence (D'Allessandro \& Chitty, 2011). 


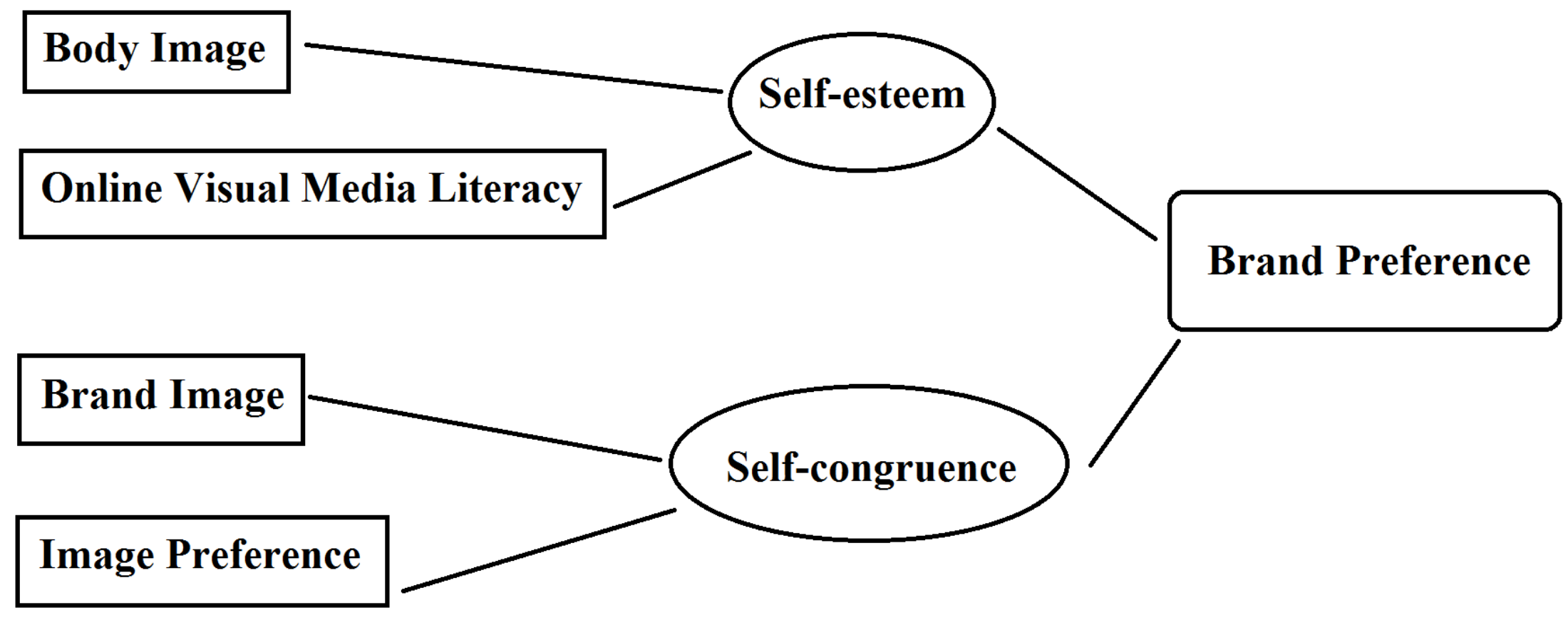

Figure 2.1. Conceptual Framework 


\section{Hypotheses}

There were a total of six hypotheses extracted based on the literature review in the earlier section. The following section includes explanations of how each hypothesis was extracted and supports from previous studies.

Balcetis, Cole, Chelberg, and Alicke (2013) assessed the role of awareness of ideal body standards in lowering young women's self-esteem by creating a computer questionnaire that measured participants' eye movements. They discovered through the female participants' eye movements that the awareness of the "thin ideal" can adversely affect the body image and selfesteem among college aged women. Hume and Mills (2013) established that women with a highperceived body-image and high self-esteem were more likely to purchase lingerie as a form of fun while women with lower levels of self-image purchased underwear for functional use only. By investigating relationships between body image and self-esteem, Lennon and Rudd (1994) concluded that among college women eight percent of the variance in self-esteem was due to body satisfaction. Lennon, Rudd, Sload, and Kim (1999) surveyed women of a variety of ethnic and cultural backgrounds (i.e., Korean, Singaporean, African-American, and CaucasianAmerican women) and found that women with high self-esteem associated with positive body image. Mendelson, Mendelson, and White (2010) surveyed young adults and discovered a relationship between global self-esteem and feelings about appearance. These studies indicated that body image perception may alter a subjects' level of self-esteem. Based on the above previous study results, we extracted $\mathrm{H} 1$ to examine the relationship between perceived body image and self-esteem.

O H1 There is a relationship between body image and self-esteem. 
Davidson, and O'Dea (2003) studied the effectiveness of media literacy education. The participants in the media literacy education group showed enhanced self-esteem. Tirlea, Truby, and Haines (2013) created a program combining healthy living and media literacy for elementary and middle school aged girls. After the ten week program, both sets of girls displayed increased levels of self-esteem. Chona, Foster, and Radford (2007) investigated women's self-esteem after showing a media literacy film. Their results concluded that the women had more positive thoughts toward themselves and exhibited higher levels of global self-esteem. The above studies suggested that when females are given a media literacy tool, their self-esteem levels are altered. Through the supports of the above previous literature, $\mathrm{H} 2$ was extracted as below.

○ H2 There is a relationship between online visual media literacy and self-esteem.

Hu, Liu, Wang, and Yang (2012) discovered that consumers' perception of brand image can become negative if the brand differs from the consumers' expectations. Mulyanegara and Tsarenko (2009) found that a consumer's type of personality, personal values, and prestige sensitivity played a role in the creation of brand image. Cho, Fiore, and Russell (2015) uncovered that self-congruence played a role in the consumer cognitive associations, reflecting an individual's self-image. Based on the above reports of previous research, the following hypothesis was extracted based on the previous findings of relationships between brand image and user self-congruence.

- H3a A consumer's perceived brand image of the brand Victoria Secret affects their self-congruence with the brand.

- H3b A consumer's perceived brand image of the brand Aerie affects their selfcongruence with the brand. 
D'Alessandro and Chitty (2011) found that when female participants were exposed to a thin or average sized model in a fashion ad, they developed a more favorable attitude toward the brand. D'Allesandro and Chitty also determined that ethnicity played a role in image preference as Singaporean respondents demonstrated a greater interest in a brand when Chinese models were featured in the ads instead of Western models. This finding exhibits that there is a relationship between image preference and consumers' self-congruence. The above studies indicated that when consumers demonstrated a preference for an advertising image, they were more likely to identify with the brand on a personal level, demonstrating self-congruence.

- H4a There is a relationship between Victoria's Secret image preference and self-congruence.

- H4b There is a relationship between Aerie image preference and selfcongruence.

Malär, Krohmer, Hoyer, and Nyffenegger (2011) found that consumers with high selfesteem were attracted to a brand that matches their sense of self whereas respondents with low self-esteem were drawn to brands that corresponded with their ideal self and viewed brands that were congruent with the actual self as negative. Aagerup (2011) demonstrated that self-esteem and brand congruence are effective predictors of women's clothing preferences and the brands they purchase. Based on the previous research findings above, H5 was extracted.

○ H5 A consumer's level of self-esteem has a relationship with brand preference toward a fashion brand.

Mason and Mayer (1970) found that shoppers ranked the store they were patroning as high status versus the stores they did not shop at as low status, indicating a connection between preference and the self. Dolich's (1969) findings gathered that among college students, preferred 
brands were ranked as similar to their own self-concepts and the items that the respondents labeled as least preferred did not coincide with their self-concept. Piacentini and Mailer (2004) found that adolescents wore clothing brands in order to indicate the level of their family's income and to find acceptance among peers. Sirgy, Grewal, Mangleburg, Park, Chon, Clairborne, and Berkman (1997) concluded that consumers demonstrate a brand preference toward athletic footwear when the brand of footwear corresponds with the consumer's selfimage. The above studies indicated that there is a relationship between consumers' brand preference and their self-identity. Based on the above findings, H6a and H6b were extracted.

- H6a Consumers who feel themselves congruent with Victoria's Secret prefers the brand Victoria's Secret.

- H6b Consumers who feel themselves congruent with Aerie prefers the brand Aerie.

In summary, a review of literature included prior investigations which analyzed (1) body image, (2) online visual media literacy, (3) brand image, (4) image preference, (5) self-esteem, (6) self-congruence, and (6) brand preference, revealing connections among the variables. 


\section{Chapter Three}

\section{Methods}

The purpose of this research is to understand consumer perceptions of fashion advertisements and the role of Photoshop in determining brand image and brand relationships with the customers. The researcher adopted survey, as a quantitative research method, for this study. The goal of the survey was to assess the participants' perceptions and levels of body image, self-esteem, online visual media literacy, brand image preference, self-esteem, selfcongruence with a brand, and brand preference. In order to address the research questions, the following variables included in the conceptual framework were examined to create the survey instrument. The committee members of this research agreed upon the instrument's validity.

\section{Questionnaire Development}

In the following section, the description of how the questions included in each variable were adopted or adapted is included.

Body Image. Body image is defined as "the mental picture we have in our minds of the size, shape and form of our bodies and our feelings concerning these characteristics and one's body parts" (Greene, 2011, p vii). Based off of this definition, the researcher has adopted questions from the Body Cathexis scale (Secord \& Jourard, 1953) and from Mendelson, Mendelson, and White's (2001) body image scale. The former focuses on the respondents' perceptions on physical body parts while the latter delves into the socio-psychological aspect of body image. In this research, especially considering the definition of the body image, both physical and socio-psychological aspects were considered to be important consumer characteristics. 
The Body Cathexis scale asks participants to rank their satisfaction regarding their specific physical features (see Table 3.1). The list of physical features from the Body Cathexis scale uses a six point Likert scale ( $1=$ very dissatisfied, $2=$ dissatisfied, $3=$ slightly dissatisfied, $4=$ slightly satisfied, $5=$ satisfied, $6=$ very satisfied). The validity of the Body Cathexis was tested to be acceptable in Secourd and Jourard (1953). The reliability of the Body Cathexis Scale was determined through the split half methods and exhibited a Spearman Brown rank of .81 for Body Cathexis. Previous studies have utilized the Body Cathexis scale to measure participants' body image (Alexander, Conell \& Presley, 2005; Balogun, 1986; Mahoney \& Finch, 1976).

Using the Body Cathexis scale, explained above, helped the researcher determine the mental picture that a participant has of their physical size, shape, and form. In addition to that, understanding the mental picture of a participant may aid in the research of comprehending the socio-psychological aspect of the feelings related to the body image. 
Table 3.1

Body Cathexis Scale

\begin{tabular}{ll}
\hline Author & Original Listing \\
\hline Secord \& Jourard (1953) & Facial features \\
& Complexion \\
& Hair \\
& Hips \\
& Thighs \\
& Buttocks \\
& Legs \\
& Waist \\
Stomach or abdomen & Bust or breasts \\
Shoulders \\
Arms \\
Muscle tone \\
Weight \\
Height \\
Overall appearance \\
\end{tabular}


While the Body Cathexis scale focused on satisfaction or dissatisfaction of one's physical appearance, the Body Esteem Scale for Adolescents and Adults (BESAA) (Mendelson, Mendelson \& White, 2001) assessed body image by asking participants to rank their agreement with phrases that measure participants' perceptions of themselves. The researcher adopted questions from the BESAA scale to measure body image because the statements used in the scale reflect on the participant's level of social comparison and perceptions of how others view them. In Mendelson et al.'s (2001) body image scale, reliability was measured using test-retest. The test-retest demonstrated high correlations between Body Esteem and Appearance: $r(95)=.89$, $\mathrm{p}<.001$; Body Esteem and Weight: $\mathrm{r}(95)=.92, \mathrm{p}<.001$; and Body Esteem and Attribution: $\mathrm{r}(95)$ $=.83, \mathrm{p}<.001$. Discriminant validity was confirmed by analyzing the correlations between the Body Esteem measures and Neeman and Harter's (1986) subscales of appearance, close friendships, social acceptance, romantic relationships, and parental relationships.

The scale originally used a five point Likert scale (never to always), but to ensure consistency within the instrument the researcher adapted the scale to use a six point Likert scale ( $1=$ strongly disagree, $2=$ disagree, $3=$ slightly disagree, $4=$ slightly agree, $5=$ agree, and $6=$ strongly agree). Phrases from the BESAA scale demonstrated instances where participants may identify with having a low sense of body image or a higher level of body image (see Table 3.2). 
Table 3.2.

Body Esteem Scale for Adolescents and Adults

\begin{tabular}{|c|c|}
\hline Author & Original Questions \\
\hline \multirow{20}{*}{$\begin{array}{l}\text { Mendelson, Mendelson \& } \\
\text { White (2001) }\end{array}$} & I like what I look like in pictures. \\
\hline & Other people consider me good looking. \\
\hline & I'm proud of my body. \\
\hline & I am preoccupied with trying to change my body weight. \\
\hline & I think my appearance would help me get a job. \\
\hline & I like what I see when I look in the mirror. \\
\hline & $\begin{array}{l}\text { There are lots of things I'd change about my looks if I } \\
\text { could. }\end{array}$ \\
\hline & I am satisfied with my weight. \\
\hline & I wish I looked better. \\
\hline & I really like what I weigh. \\
\hline & I wish I looked like someone else. \\
\hline & People my own age like my looks. \\
\hline & My looks upset me. \\
\hline & I'm as nice looking as most people. \\
\hline & I'm pretty happy about the way I look. \\
\hline & I feel I weigh the right amount for my height. \\
\hline & I feel ashamed of how I look. \\
\hline & Weighing myself depresses me. \\
\hline & My weight makes me unhappy. \\
\hline & My looks help me get dates. \\
\hline
\end{tabular}


I worry about the way I look.

I think I have a good body.

I'm looking as nice as I'd like to.

The following phrases illustrate instances of high level of body image: "I like what I look like in pictures," "Other people consider me good looking" which considers one's perception of how others view themselves and their perceptions on how others may see them, "I think my appearance would help me get a job," "I like what I see when I look in the mirror," "I am satisfied with my weight," "I really like what I weigh," "People my own age like my looks," "I'm as nice looking as most people," "I'm pretty happy about the way I look," "I feel I weigh the right amount for my height," "My looks help me get dates," "I think I have a good body," and "I'm looking as nice as I'd like to."

The following phrases illustrate negative views of body image: "I am preoccupied with trying to change my body weight," "There are lots of things I'd change about my looks if I could," ““"My weight makes me unhappy," "I wish I looked better," "I wish I looked like someone else," "My looks upset me," "I feel ashamed of how I look," "Weighing myself depresses me," and "I worry about the way I look."

The BESAA scale has been a frequently used scale in other studies (Mendelson, Mendelson \& Andrews, 2000; Mendelson \& White, 1993; 1994; Mendelson, White \& Balfour, 1995; Mendelson, White \& Mendelson, 1996; 1997).

Online Visual Media Literacy. Online visual media literacy is defined as the knowledge of digital manipulation of a fashion advertising photograph and the ability to analyze the media's 
usage in an online environment. The term online visual media literacy is a combination of the definitions of visual literacy. Bissell (2006) defined visual literacy as "knowledge of digital manipulation in fashion and entertainment images" (p.4). Buckingham (2003) defined media literacy as "the knowledge, skills, and competencies required in order to use and interpret media" (p. 36). Using the above definition of online visual media literacy, questions from Kretz (2011) were used to measure the consumer perceptions on the digital manipulation of fashion models' images. The original scale adapted for this study asked participants to rate their digital alteration awareness on a seven point Likert scale ranging from 1 (not aware at all) to 7 (fully aware) on fashion magazine advertisements. For the use of this research, questions have been formatted into phrases and the scale adapted for a six point Likert scale ranging from 1 (strongly disagree) to 6 (strongly agree) (see Table 3.3). In terms of reliability of the scale, Cronbach's Alpha ranged from .60 to .82 . Kretz (2011) separately tested the reliability for the four stimuli (i.e. four magazines). The Cronbach's Alpha for the four different stimuli were as follows: Magazine Page 1: Cronbach’s alpha $=.599$, Magazine Page 2: Cronbach’s alpha $=.801$, Magazine Page 3: Cronbach's alpha $=.656$, Magazine Page 4: Cronbach's alpha $=.816$. According to Malhotra (1993), a scale with a Cronbach's alpha of 0.60 or higher is considered to be reliable, and therefore, Kretz's scale was considered to be reliable. To establish convergent validity, correlation analyses between the perceived reality of magazine images scale items and the general reality judgment were conducted toward the advertisements used in this study. The three factors that demonstrated convergent validity were real world, factuality, and emotional involvement. 
Table 3.3.

Perceived Reality of Magazine Images of Women Scale

\begin{tabular}{|c|c|c|}
\hline Author & Original Question & Revised Question \\
\hline \multicolumn{3}{|c|}{ Awareness of digital alteration technology subscale } \\
\hline \multirow[t]{5}{*}{ Kretz (2011) } & $\begin{array}{l}\text { How widespread is the use } \\
\text { of computer software to } \\
\text { alter the images of women } \\
\text { in magazines? (Not at all } \\
\text { widespread - Very } \\
\text { widespread) }\end{array}$ & $\begin{array}{l}\text { Computer software is used frequently } \\
\text { to alter the images of women in online } \\
\text { fashion advertisements (Strongly } \\
\text { disagree - Strongly agree) }\end{array}$ \\
\hline & $\begin{array}{l}\text { It's not possible for a real } \\
\text { woman to look like the } \\
\text { model shown in this } \\
\text { magazine page. }\end{array}$ & $\begin{array}{l}\text { It's not possible for a real woman to } \\
\text { look like the model shown in this } \\
\text { online fashion advertisement. }\end{array}$ \\
\hline & $\begin{array}{l}\text { A photo of the model } \\
\text { shown here was taken for } \\
\text { the magazine and used } \\
\text { exactly as it was taken. }\end{array}$ & $\begin{array}{l}\text { A photo of the model shown here was } \\
\text { taken for the online fashion } \\
\text { advertisement and used exactly as it } \\
\text { was taken. }\end{array}$ \\
\hline & $\begin{array}{l}\text { This magazine page looks } \\
\text { like it was created by a } \\
\text { professional designer. }\end{array}$ & $\begin{array}{l}\text { This online fashion advertisement } \\
\text { looks like it was created by a } \\
\text { professional photographer, graphic } \\
\text { designer, or photo retoucher. }\end{array}$ \\
\hline & $\begin{array}{l}\text { The photo of the model in } \\
\text { this image was airbrushed } \\
\text { or altered on a computer. }\end{array}$ & \\
\hline
\end{tabular}


In order to make the statements cohesive with the rest of the survey, each statement that used a seven point Likert scale ranging 1 (not aware at all) to 7 (fully aware) was adjusted to a six point Likert scale $(1=$ strongly disagree, 2 = disagree, $3=$ slightly disagree, $4=$ slightly agree, $5=$ agree, $6=$ strongly agree) to match the other survey portions. The phrases "The Photo in this magazine looks real," "It's not possible for a real woman to look like the model shown in this magazine page," and "A photo of the model shown here was taken for the magazine and used exactly as it was taken" have been altered to better fit the study by replacing the word "magazine" or "magazine page" with "online fashion advertisement", because this study does not utilize magazines as the focus of the medium. Additionally, the phrase "This magazine page looks like it was created by a professional designer" has been adapted to be "This online fashion advertisement looks like it was created by a professional photographer, graphic designer, or photo retoucher" as it elaborates on the specific type of work has been done to the online fashion advertisement photo.

Self Esteem. Self-esteem is defined by Rosenberg (1965) as a favorable or unfavorable attitude toward the self (p. 15). With this definition in mind, the researcher adopted questions from the Rosenberg Self Esteem scale (see Table 3.4). Each phrase from the scale is applicable to participants of any age, gender, or background, and therefore, the phrases within the scale was adopted as is. However, the scale originally uses a four point Likert rating of strongly agree, agree, disagree, and strongly disagree, which has been altered to be a six point Likert type scale ( strongly disagree $=1$, disagree $=2$, slightly disagree $=3$, slightly agree $=4$, agree $=5$, strongly agree $=6$ ) to stay consistent with the instruments for measuring other variables. 
Table 3.4.

Rosenberg Self-Esteem Scale

\begin{tabular}{|c|c|}
\hline Author & Original Question \\
\hline \multirow[t]{10}{*}{ Rosenberg (1965) } & $\begin{array}{l}\text { I feel that I am a person of worth, at least on an equal } \\
\text { plane with others. }\end{array}$ \\
\hline & I feel that I have a number of good qualities. \\
\hline & All in all, I am inclined to feel that I am a failure. \\
\hline & I am able to do things as well as most other people. \\
\hline & I feel I do not have much to be proud of. \\
\hline & I take a positive attitude toward myself. \\
\hline & On the whole, I am satisfied with myself. \\
\hline & I wish I could have more respect for myself. \\
\hline & I certainly feel useless at times. \\
\hline & At times I think I am no good at all. \\
\hline
\end{tabular}


The Rosenberg Self-Esteem scale (RSE) demonstrates a Guttman scale coefficient of reproducibility of .92 , indicating excellent internal consistency. Using test-retest reliability over a revealed correlations of .85 and .88 . Validity was determined through concurrent, predictive and construct validity using known groups, and were tested acceptable.

Previous literature including Hensley, (1977), Robins, Hendin, and Trzesniewski (2001), and Tafarodi, and Milne (2002) used the Rosenberg Self-Esteem scale in their studies, illustrating the usefulness of the scale.

Self-Congruence. Self-congruence is described as the match/mismatch between the brand user image and the consumer actual self-image, ideal self-image, social self-image, and/or ideal social self-image (Johar \& Sirgy 1991). Sirgy, Grewal, Mangleburg, Park, Chon, Claiborne, and Berkman (1997) created a Self-image Congruence scale. This research adapted questions from the Self-image Congruence scale from Sirgy et al. (1997) (see Table 3.5.). In terms of reliability of the original scale, Cronbach's alpha was .83 for self-image congruence, which was acceptable. The Self-Image Congruence scale has been used in various studies (Bosnjak \& Rudolph, 2008; Hosany \& Martin, 2012; Kwak \& Kang, 2009). 
Table 3.5.

Self-Image Congruence Scale

\begin{tabular}{|c|c|c|}
\hline Authors & Original Question & Revised Question \\
\hline \multirow[t]{7}{*}{$\begin{array}{l}\text { Sirgy, Grewal, } \\
\text { Mangleburg, } \\
\text { Park, Chon, } \\
\text { Claiborne, \& } \\
\text { Berkman } \\
\text { (1997) }\end{array}$} & $\begin{array}{l}\text { Wearing Reebox shoes in } \\
\text { casual situations is } \\
\text { consistent with how I see } \\
\text { myself }\end{array}$ & $\begin{array}{l}\text { Wearing Aerie underwear is consistent } \\
\text { with how I see myself }\end{array}$ \\
\hline & $\begin{array}{l}\text { Wearing Reebok shoes in } \\
\text { casual situations reflects } \\
\text { who I am }\end{array}$ & $\begin{array}{l}\text { Wearing Victoria's Secret underwear in } \\
\text { reflects who I am }\end{array}$ \\
\hline & & $\begin{array}{l}\text { Wearing Aerie underwear in reflects who } \\
\text { I am }\end{array}$ \\
\hline & $\begin{array}{l}\text { People similar to me } \\
\text { wear Reebox shoes in } \\
\text { casual situations }\end{array}$ & $\begin{array}{l}\text { People similar to me wear Aerie } \\
\text { underwear }\end{array}$ \\
\hline & & $\begin{array}{l}\text { People similar to me wear Victoria's } \\
\text { Secret underwear }\end{array}$ \\
\hline & $\begin{array}{l}\text { The image of the user of } \\
\text { [brand] is highly } \\
\text { consistent with how I see } \\
\text { myself. }\end{array}$ & $\begin{array}{l}\text { The image of the use of Victoria's Secret } \\
\text { is highly consistent with how I see } \\
\text { myself. }\end{array}$ \\
\hline & & $\begin{array}{l}\text { The image of the use of Aerie is highly } \\
\text { consistent with how I see myself. }\end{array}$ \\
\hline
\end{tabular}


Sigry et al. (1997) used the Self-Image Congruence scale used a five point Likert scale (strongly disagree to strongly agree), but for this study the scale was adapted to a six point Likert scale to keep consistent with the rest of the instrument. The new six point Likert scale (strongly disagree $=1$, disagree $=2$, slightly disagree $=3$, slightly agree $=4$, agree $=5$, strongly agree $=6$ ) has been applied to the following phrases: "Wearing Reebox shoes in casual situations is consistent with how I see myself" and "Wearing Reebok shoes in casual situations reflects who I am." For this research, questions were adapted by changing the brand of study and removing "casual situations," as underwear is something worn for necessity. The new questions are "Wearing Victoria's Secret underwear is consistent with how I see myself," "Wearing Aerie underwear is consistent with how I see myself," "Wearing Victoria's Secret underwear in reflects who I am," and "Wearing Aerie underwear in reflects who I am."

Image Preference. Image preference is defined as "a greater liking for one image over another" (Oxford Dictionaries, n.d.).The researcher has adapted questions from the Perceived Reality of Magazine Images of Women scale to be applied to online fashion advertising images instead of magazine images. The questions adapted from the Perceived Reality of Magazine Images of Women scale are as follows (see Table 3.6): “I don't like looking at this magazine page," "The model shown in this magazine page is attractive," and "Looking at this image makes me feel happy." 
Table 3.6.

Perceived Reality of Magazine Images of Women Scale

\begin{tabular}{|c|c|c|}
\hline Author & Original Question & Revised Question \\
\hline \multirow[t]{3}{*}{ Kretz (2011) } & $\begin{array}{l}\text { I don't like looking at this } \\
\text { magazine page. }\end{array}$ & $\begin{array}{l}\text { I don't like looking at this } \\
\text { online fashion advertisement. }\end{array}$ \\
\hline & $\begin{array}{l}\text { The model shown in this } \\
\text { magazine page is attractive. }\end{array}$ & $\begin{array}{l}\text { The model shown in this online } \\
\text { fashion advertisement is } \\
\text { attractive. }\end{array}$ \\
\hline & $\begin{array}{l}\text { Looking at this image makes } \\
\text { me feel happy. }\end{array}$ & \\
\hline
\end{tabular}


In terms of reliability, Cronbach's Alpha was used to measure the four different stimuli of this scale (Magazine Page 1: Cronbach's alpha $=.599$, Magazine Page 2: Cronbach's alpha $=$ .801 , Magazine Page 3: Cronbach's alpha $=.656$, Magazine Page 4: Cronbach's alpha $=.816$ ). To establish convergent validity, a confirmatory factor analysis of the scale was conducted was evaluated by correlating the subjects' responses on the attitude scales toward the advertisements used in this study. Convergent validity was demonstrated for the three factors: real world, factuality, and emotional involvement.

Brand Image. Brand image is defined as consumers' perception of a brand (Keller, 1993). To measure consumers' brand perception, this research selected related questions and adopt the questions from the Fashion Brand Image scale, developed by Cho, Fiore and Russell (2015). Using a six point Likert scale (strongly disagree to strongly agree), each statement (see Table 3.7) applies to the various elements of purchasing fashion items from the user's opinion of the product, style of marketing, and overall impression of the brand. These factors apply not only to retail environments but to online shopping as well. The element of mystery demonstrated a consumer's thoughts, product features, functionality, and symbolic meaning (Chang \& Chieng, 2006). Sensuality reflected a consumer's associations of the brand such as its appearance, scent, or texture (Roberts, 2005). Brand Respect referred to the positive thoughts that consumers have toward a brand based on brand performance, trust, and reputation (Roberts, 2005). However, other items from the scale such as store layout and window displays were not kept for this study because such item were not related to the topic of the study. One statement, "I approve of this brand's performance," was removed from the instrument as the research does not measure performance. 
Table 3.7.

Fashion Brand Image Scale

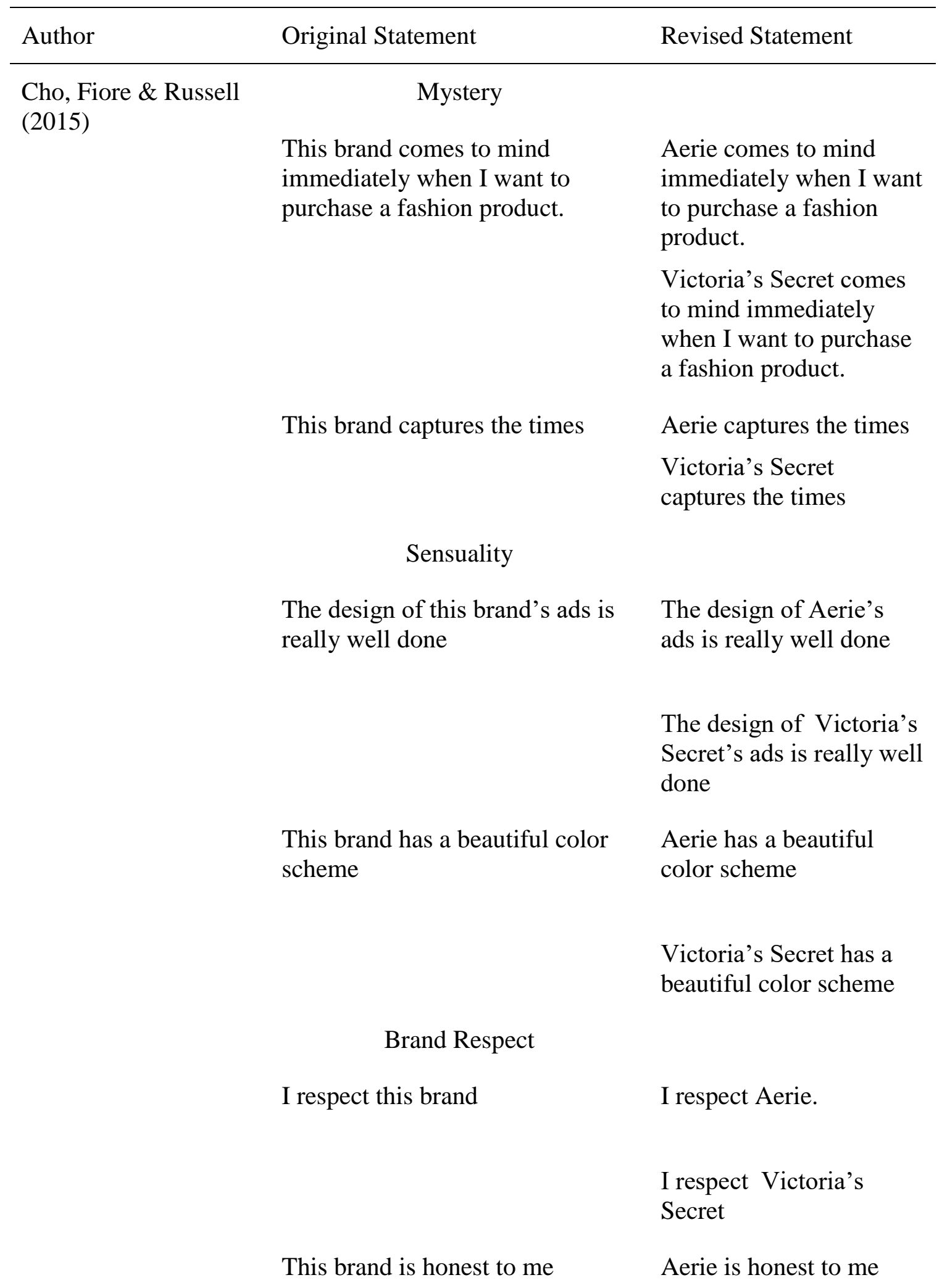


Victoria's Secret is

honest to me

This brand leads fashion trend season to season

Aerie leads fashion trend season to season

Victoria's Secret leads

fashion trend season to

season 
Convergent validity in the original scale (Cho et al., 2015) was determined by

measurement model testing using confirmatory factor analysis (CFA). Nomological validity was assessed through structural equation modeling (SEM), testing a structural model, including variables reflecting Roberts' (2005) framework of three dimensions of brand associations mystery, sensuality, and intimacy. Cho, et al. tested convergent validity based on factor loadings from the measurement model. All factor loadings were greater than 0.79 with highly significant values ranging from 24.75 to 124.56 , which supported the convergent validity of the measures (Bagozzi \& Yi, 1988). Regarding reliability, Cronbach's Alpha was .92 for the three dimensions of fashion brand image.

Brand Preference. Brand preference is defined as "the extent to which a customer favors particular offering in relation to an offering by another provider" (Hellier, Geursen, Carr, \& Rickard, 2003, p. 1765). Sirgy, Grewal, Mangleburg, Park, Chon, Claiborne, \& Berkman (1997) created a Self-image Congruence scale in order to predict consumer behavior. This research adapted questions from the Self-image Congruence scale (Sirgy et al., 1997).

Sigry et al. used the Self-Image Congruence scale to predict brand preference among college students for various items such as: cars, cameras, tires, watches, soft drinks, television, beer, and medicine. Using a five point Likert scale (strongly disagree to strongly agree) for phrases such as "People who use [focal brand] are much more like me than people who use [referent brand]," "I can identify with those people who prefer a [focal brand] rather than [referent brand]," "I am very much like the typical person who prefers to use [focal brand] rather than a [referent brand]," "The image of the user of [focal brand] is highly consistent with how I see myself," "I like [focal brand] better than [referent brand],,"'I would use [brand] more than I would use [other brand]," "[Brand] is my preferred brand over [other brand]," and "I would be 
inclined to buy a [brand] over a [other brand]." Regarding reliability, this study had Cronbach's alpha of .72 to .98 for varying brands regarding consumer brand preference. Research by Bosnjak and Rudolph (2008), Kwak and Kang (2009), and Hosany and Martin (2012) utilized the above scale.

In the current study, each phrase from the Sirgy et al. has been adapted to fit the two brands examined - Aerie and Victoria's Secret (see Table 3.8). For this research, statements were adapted by inserting the brands of study to make the questions relevant to the research. The adapted questions are: "People who use Victoria's Secret are much more like me than people who use Aerie," "I can identify with those people who prefer Aerie rather than Victoria's Secret," "I am very much like the typical person who prefers to use Victoria's Secret rather than a Aerie," "The image of the user of Aerie is highly consistent with how I see myself," "I like Victoria's Secret better than Aerie," "I would use Aerie more than I would use Victoria's Secret," "Victoria's Secret is my preferred brand over Aerie," "I would be inclined to buy a Aerie over Victoria's Secret." These questions have been duplicated and the brand names order switched, in order to avoid a research bias within the instrument. The duplicated questions are as follows: "People who use Aerie are much more like me than people who use Victoria's Secret," "I can identify with those people who prefer Victoria's Secret rather than Aerie," "I am very much like the typical person who prefers to use Aerie rather than Victoria's Secret," "The image of the user of Victoria's Secret is highly consistent with how I see myself," "I like Aerie better than Victoria's Secret," "I would use Victoria's Secret more than I would use Aerie," "Aerie is my preferred brand over Victoria's Secret," "I would be inclined to buy Victoria's Secret over Aerie." 
Table 3.8.

Self-Image Congruence Scale for Brand Preference

\begin{tabular}{|c|c|c|}
\hline Author & Original Question & Revised Question \\
\hline \multirow[t]{8}{*}{$\begin{array}{l}\text { Sirgy, Grewal, Mangleburg, } \\
\text { Park, Chon, Claiborne, \& } \\
\text { Berkman (1997) }\end{array}$} & $\begin{array}{l}\text { People who use [focal } \\
\text { brand] are much more like } \\
\text { me than people who use } \\
\text { [referent brand] }\end{array}$ & $\begin{array}{l}\text { People who use Victoria's } \\
\text { Secret are much more like } \\
\text { me than people who use } \\
\text { Aerie }\end{array}$ \\
\hline & & $\begin{array}{l}\text { People who use Aerie are } \\
\text { much more like me than } \\
\text { people who use Victoria's } \\
\text { Secret }\end{array}$ \\
\hline & $\begin{array}{l}\text { I can identify with those } \\
\text { people who prefer a [focal } \\
\text { brand] rather than [referent } \\
\text { brand]. }\end{array}$ & $\begin{array}{l}\text { I can identify with those } \\
\text { people who prefer Aerie } \\
\text { rather than Victoria's } \\
\text { Secret. }\end{array}$ \\
\hline & & $\begin{array}{l}\text { I can identify with those } \\
\text { people who prefer } \\
\text { Victoria's Secret. rather } \\
\text { than Aerie }\end{array}$ \\
\hline & $\begin{array}{l}\text { I am very much like the } \\
\text { typical person who prefers } \\
\text { to use [focal brand] rather } \\
\text { than a [referent brand]. }\end{array}$ & $\begin{array}{l}\text { I am very much like the } \\
\text { typical person who prefers } \\
\text { to use Victoria's Secret } \\
\text { rather than Aerie. }\end{array}$ \\
\hline & & $\begin{array}{l}\text { I am very much like the } \\
\text { typical person who prefers } \\
\text { to use Aerie rather than } \\
\text { Victoria's Secret. }\end{array}$ \\
\hline & $\begin{array}{l}\text { The image of the user of } \\
\text { [focal brand] is highly } \\
\text { consistent with how I see } \\
\text { myself. }\end{array}$ & $\begin{array}{l}\text { The image of the user of } \\
\text { Aerie is highly consistent } \\
\text { with how I see myself. }\end{array}$ \\
\hline & & $\begin{array}{l}\text { The image of the user of } \\
\text { Victoria's Secret is highly }\end{array}$ \\
\hline
\end{tabular}


consistent with how I see

myself.

I like [focal brand] better than [referent brand].

I would use [focal brand] more than I would use [referent brand].

[Focal brand] is my preferred brand over [referent brand].
I like Victoria's Secret better than Aerie.

I like Aerie better than Victoria's Secret.

I would use Aerie more than I would use Victoria's Secret.

I would use Victoria's Secret more than I would use Aerie.

Victoria's Secret is my preferred brand over Aerie.

Aerie is my preferred brand over Victoria's Secret.

I would be inclined to buy a [focal brand] over a [referent brand].
I would be inclined to buy Aerie over Victoria's Secret.

I would be inclined to buy Victoria's Secret over Aerie.

\section{Data Collection Procedure}

An online survey was created and distributed to gather the data necessary for this study. An online survey is low cost and has a fast response rate (Ilieva, Baron, \& Healey, 2002). The target sample was young female consumers. Ninety-six percent of millennials use the Internet for email (Pew Research Center, 2010), allowing for the researchers to most effectively reach the target subjects. It is also considered to be cost-effective and resource-saving. The research used 
females of ages eighteen to twenty-five as they are most susceptible to the media's messages (Groesz, Levine, \& Murnen, 2002) and are the target audience for the undergarments advertised in the online fashion advertisements from Victoria's Secret and Aerie (Mintel, 2011), which are the selected product category and brands for this study. Upon approval from the Institutional Review Board (IRB) at West Virginia University (WVU), the researcher formatted the survey as an online instrument using online survey website, Qualtrics, as a method of deliverance and collection. Once the instrument was approved by the IRB, the instrument was created in the digital format so it may be delivered to the survey respondents. Using Qualtrics as a marketing research company that provides national data collection service, the online link was sent to a national pool of the members of the Qualtrics consumer panel, who meet the criteria of being a female between the ages of eighteen and twenty-five.

The aggregate raw data was coded in an excel spreadsheet, which was later recorded in an SPSS file. Quantitative data analyses were conducted using the SPSS 23.0 software. The method of data analyses included descriptive statistics, reliability test such as Cronbach's alpha, factor analysis, and multiple regression analyses. 


\section{Chapter Four}

\section{Results}

In this chapter, the results of the data analyses are presented and discussed. The second section is a discussion of the results of the preliminary data analysis, including (a) factor analysis of the variables that were measured with more than one item (i.e., body image and self-esteem) and (b) descriptive statistics (e.g. means, ranges of all variables), and comparisons of means among brand image, image preference, self-congruence, online visual media literacy, and brand preference. The third section presents the results of statistical analyses to test the hypotheses (Hypotheses 1 to 6 ) that were extracted from the conceptual framework discussed in the last chapter.

\section{Profile of the Respondents}

A total of 405 participants completed the survey. Four hundred and five female adult panel members in the United States (U.S.) from the aggregate data collection company, Qualtrics, accessed the online survey and solicited participation among the pool of Qualtrics consumer panel. To better identify the profile of customers of Victoria's Secret and Aerie branded undergarments, the respondent recruitment criteria set in this study were consumers who reside in the U.S., were females of age 18 years to 25 years old. The respondents who completed the survey were rewarded with points which could be used towards a redemption for gift cards.

Table 4.1 shows the online survey respondents' demographic characteristics (i.e., age, ethnicity, and education level). 
Table 4.1

Demographic Characteristics of the Survey Respondents

\begin{tabular}{|c|c|c|}
\hline $\begin{array}{c}\text { Demographic } \\
\text { Variable }\end{array}$ & Category & $\begin{array}{c}\text { Current Study } \\
(\%)(\mathrm{N})\end{array}$ \\
\hline \multirow[t]{2}{*}{ Age } & $18-20$ & $\begin{array}{c}34 \% \\
(136)\end{array}$ \\
\hline & $21-25$ & $\begin{array}{l}66 \% \\
(269)\end{array}$ \\
\hline \multirow{11}{*}{$\begin{array}{l}\text { Ethnicity } \\
\text { (Race) }\end{array}$} & Native American or & $1 \%$ \\
\hline & Alaska Native & (5) \\
\hline & Asian & $\begin{array}{l}6 \% \\
(23)\end{array}$ \\
\hline & Black or African & $9 \%$ \\
\hline & American & $(37)$ \\
\hline & Native Hawaiian or & $0 \%$ \\
\hline & Other Pacific Islander & $(0)$ \\
\hline & White or Caucasian & $\begin{array}{l}67 \% \\
(270)\end{array}$ \\
\hline & Hispanic or Latino & $\begin{array}{l}12 \% \\
(48)\end{array}$ \\
\hline & $\begin{array}{l}\text { A combination of one } \\
\text { or more of these }\end{array}$ & $\begin{array}{l}5 \% \\
(19)\end{array}$ \\
\hline & None of these & $\begin{array}{l}1 \% \\
(3)\end{array}$ \\
\hline \multirow[t]{7}{*}{$\begin{array}{l}\text { Education } \\
\text { Level }\end{array}$} & High School & $\begin{array}{l}26 \% \\
(106)\end{array}$ \\
\hline & GED & $\begin{array}{l}5 \% \\
(21)\end{array}$ \\
\hline & Some College & $\begin{array}{l}41 \% \\
(167)\end{array}$ \\
\hline & Associate Degree & $\begin{array}{l}10 \% \\
(39)\end{array}$ \\
\hline & Bachelor's Degree & $\begin{array}{l}14 \% \\
(57)\end{array}$ \\
\hline & Master's Degree & $\begin{array}{l}3 \% \\
(14\end{array}$ \\
\hline & Doctoral Degree & $\begin{array}{l}0 \% \\
(1)\end{array}$ \\
\hline
\end{tabular}




\section{Preliminary Data Analyses}

Preliminary data analyses were performed in two parts. First, factor analyses were conducted to strengthen the validity of measures used in the statistical analyses. In addition, in order to test the reliability of measures, Cronbach's Alpha was calculated for each measure.

\section{Factor Analysis}

To increase validity and to identify the underlying constructs, factor analyses were completed. Exploratory factor analyses were conducted for all variables, and as a result two variables (i.e., body image and self-esteem) extracted two or more factors within the variable. Principal component analysis with Varimax rotation was used to obtain a clear pattern of loadings.

As mentioned above, the factor analyses results showed that all variables except two (i.e., body image and self-esteem) extracted only one factor for each variable. The values of Cronbach's alpha for each variable with one factor are specified in Table 4.2. The Cronbach's alpha for all variables ranged from .70 to .98 , indicating a high internal consistency. According to Nunnaly (1978), a scale with a Cronbach's alpha of 0.70 or higher is considered to be reliable.

Table 4.2.

Cronbach's Alpha of One-Factor Variables

\begin{tabular}{lc}
\hline Variable & Cronbach's alpha \\
\hline Victoria's Secret Image Preference & 0.70 \\
Aerie Image Preference & 0.76 \\
Victoria's Secret Brand Image & 0.93 \\
Aerie Brand Image & 0.94 \\
Victoria's Secret Brand Preference & 0.98 \\
Aerie Brand Preference & 0.98 \\
Victoria's Secret Self-Congruence & 0.94 \\
Aerie Self-Congruence & 0.96 \\
Online Visual Media Literacy & 0.95 \\
\hline
\end{tabular}


Two variables, body image and self-esteem extracted factors. Body image extracted three factors - confidence in body image, anxiety in body image, and weight perception. Greene (2011) defined body image as the mental picture we have in our minds of the size, shape and form of our bodies and our feelings concerning these characteristics and one's body parts.

Confidence in body image, the first factor extracted from factor analysis, is defined by Avalos, Tylka, and Wood-Barcalow (2005) as favorable opinions of the body and body acceptance. While anxiety in body image refers to the extent in which a woman feels at unease about her body and physical appearance (Pidgeon \& Harker, 2013). The last factor extracted from the Body Image factor analyses was weight perception, defined by Gillen and Lefkowitz (2011) as the subjective appraisal of actual weight status, and is impacted by social and ethnic factors. Based on these definitions provided in the previous research and thoroughly reviewing the meanings of each question item, the researcher of this study labeled the three factors as such. Each extracted factor - confidence in body image, anxiety in body image, and weight perception is displayed in Table 4.3. The items in the first factor, confidence in body image, were related to a positive outlook concerning one's appearance, and eleven questions were rotated to be this factor. One of the questions that belonged to the confidence in body image factor included, "I'm looking as nice as I'd like to." This factor accounted for $25.40 \%$ of the variance in body image. The items in the second factor, anxiety in body image, were related to negative thoughts on physical appearance accounting for $22.18 \%$ of the variance in body image. There were nine questions in this factor. One of the questions that belonged to the anxiety in body image factor included, I worry about the way I look.” Because the items were designed to measure respondents' negative ideals on their body, the scores were reverse-coded. The three items in the third factor were related to one's own physical weight and was named "weight perception" This 
factor accounted for $19.74 \%$ of the variance in body image. One of the questions that belonged to weight perception factor included, "I really like what I weigh.” The Cronbach's alpha

were $.91, .93$, and .91 , indicating that the measurement items included in each of the two factors consistently measured a same construct according to Nunnaly (1978) because Cronbach's alpha values were higher than 0.7 .

Table 4.3

Factor Analysis for Body Image

\begin{tabular}{|c|c|c|c|c|}
\hline Factor labels and statements & Eigenvalue & $\begin{array}{l}\text { Factor } \\
\text { loading }\end{array}$ & $\begin{array}{c}\% \text { of } \\
\text { explained } \\
\text { variance }\end{array}$ & $\begin{array}{c}\text { Coefficient } \\
\text { alpha }\end{array}$ \\
\hline Confidence in Body Image & 11.24 & & 25.39 & 0.93 \\
\hline I'm looking as nice as I'd like to. & & .67 & & \\
\hline I think I have a good body. & & .85 & & \\
\hline My looks help me get dates. & & .58 & & \\
\hline I'm pretty happy about the way I look. & & .87 & & \\
\hline I'm as nice looking as most people. & & .75 & & \\
\hline People my own age like my looks. & & .68 & & \\
\hline I like what I see when I look in the mirror. & & .85 & & \\
\hline $\begin{array}{l}\text { I think my appearance would help me get a } \\
\text { job. }\end{array}$ & & .54 & & \\
\hline I'm proud of my body. & & .86 & & \\
\hline $\begin{array}{l}\text { Other people consider me good looking. } \\
\text { I like what I look like in pictures. }\end{array}$ & & .62 & & \\
\hline & & & & \\
\hline $\begin{array}{l}\text { Anxiety in Body Image (Scores were reverse- } \\
\text { coded) }\end{array}$ & 2.60 & & 22.18 & 0.91 \\
\hline I worry about the way I look. & & .50 & & \\
\hline My weight makes me unhappy. & & .73 & & \\
\hline Weighing myself depresses me. & & .72 & & \\
\hline I feel ashamed of how I look. & & .78 & & \\
\hline My looks upset me. & & .78 & & \\
\hline I wish I looked like someone else. & & .59 & & \\
\hline I wish I looked better. & & .69 & & \\
\hline There are lots of things I'd change about & & & & \\
\hline my looks if I could. & & .64 & & \\
\hline $\begin{array}{l}\text { I am preoccupied with trying to change my } \\
\text { body weight. }\end{array}$ & & .48 & & \\
\hline Weight Perception & 1.64 & & 19.74 & 0.93 \\
\hline
\end{tabular}


I feel I weigh the right amount for my

height.

I really like what I weigh.

I am satisfied with my weight.

.79

Another factor analyses was conducted for the variable self-esteem. Self-esteem is explained by Rosenberg (1965) as a "favorable or unfavorable attitude toward the self" (p.15).

Self-esteem extracted two factors - self-worth and self-respect. Rawls (1999) defined selfrespect as one's power to fulfill one's intentions. The other factor extracted, self-worth, was defined by Covington (1992) as the tendency to maintain a positive image of oneself.

Table 4.4 shows the results of the factor analysis for self-esteem. Because all items in the first factor were related to empowering ideas regarding one's self, the factor was labeled "SelfRespect", based on Rawls's definition above. This factor contained five items, accounting for $36.90 \%$ of the variance in self-esteem. The second factor was named "Self-Worth" because all items in the second factor were related to the respondent's perception on maintaining a positive self-image. This factor contained five items, accounting for $34.9 \%$ of the variance in self-esteem. The Cronbach's alpha of the two factors were .91 and .88 , indicating a high internal consistency in both factors.

Table 4.4

Factor Analysis for Self-Esteem

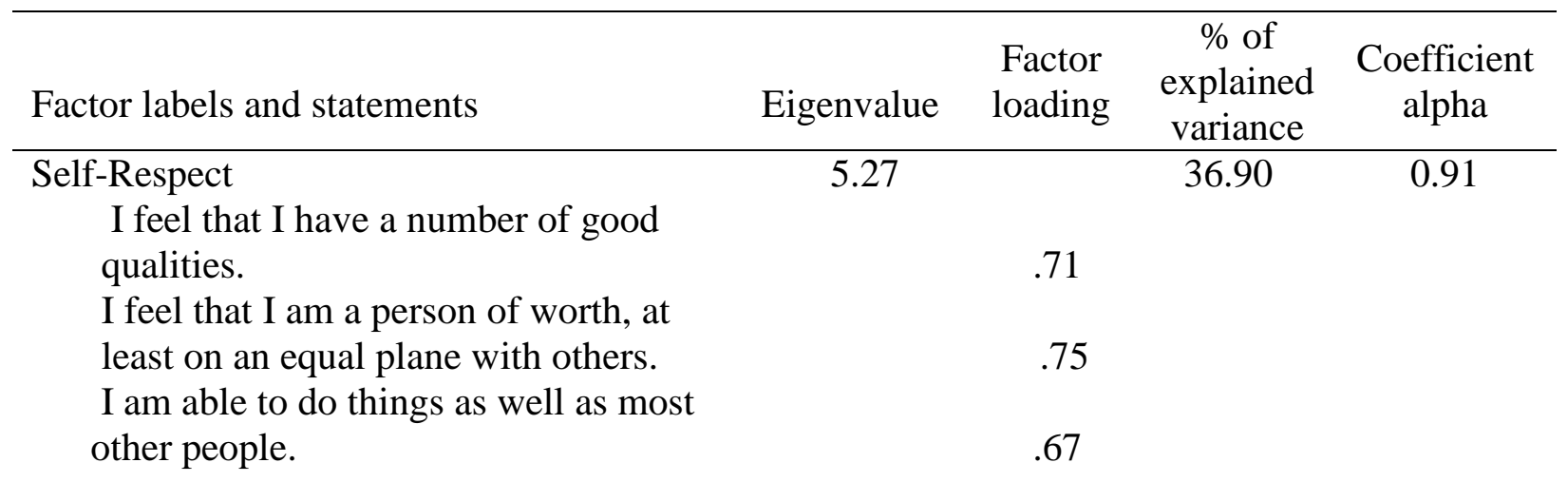


I take a positive attitude toward myself.

On the whole I am satisfied with myself.

Self-Worth (Scores were reverse-coded)

All in all, I am inclined to feel that I am a failure.

I feel I do not have much to be proud of.

I wish I could have more respect for myself.

\section{Results of Statistical Analysis to Test Hypotheses}

In Chapter 3, a framework model was developed and six hypotheses, Hypotheses 1 - 6, were formulated to test the relationships proposed in the framework. To test these hypotheses, stepwise multiple regression analyses were used because stepwise multiple regression analysis helps to identify the most predictive variables in the order of the level of statistical significance.

\section{Testing the Proposed Framework}

Hypotheses 1 - 6, were formulated to test the relationships among the variables included in the framework (i.e., relationships among confidence in body image, anxiety in body image, weight perception, self-worth, self-respect, self-congruence, online visual media literacy, brand image, image preference, and brand preference). Based on the above factor analyses results, the sub-hypotheses were created. The following hypotheses are tests.

O H1a There is a relationship between confidence in body image and self-respect.

○ H1b There is a relationship between anxiety in body image and self-respect.

O H1c There is a relationship between the perceived weight and self-respect.

O H1d There is a relationship between confidence in body image and self-worth. 
- H1e There is a relationship between anxiety in body image and self-worth.

- H1f There is a relationship between the perceived weight and self-worth.

- H2a Online visual media literacy affects self-respect.

- H2b Online visual media literacy affects self-worth.

- H3a A consumer's perceived brand image of Victoria's Secret affect their selfcongruence with the brand Victoria's Secret.

- H3b A consumer's perceived brand image of Aerie affect their self-congruence with the brand Aerie.

$\circ \mathrm{H} 4 \mathrm{a}$ There is a relationship between Victoria's Secret image preference and selfcongruence.

- $\mathrm{H} 4 \mathrm{~b}$ There is a relationship between Aerie image preference and self-congruence.

- H5a A consumer's level of self-respect has a relationship with brand preference toward Victoria's Secret.

- H5b A consumer's level of self-worth has a relationship with brand preference toward Victoria's Secret.

$\circ \mathrm{H} 5 \mathrm{c}$ A consumer's level of self-respect has a relationship with brand preference toward Aerie.

- H5d A consumer's level of self-worth has a relationship with brand preference toward Aerie.

- H6a Consumers who feel themselves congruent with Victoria's Secret prefers the brand Victoria's Secret.

- H6b Consumers who feel themselves congruent with Aerie prefers the brand Aerie. 
The examination of each hypothesis was discussed below:

\section{Relationship between Body Image and Self-Respect and Body Image and Self-Worth (Hypothesis 1)}

Hypothesis 1 (H1) was formulated to test the relationship between body image (i.e. confidence in body image, anxiety in body image, and weight perception), self-respect, and selfworth. H1 was formulated as below:

○ H1a There is a relationship between confidence in body image and self-respect.

- H1b There is a relationship between anxiety in body image and self-respect.

- H1c There is a relationship between the perceived weight and self-respect.

O H1d There is a relationship between confidence in body image and self-worth.

O H1e There is a relationship between anxiety in body image and self-worth.

- H1f There is a relationship between the perceived weight and self-worth.

The exploratory factor analysis extracted three factors in body image; confidence in body image, anxiety in body image, and weight perception. Therefore, three independent variables (i.e., confidence in body image, anxiety in body image, and weight perception) were included in the stepwise regression analysis to test the relationships with self-respect and self-worth, respectively.

Upon testing the relationships between confidence in body image, anxiety in body image, and weight perception with self-respect, the results of the stepwise multiple regression showed that confidence in body image, was a significant variable included in the final regression equation (see Table 4.5 and Figure 4.1). The significant $F$ value indicated that the equation was significant in predicting a relationship with confidence in body image and self-respect $[F(1,404)$ $=534.01, p<.001]$. The $t$-values showed that the variable confidence in body image 
significantly contributed to a relationship with self-respect. The coefficient of multiple correlation $(R)$ was .76 , and the square of the correlation coefficient $\left(R^{2}\right)$ was .57 , indicating that $57 \%$ of the variance in self-respect was explained by the equation that included confidence in body image. The standardized regression coefficients $(\beta)$ showed that confidence in body image $(\beta=.76, p<.001)$ contributed in predicting self-respect. The variables anxiety in body image $(\beta$ $=.05, p<.05)$ and weight perception $(\beta=-.08, p<.05)$ were not significant. These results showed that the respondents who demonstrated confidence in body image had more self-respect.

Table 4.5

Relationship between Body Image and Self-Respect (Hypothesis 1)

\begin{tabular}{lccccc}
\hline Step and predictor variable & $R^{2}$ & $\mathrm{~B}$ & $\beta$ & $t$ & $P$ \\
\hline $\begin{array}{l}\text { Step } 1 \\
\quad \text { Constant } \\
\quad \text { Confidence in Body }\end{array}$ & .57 & & & & \\
$\quad$ & & 1.69 & & & \\
Image & & .75 & .76 & 23.11 & \\
${ }^{*} p<.001$ & & &
\end{tabular}




\begin{tabular}{|l|r|}
\hline \multicolumn{1}{|c|}{ Body Image } & H1a: $23.11^{* *}(.76)$ \\
\cline { 1 - 1 } Confidence in body image & $\mathrm{H1b}$ \\
Anxiety in body image & Self-Respect \\
$\left(R^{2}=.57\right)$
\end{tabular}

Notes: $t$ value and standardized regression coefficients were presented.

A solid line indicated a significant relationship existed between the two variables and a $* * p<.001$

dash line indicated the two variables were not significant related.

Figure 4.1 Relationship between Body Image and Self-Respect (Hypothesis 1a to 1c)

Based on the above results, H1a were supported while $\mathrm{H} 1 \mathrm{~b}$ and $\mathrm{H} 1 \mathrm{c}$ were statistically not significant. H1a proves to have the most meaningful relationship with self-respect. In other words, among the three factors of body image (i.e., confidence in body image, anxiety in body image, weight perception), only confidence in body image turned out to be the predictor of selfrespect.

Testing the relationships between confidence in body image, anxiety in body image, and weight perception with self-worth, the results of the stepwise multiple regression showed that confidence in body image, anxiety in body image, and weight perception were the three significant variables included in the final regression equation (see Table 4.6 and Figure 4.2). The significant $F$ value indicated that the equation was significant in illustrating a relationship self-worth has with confidence in body image, anxiety in body image, and weight perception $[F(3,404)=113.40, p<.001]$. The $t$-values showed that these three variables significantly contributed to the relationship confidence in body image, anxiety in body image, and weight perception has with self-worth. The coefficient of multiple correlation $(R)$ was .68 , 
and the square of the correlation coefficient $\left(R^{2}\right)$ was .45 , indicating that $45 \%$ of the variance in self-respect was explained by the equation that included confidence in body image, anxiety in body image, and weight perception. The standardized regression coefficients $(\beta)$ showed that anxiety in body image $(\beta=.69, p<.05)$ contributed the most in predicting self-worth, followed by weight perception $(\beta=-.26, p<.05)$ and then confidence in body image $(\beta=.19, p<.001)$. These results showed that the respondents who demonstrated anxiety in body image had a strong relationship with self-worth and worry about their appearance, causing negative thoughts on their self-image affecting their overall self-worth.

Table 4.6

Relationship between Body Image and Self-Worth (Hypothesis 1)

\begin{tabular}{|c|c|c|c|c|c|}
\hline Step and predictor variable & $R^{2}$ & $\mathrm{~B}$ & $\beta$ & $t$ & $p$ \\
\hline Step 1 & .42 & & & & \\
\hline Constant & & 1.33 & & & \\
\hline Anxiety in Body Image & & .72 & .65 & 17.20 & \\
\hline Step 2 & .44 & & & & \\
\hline Constant & & 1.42 & & & \\
\hline Anxiety in Body Image & & .83 & .75 & 16.18 & \\
\hline Weight Perception & & -.15 & -.17 & -3.57 & \\
\hline Step 3 & .46 & & & & \\
\hline Constant & & 1.08 & & & \\
\hline Anxiety in Body Image & & .76 & .69 & 14.31 & .003 \\
\hline Weight Perception & & -.24 & -.26 & -4.95 & .005 \\
\hline Confidence in Body & & & & & .000 \\
\hline Image & & .22 & .19 & 3.65 & \\
\hline
\end{tabular}




\begin{tabular}{|c|c|c|}
\hline Body Image & & \multirow{3}{*}{$\begin{array}{l}\text { Self-Worth } \\
\left(R^{2}=.45\right)\end{array}$} \\
\hline Confidence in body image & H1d: $3.65 * *(.19)$ & \\
\hline \multirow[t]{2}{*}{ Anxiety in body image } & H1e: $14.31 *(.69)$ & \\
\hline & H1f: $-4.94 *(-.26)$ & \\
\hline Weight Perception & & \\
\hline
\end{tabular}

Notes: $t$ value and standardized regression coefficients were presented.

A solid line indicated a significant relationship existed between the two variables.

$* p<.01 ; * * p<.001$

Figure 4.2 Relationship between Body Image and Self-Worth (Hypothesis 1d to 1f)

Based on the above results, H1d, H1e, and H1f were supported indicating confidence in body image, anxiety in body image, and weight perception each share a relationship with selfworth. In other words, out of the three factors of body image (i.e., confidence in body image, anxiety in body image, weight perception), each factor contributed to predicting a relationship with self-worth.

\section{Relationship between Online Visual Media Literacy and Self-Respect and Online Visual Media Literacy and Self-Worth (Hypothesis 2)}

Hypothesis 2 (H2) was formulated to test the relationship between online visual media literacy, self-respect, and self-worth. $\mathrm{H} 2$ was formulated as below:

- H2a Online visual media literacy affects self-respect.

○ H2b Online visual media literacy affects self-worth.

The relationships between online visual media literacy with self-respect and self-worth were tested using multiple regression. The results showed that online visual media literacy is a 
significant predictor of self-respect (see Table 4.7 and Figure 4.3). The significant $F$ value indicated that the equation was significant in showing a relationship between online visual media literacy and self-respect $[F(1,404)=8.54, p<.001]$. The $t$-values showed that online visual media literacy significantly contributed to the relationship with self-respect. The coefficient of multiple correlation $(R)$ was .14 , and the square of the correlation coefficient $\left(R^{2}\right)$ was .02, indicating that $2 \%$ of the variance in self-respect was explained by the equation that included online visual media literacy. The standardized regression coefficients $(\beta)$ showed online visual media literacy $(\beta=.14, p<.05)$ contributed in predicting self-respect. These results showed that the respondents who demonstrated online visual media literacy shared a relationship with selfrespect.

Table 4.7

Relationship between Online Visual Media Literacy and Self-Respect (Hypothesis 2)

Step and predictor variable $R^{2} \quad$ B $\beta \quad t$ $p$

Step 1

Constant

Online Visual Media ${ }^{* *} p<.001$
.02

\subsection{5}

.13

.000 2.92 .14

(n)

\begin{tabular}{|l|l|l|}
\hline \multirow{2}{*}{ Online Visual Media Literacy } & $\mathrm{H} 2 \mathrm{a}: 2.92 * *(.14)$ \\
& $\begin{array}{c}\text { Self-Respect } \\
\left(R^{2}=.02\right)\end{array}$ \\
\hline
\end{tabular}

Notes: $t$ value and standardized regression coefficients were presented. A solid line indicated a significant relationship existed between the two variables. $* * p<.001$

Figure 4.3 Relationship between Online Visual Media Literacy and Self-Respect (Hypothesis 2a) 
Based on the above results, H2a was supported implying a significant relationship between online visual media literacy and self-respect.

The relationships between online visual media literacy with self-worth were tested using multiple regression. The results showed that online visual media literacy is a significant variable included in the final regression equation (see Table 4.8 and Figure 4.4). The significant $F$ value indicated that the equation was significant in predicting self-worth $[F(1,404)=7.44, p<.001]$. The $t$-values showed that online visual media literacy did significantly contribute to the relationship with self-worth, meaning that the respondent that did not possess online visual media literacy demonstrated a lower sense of self-worth than if they had online visual media literacy. The coefficient of multiple correlation $(R)$ was .14 , and the square of the correlation coefficient $\left(R^{2}\right)$ was .02 , indicating that $2 \%$ of the variance in self-worth was explained by the equation that included online visual media literacy. The standardized regression coefficients $(\beta)$ showed online visual media literacy $(\beta=-.14, p<.05)$ contributed in predicting self-worth. These results showed that the respondents who did not exhibit online visual media literacy shared a relationship with self-worth.

Table 4.8

Relationship between Online Visual Media Literacy and Self-Worth (Hypothesis 2)

\begin{tabular}{lccccc}
\hline Step and predictor variable & $R^{2}$ & $\mathrm{~B}$ & $\beta$ & $t$ & $p$ \\
\hline & & & & & \\
$\quad$ Step 1 & .02 & & & & \\
$\quad$ Constant & & 4.60 & & & \\
$\quad \begin{array}{l}\text { Online Visual Media } \\
\text { Literacy }\end{array}$ & & -.15 & -.14 & -2.73 & \\
${ }^{*} p<.01$ & & &
\end{tabular}




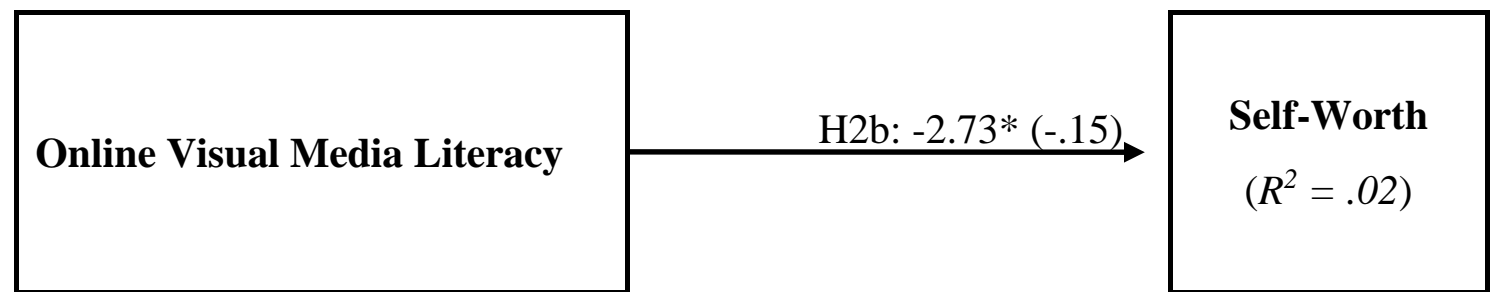

Notes: $t$ value and standardized regression coefficients were presented.

A solid line indicated a significant relationship existed between the two variables.

$* p<.01$

Figure 4.4 Relationship between Online Visual Media Literacy and Self-Worth (Hypothesis 2b)

Based on the above results, $\mathrm{H} 2 \mathrm{~b}$ was found to be significant, implying a connection between online visual media literacy and self-worth. This relationship demonstrates that when an individual does possess online visual media literacy, they will not have a strong sense of selfworth, attempting to maintain a positive self-image.

\section{Relationship between Victoria's Secret Brand Image and Self-Congruence, and Aerie Brand Image and Self-Congruence (Hypothesis 3)}

Hypothesis 3 (H3) was formulated to test the relationship between Victoria's Secret brand image, Aerie Brand Image and self-congruence. H3 was formulated as below:

○ H3a A consumer's perceived brand image of Victoria's Secret affect their selfcongruence with the brand Victoria's Secret.

- H3b A consumer's perceived brand image of Aerie affect their self-congruence with the brand Aerie.

Using multiple regression, the relationship between a consumer's perceived brand image of Victoria's Secret and her self-congruence with the brand was tested. The results showed that Victoria's Secret brand image is a significant predictor of the self-congruence with the Victoria Secret brand (see Table 4.9 and Figure 4.5). The significant $F$ value indicated that the equation 
was significant in predicting perceived Victoria's Secret brand image $[F(1,404)=344.73, p<$ .001]. The $t$-values showed that the perception of Victoria's Secret brand image significantly contributed to the relationship with self-congruence. For Victoria's Secret brand image, the coefficient of multiple correlation $(R)$ was .68, and the square of the correlation coefficient $\left(R^{2}\right)$ was .46 , indicating that $46 \%$ of the variance in self-congruence was explained by the equation that included Victoria's Secret brand image perception. The standardized regression coefficients $(\beta)$ showed Victoria's Secret brand image $(\beta=.68, p<.05)$ contributed in predicting selfcongruence. These results showed that the respondents who responded positively about Victoria's Secret brand image share a relationship with self-congruence for the brand.

Table 4.9

Relationship between Victoria's Secret Brand Image and Self-Congruence (Hypothesis 3)

\begin{tabular}{lccccc}
\hline Step and predictor variable & $R^{2}$ & $\mathrm{~B}$ & $\beta$ & $t$ & $P$ \\
\hline $\begin{array}{l}\text { Step 1 } \\
\quad \text { Constant } \\
\quad \text { Victoria's Secret Brand }\end{array}$ & .46 & & & & \\
$\quad$ & -.49 & & & \\
$\quad$ Image & & & & \\
${ }^{* * *} p<.001$ & & & & & \\
\end{tabular}

\section{Victoria's Secret Brand Image}

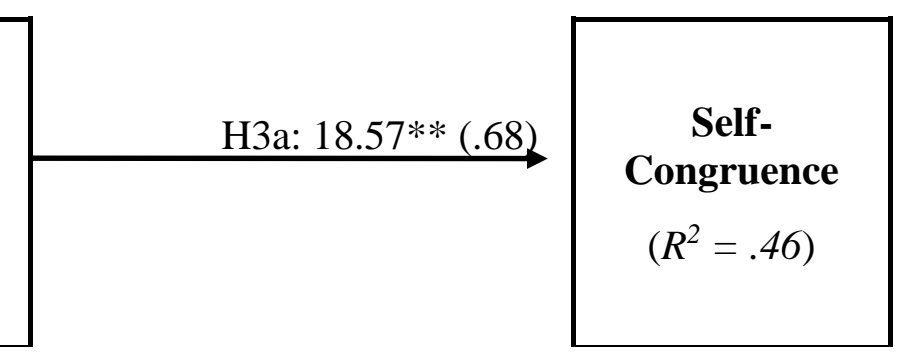

Notes: $t$ value and standardized regression coefficients were presented.

A solid line indicated a significant relationship existed between the two variables. $* * p<.001$

Figure 4.5 Relationship between Victoria's Secret Brand Image and Self-Congruence (Hypothesis 3a) 
Based on the above results, H3a was supported implying a significant relationship between Victoria's Secret brand image perception and self-congruence.

Using the multiple regression, the relationship between a consumer's perceived brand image of Aerie and her self-congruence was tested. The result showed that Aerie brand image is a significant predictor of the self-congruence with the Aerie brand (see Table 4.10, and Figure 4.6). The significant $F$ value indicated that the equation was significant in predicting perceived Aerie brand image $[F(1,404)=179.06, p<.001]$. The $t$-values showed that the perception of Aerie brand image significantly contributed to the relationship with self-congruence. Regarding Aerie brand image, the coefficient of multiple correlation $(R)$ was .56, and the square of the correlation coefficient $\left(R^{2}\right)$ was .31 , demonstrating that $31 \%$ of the variance in self-congruence was described by the equation that included Aerie brand image perception. The standardized regression coefficients $(\beta)$ showed Aerie brand image $(\beta=.56, p<.05)$ contributed in predicting self-congruence. The result showed that the respondents who thought highly of Aerie's brand image also demonstrated self-congruence for the brand.

Table 4.10

Relationship between Aerie Brand Image and Self-Congruence (Hypothesis 3)

\begin{tabular}{lccccc}
\hline Step and predictor variable & $R^{2}$ & $\mathrm{~B}$ & $\beta$ & $t$ & $P$ \\
\hline Step 1 & & & & & \\
$\quad .31$ & & & & \\
$\quad$ Constant & & -.49 & & & \\
$\quad$ Aerie Brand Image & & .74 & .56 & 13.38 & .000 \\
${ }^{* *} p<.001$ & & & & &
\end{tabular}




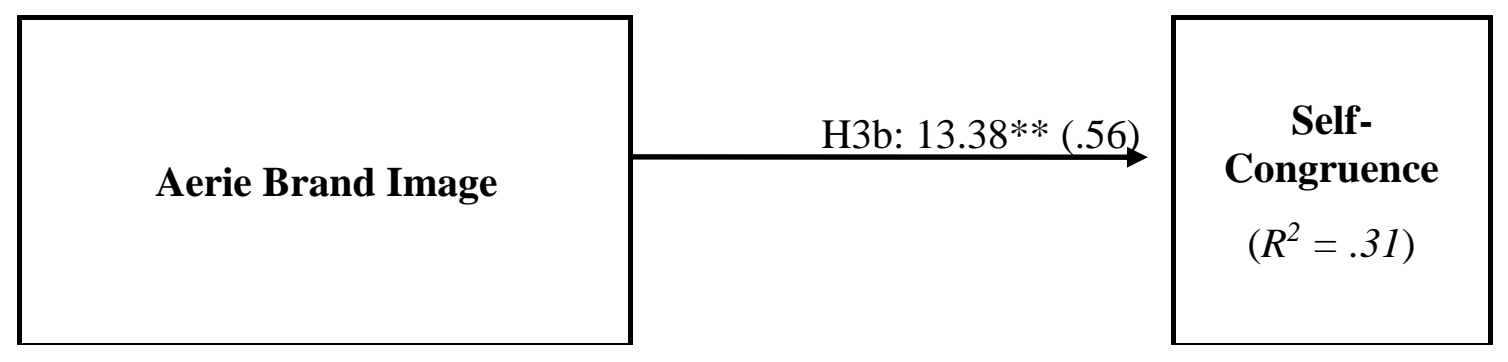

Figure 4.6 Relationship between Aerie Brand Image and Self-Congruence (Hypothesis 3)

Notes: $t$ value and standardized regression coefficients were presented.

A solid line indicated a significant relationship existed between the two variables. $* * p<.001$

$\mathrm{H} 3 \mathrm{~b}$ was also supported indicating a relationship between Aerie brand image perception and self-congruence.

\section{Relationship between Victoria's Secret Image Preference and Self-Congruence and Aerie Image Preference and Self-Congruence (Hypothesis 4)}

Hypothesis 4 (H4) was formulated to test the relationship between Victoria's Secret image preference, Aerie Brand image preference and self-congruence. H4 was formulated as below:

- H4a There is a relationship between Victoria's Secret image preference and selfcongruence.

- $\mathrm{H} 4 \mathrm{~b}$ There is a relationship between Aerie image preference and self-congruence.

The relationships between a consumer's image preference of a Victoria Secret's online advertising photo and her self-congruence with the brand were tested using multiple regression. The results showed that Victoria's Secret image preference is a predictor of the self-congruence with the brand (see Table 4.11 and Figure 4.6). The significant $F$ value indicated that the equation was significant in predicting Victoria's Secret image preference $[F(1,404)=179.06, p$ 
$<.001$. The $t$-values showed that Victoria's Secret image preference significantly contributed to the relationship with self-congruence. The coefficient of multiple correlation $(R)$ was .45 , and the square of the correlation coefficient $\left(R^{2}\right)$ was .20 , indicating that $20 \%$ of the variance in selfcongruence was explained by the equation that included Victoria's Secret image preference. The standardized regression coefficients $(\beta)$ showed Victoria's Secret image preference $(\beta=.45, p$ $<.05)$ contributed in predicting self-congruence. These results showed that the respondents who demonstrated a preference for a brand specific advertising photo, such as Victoria's Secret shared a relationship with self-congruence for the brand.

Table 4.11

Relationship between Victoria's Secret Image Preference and Self-Congruence (Hypothesis 4)

\begin{tabular}{lccccc} 
Step and predictor variable & $R^{2}$ & $\mathrm{~B}$ & $\beta$ & $t$ & $p$ \\
\hline Step 1 & & & & & \\
$\quad$ Constant & .31 & & & & \\
$\quad$ Victoria's Secret Image & & .89 & & & \\
$\quad$ Preference & & .64 & .45 & 9.97 & .000 \\
${ }^{* *} p<.001$ & & & &
\end{tabular}

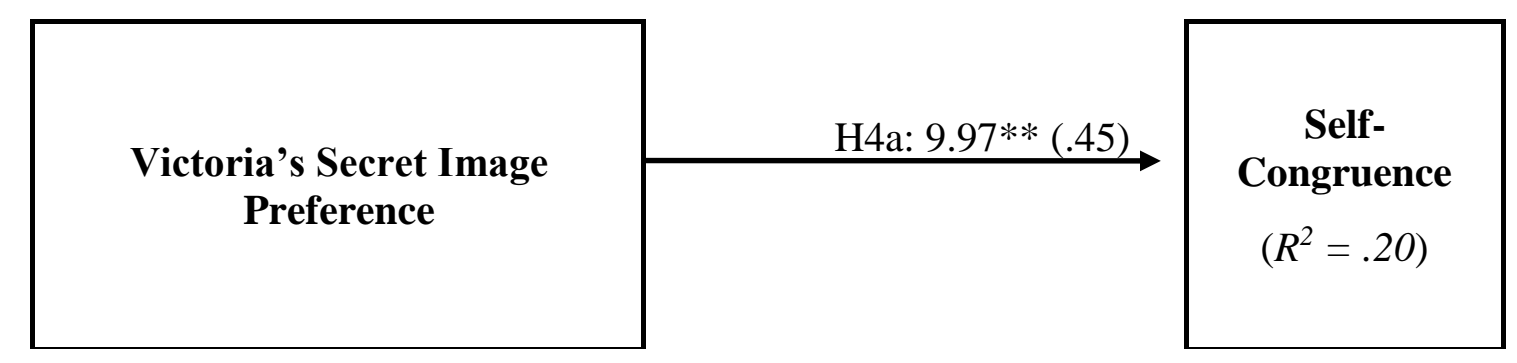

Notes: $t$ value and standardized regression coefficients were presented.

A solid line indicated a significant relationship existed between the two variables. ** $p<.001$

Figure 4.7 Relationship between Victoria's Secret Image Preference and Self-Congruence (Hypothesis 4) 
Using stepwise multiple regression, the relationships between a consumer's image preference of an online advertising Aerie image and their self-congruence were tested. The results showed that Aerie image preference is a significant variable included in the final regression equation (see Table 4.12 and Figure 4.7). The significant $F$ value indicated that the equation was significant in predicting Aerie image preference $[F(1,404)=70.4, p<.001$. The $t$ values showed that Aerie image preference significantly contributed to the relationship with selfcongruence. The coefficient of multiple correlation $(R)$ was .39 , and the square of the correlation coefficient $\left(R^{2}\right)$ was .15 , indicating that $15 \%$ of the variance in self-congruence was explained by the equation that included Aerie image preference. The standardized regression coefficients $(\beta)$ showed Aerie $(\beta=.39, p<.05)$ contributed in predicting self-congruence. These results showed that the respondents who demonstrated a preference for Aerie's online advertising image shared a relationship with self-congruence for the brand.

Table 4.12

Relationship between Aerie Image Preference and Self-Congruence (Hypothesis 4)

\begin{tabular}{|c|c|c|c|c|c|}
\hline Step and predictor variable & $R^{2}$ & $\mathrm{~B}$ & $\beta$ & $t$ & $p$ \\
\hline Step 1 & .15 & & & & \\
\hline Constant & & 1.02 & & & \\
\hline Aerie Image Preference & & .49 & .39 & 8.37 & .000 \\
\hline
\end{tabular}




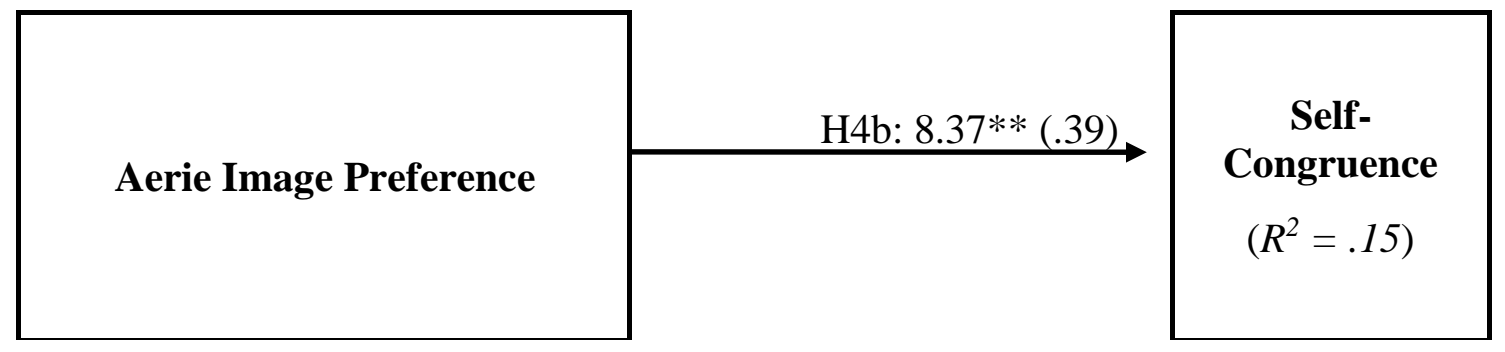

Notes: $t$ value and standardized regression coefficients were presented.

A solid line indicated a significant relationship existed between the two variables. $* * p<.001$

Figure 4.8 Relationship between Aerie Image Preference and Self-Congruence (Hypothesis 4)

Based on the above results, H4b were supported implying a significant relationship between Aerie image preference and self-congruence. These relationships imply that if a respondent prefers a brand's online advertising image they will personally identify with the brand on a deeper level.

Relationship between Victoria's Secret Brand Preference, Self-Respect and Self-Worth and Aerie Brand Preference, Self-Respect, and Self-Worth (Hypothesis 5)

Hypothesis 5 (H5) was formulated to test the relationship between Victoria's Secret brand image, Aerie Brand Image and self-congruence. H5 was formulated as below:

○ H5a A consumer's level of self-respect has a relationship with brand preference toward Victoria's Secret.

○ H5b A consumer's level of self-worth has a relationship with brand preference toward Victoria's Secret.

○ H5c A consumer's level of self-respect has a relationship with brand preference toward Aerie. 
○ H5d A consumer's level of self-worth has a relationship with brand preference toward Aerie.

The relationship between self-respect, self-worth and Victoria's Secret brand preference were tested using stepwise multiple regression. The results showed that self-respect is a significant variable included in the final regression equation (see Table 4.13 and Figure 4.9). The significant $F$ values for self-respect $[F(1,404)=14.56, p<.001]$ indicated that the equation was significant in predicting Victoria's Secret brand preference. The $t$-values showed that the perception of self-respect significantly contributed to the relationship with Victoria's Secret brand preference. For self-respect, the coefficient of multiple correlation $(R)$ was .19, and the square of the correlation coefficient $\left(R^{2}\right)$ was .04 , indicating that $4 \%$ of the variance in Victoria's Secret brand preference was explained by the equation that included self-respect. The standardized regression coefficients $(\beta)$ showed self-respect $(\beta=.19, p<.05)$ played a role in predicting Victoria's Secret brand preference.

In regards to self-worth, the standardized regression coefficients $(\beta)$ showed $(\beta=-.04, p$ $<.05)$ did not play a role in predicting Victoria's Secret brand preference. These results indicate that self-respect shares a relationship with Victoria's Secret brand preference while self-worth did not.

Table 4.13

Relationship between Self-Respect, Self-Worth, and Victoria's Secret Brand Preference (Hypothesis 5)

\begin{tabular}{lrrrrr} 
Step and predictor variable & $R^{2}$ & $\mathrm{~B}$ & $\beta$ & $t$ & $p$ \\
\hline Step 1 & & & & & \\
$\quad$ Constant & .04 & & & & \\
Self-Respect & & 2.60 & & 3.82 & .000 \\
\hline
\end{tabular}




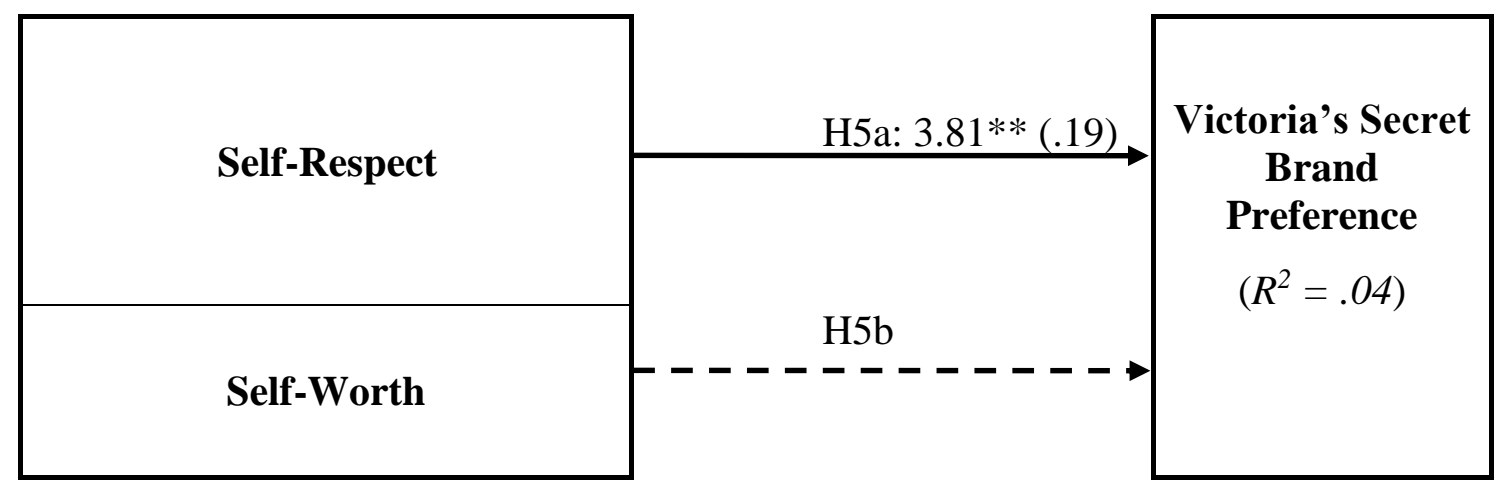

Notes: $t$ value and standardized regression coefficients were presented.

A solid line indicated a significant relationship existed between the two variables and a dash line indicated the two variables were not significant related.

$* * p<.001$

Figure 4.9 Relationship between Self-Worth and Victoria's Secret Brand Preference (Hypothesis $5 a-5 b)$

Based on the above results, H5b was partially supported as there is a shared relationship between self-respect and Victoria's Secret Brand Preference.

The relationship between self-respect and self-worth, and Aerie brand preference were tested using stepwise multiple regression. The results showed that self-worth is a significant variable included in the final regression equation (see Table 4.14 and Figure 4.10). The significant $F$ values for self-worth $[F(1,404)=11.28, p<.001]$ indicated that the equation was significant in predicting perceived Aerie brand preference. The $t$-values showed that self-worth significantly contributed to the relationship with Aerie brand preference. The coefficient of multiple correlation $(R)$ was .17 , and the square of the correlation coefficient $\left(R^{2}\right)$ was .03 , indicating that $3 \%$ of the variance in Aerie brand preference was explained by the equation that included self-worth. The standardized regression coefficients $(\beta)$ showed self-worth $(\beta=-.17, p$ 
$<.01)$ played a role in predicting Aerie brand preference. These results indicate that there is a stronger relationship between self-worth and Aerie brand preference than there is with selfrespect and Aerie brand preference. This relationship indicates that respondents with lower selfworth prefer the brand Aerie.

Table 4.14

Relationship between Self-Respect, Self-Worth, and Aerie Brand Preference (Hypothesis 5)

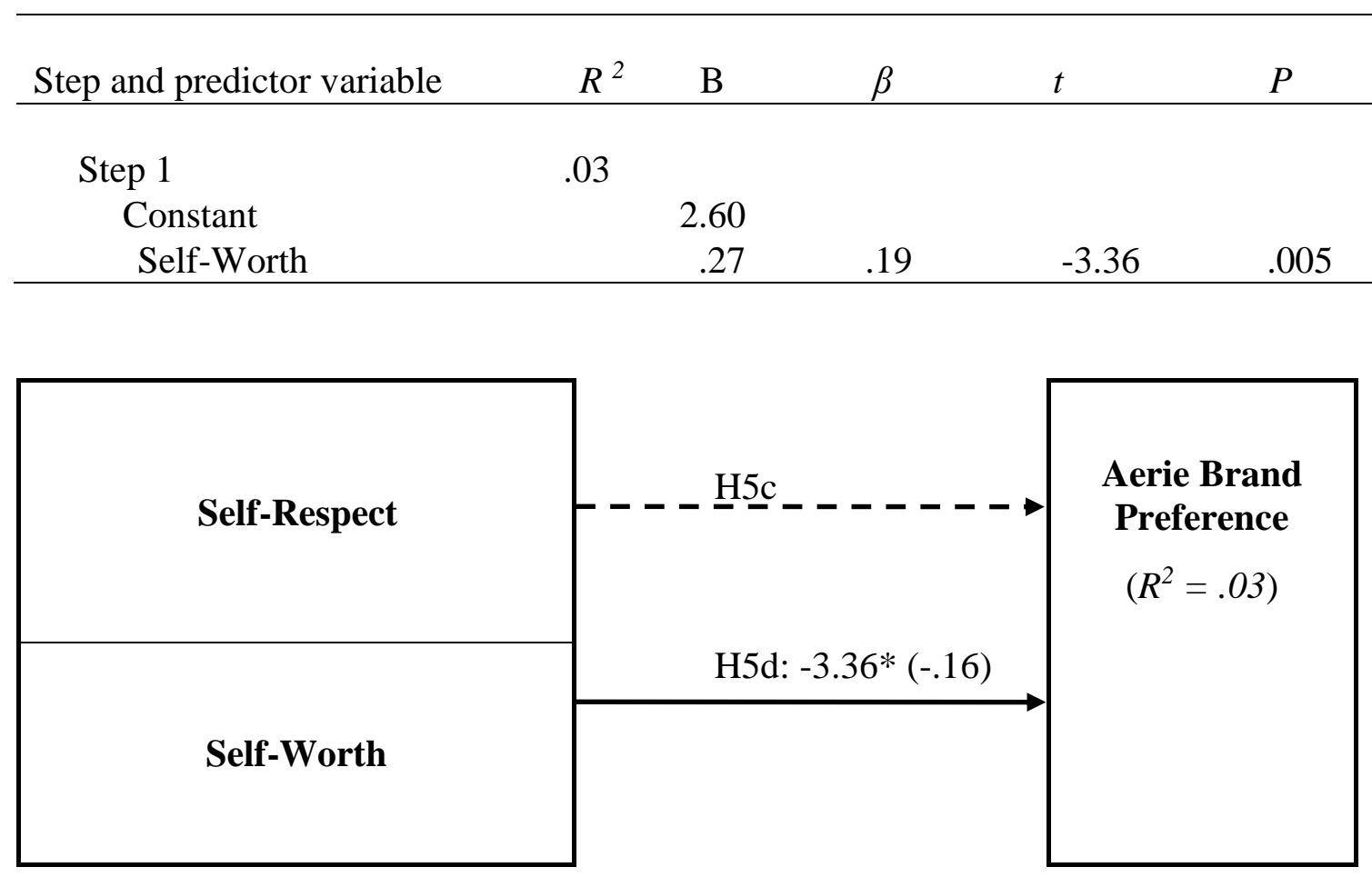

Notes: $t$ value and standardized regression coefficients were presented.

A solid line indicated a significant relationship existed between the two variables and a dash line indicated the two variables were not significant related.

$* p<.01$

Figure 4.10 Relationship between Self-Worth and Aerie Brand Preference (Hypothesis 5c-5d)

Based on the above results, the relationship between self-respect and Aerie Brand Preference was not significant, so H5c was not supported. H5d was supported as there is a strong relationship with self-worth and Aerie Brand Preference. This relationship implies that a 
respondent's level of self-worth correlates with their brand preference toward Aerie. Self-respect did not share a significant relationship with Aerie brand preference.

\section{Relationship between Self-Congruence and Victoria's Secret Brand Preference and Self- Congruence and Aerie Brand Preference (Hypothesis 6)}

Hypothesis 6 (H6) was formulated to test the relationship between Victoria's Secret brand image, Aerie Brand Image and self-congruence. H6 was formulated as below:

- H6a Consumers who feel themselves congruent with Victoria's Secret prefers the brand Victoria's Secret.

- H6b Consumers who feel themselves congruent with Aerie prefers the brand Aerie.

To test the relationship between self-congruence and Victoria's Secret brand preference multiple regression was used. The result showed that self-congruence with Victoria's Secret is a predictor for the brand preference (see Table 4.15 and Figure 4.11). The significant $F$ values for self-congruence $[F(1,404)=343.08, p<.001]$ indicated that the equation was significant in predicting Victoria's Secret brand preference. The $t$-values showed that the perception of selfcongruence significantly contributed to the relationship with Victoria's brand preference. In regards to self-congruence, the coefficient of multiple correlation $(R)$ was .68 , and the square of the correlation coefficient $\left(R^{2}\right)$ was .46 , indicating that $46 \%$ of the variance in Victoria's Secret brand preference was explained by the equation that included self-congruence. The standardized regression coefficients $(\beta)$ showed self-congruence $(\beta=.68, p<.01$ played a vital role in predicting Victoria's Secret brand preference. These results indicate that there is a strong relationship between self-congruence and Victoria's Secret brand preference. This relationship 
implies that respondents who possess strong self-congruence with Victoria's Secret will prefer Victoria's Secret as a brand.

Table 4.15

Relationship between Self-Congruence and Victoria's Secret Brand Preference (Hypothesis 6)

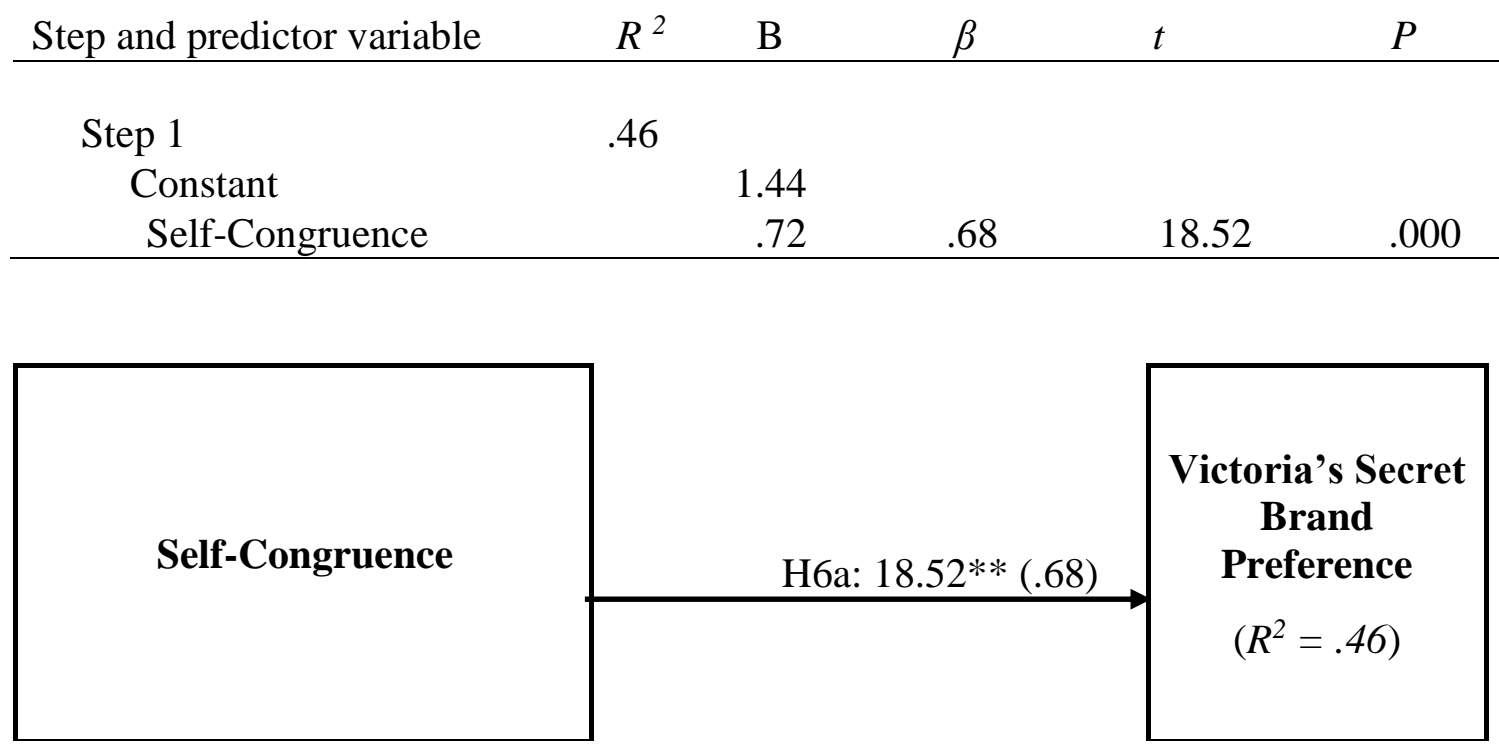

Notes: $t$ value and standardized regression coefficients were presented.

A solid line indicated a significant relationship existed between the two variables. $* * p<.001$

Figure 4.11 Relationship between Self-Congruence and Victoria's Secret Brand Preference (Hypothesis 6)

Based on the above results, H6a was supported as there is a strong relationship between self-congruence and Victoria's Secret Brand Preference. This relationship demonstrates that a respondent's level of self-congruence correlates with their brand preference toward Victoria's Secret.

To test the relationship between self-congruence and Aerie brand preference stepwise multiple regression was used. The results showed that self-congruence with the brand Aerie was a predictor of the brand preference (see Table 4.16 and Figure 4.12). The significant $F$ values for 
self-congruence $[F(1,404)=145.90, p<.001]$ indicated that the equation was significant in predicting Aerie brand preference. The $t$-values showed that the perception of self-congruence significantly contributed to the relationship with Aerie preference. In regards to self-congruence, the coefficient of multiple correlation $(R)$ was .51 , and the square of the correlation coefficient $\left(R^{2}\right)$ was .27 , indicating that $27 \%$ of the variance in Aerie brand preference was explained by the equation that included self-congruence. The standardized regression coefficients $(\beta)$ showed selfcongruence $(\beta=.52, p<.01$ helped predict Aerie brand preference. These results indicate that there is a relationship between self-congruence and Aerie brand preference. This relationship exhibits that respondents who identify themselves as congruent with Aerie will prefer the brand Aerie.

Table 4.16

Relationship between Self-Congruence and Aerie Brand Preference (Hypothesis 6)

\begin{tabular}{lllllll} 
Step and predictor variable & $R^{2}$ & $\mathrm{~B}$ & $\beta$ & $t$ & $P$ \\
\hline
\end{tabular}

Step 1

Constant Self-Congruence

Self-Congruence
.27 .52 12.08 .000

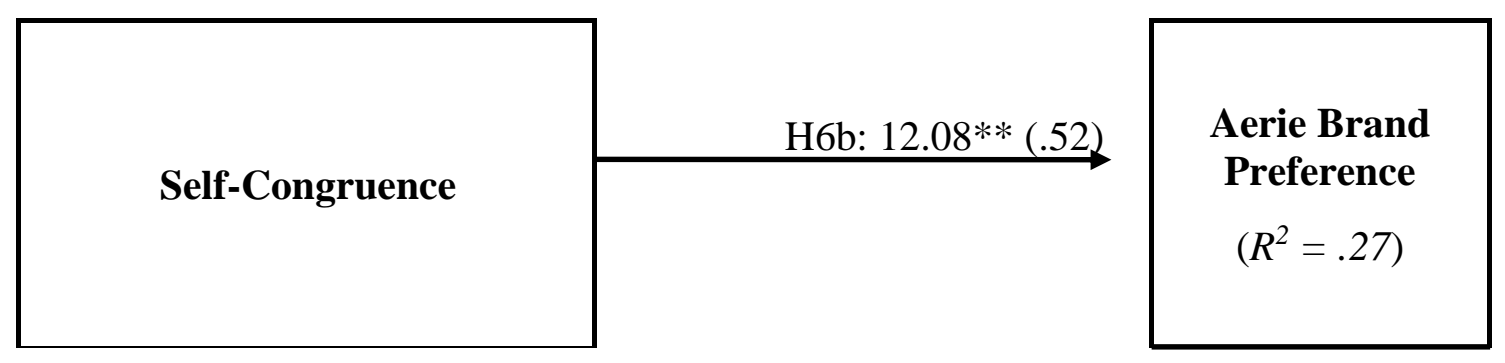

Notes: $t$ value and standardized regression coefficients were presented. A solid line indicated a significant relationship existed between the two variables. $* * p<.001$

Figure 4.12 Relationship between Self-Congruence and Aerie Brand Preference (Hypothesis 6) 
Based on these results, H6b was accepted as there is a relationship between selfcongruence and Aerie Brand Preference. This relationship demonstrates that a respondent's selfcongruence links with their brand preference toward Aerie.

Table 4.17

Hypothesized Relationships and Summary of Results

\section{Hypothesis 1}

H1a There is a relationship between confidence in body image and self-respect.

$\mathrm{H} 1 \mathrm{~b}$ There is a relationship between anxiety in body image and self-respect.

H1c There is a relationship between the perceived weight and self-respect.

H1d There is a relationship between confidence in body image and self-worth.

H1e There is a relationship between anxiety in body image and self-worth.

H1f There is a relationship between the perceived weight and self-worth.

Significant variables based on relative magnitudes of the standardized regression coefficients

1. Confidence in Body Image (H1a, H1d)

2. Anxiety in Body Image (H1e)

3. Weight Perception (H1f)

\section{Conclusion for Hypothesis 1}

H1 was partially supported. There was a relationship between self-respect and confidence in body image. There was no relationship between anxiety in body image, weight perception and self-respect. In regards to self-worth, confidence in body image, anxiety in body image, and weight perception each shared a relationship with selfworth.

$\mathrm{H} 2$.

H2a Online visual media literacy affects self-respect.

H2b Online visual media literacy affects self-worth. 


\section{Conclusion for Hypothesis 2}

$\mathrm{H} 2$ was fully supported, indicating that online visual media literacy is a predictor for both self-respect and self-worth.

H3.

H3a A consumer's perceived brand image of Victoria's Secret affect their selfcongruence.

H3b A consumer's perceived brand image of Aerie affect their self-congruence Conclusion for Hypothesis 3

H3 was fully supported, indicating a significant relationship between selfcongruence, Victoria's Secret brand image perception Aerie brand image perception. $\mathrm{H} 4$.

H4a There is a relationship between Victoria's Secret image preference and self-congruence.

$\mathrm{H} 4 \mathrm{~b}$ There is a relationship between Aerie image preference and self-congruence.

\section{Conclusion for Hypothesis 4}

H4 was fully supported, implying a strong relationship between self-congruence, Victoria's Secret image preference and Aerie image preference.

H5.

H5a A consumer's level of self-respect has a relationship with brand preference toward Victoria's Secret.

H5b A consumer's level of self-worth has a relationship with brand preference toward Victoria's Secret.

H5c A consumer's level of self-respect has a relationship with brand preference toward Aerie.

H5d A consumer's level of self-worth has a relationship with brand preference toward Aerie. 

Significant variables based on relative magnitudes of the standardized regression coefficients
1. Self-Respect
2. Self-Worth

\section{Conclusion for Hypothesis 5}
H5 was partially supported concluding that there was a relationship between Victoria's Secret brand preference and self-respect. Self-worth did not have a relationship with Victoria's Secret brand preference.

H6.

H6a The self-congruence between consumer and Victoria's Secret affects consumer brand preference.

H6b The self-congruence between consumer and Aerie affects consumer brand preference.

\section{Conclusion for Hypothesis 6}

H6 was fully supported as Victoria's Secret brand preference and Aerie brand preference share a relationship with self-congruence. H6 was fully supported as Victoria's Secret brand preference and Aerie brand preference share a relationship with self-congruence. 


\section{Chapter Five}

\section{Summary, Conclusion, Discussion and Implications}

\section{Summary}

Using multiple regression to test the hypotheses, the following conclusions were made. There was a relationship between self-respect and confidence in body image. However, selfrespect showed no association with anxiety in body image and weight perception. Self-worth shared a connection with each extracted factor from body image: confidence in body image, anxiety in body image, and weight perception. Online visual media literacy had significant associations with both self-respect and self-worth. Self-congruence exhibited a significant relationship with Victoria's Secret brand image perception, Aerie brand image perception, Victoria's Secret image preference and Aerie image preference. Self-respect confirmed a connection between Victoria's Secret brand preference, and self-worth proved to have an association with Aerie brand preference. Victoria's Secret brand preference and Aerie brand preference shared a relationship with self-congruence. The following section includes a discussion and implication based on the above findings from the hypotheses testing. The discussion of the results and implications are followed by the limitations and conclusion of this study.

\section{Discussion}

This study was designed to predict brand preference of fashion brands Victoria's Secret and Aerie, by investigating the relationships among the brand preference of the two brands, and 
body image, online visual media literacy, brand image, image preference, self-esteem, and selfcongruence.

Mendelson, Mendelson, and White (2010) determined that self-esteem influences body image perception focusing on elements such as: general feelings about appearance, weight satisfaction and evaluations attributed to others about one's body and appearance. For this study, the researcher used the Body Esteem Scale for Adolescents and Adults (BESAA) developed by Mendelson, Mendelson and White (2001) to measure body image, social comparison and perceptions of how others view them. An exploratory factor analyses was completed and body image and self-esteem both extracted factors. Body image had three factors which were labeled as confidence in body image, anxiety in body image, and weight perception.

Self-esteem extracted two factors - self-respect and self-worth. Self-respect is defined by Rawls (1999) as one's power to fulfill one's intentions. This definition focuses on an individual's drive to accomplish their goals while self-worth was described by Covington (1992) as the tendency to establish and maintain a positive self-image. Covington's definition of self-worth delves into self-image, which involves physical attributes encompassing how one views their own self. Using the Rosenberg self-esteem scale (1965), what distinguishes self-respect from self-worth is a stable, confident outlook one has on their abilities to achieve success. The extracted factor self-respect used phrases such as: "I feel that I am a person of worth, at least on an equal plane with others," "I feel that I have a number of good qualities," and "I take a positive attitude toward myself." The self-worth factor illustrated a negative perception on personal value using phrases such as: "I feel I do not have much to be proud of," "I wish I could have more respect for myself," and "I certainly feel useless at times." 
The questions that were labeled as confidence in body image ("I'm proud of my body") reflected pride in physical appearance. The findings of Golan, Hagay, and Tamir (2014) supported this connection as they determined when children completed a program to instill selfrespect, their body image perceptions were raised, giving them more confidence to accomplish their goals. These findings further justified the non- existing relationship between self-respect and anxiety in body image as the latter reflected a poor outlook on physical appearance using statements such as: "There are lots of things I'd change about my looks if I could," "I wish I looked better," and "I wish I looked like someone else." Since anxiety in body image represented a negative body image perception, these results were comparable with those of Hume and Mills (2013) who found that women with lower self-esteem had negative body image perception. While the first two body image factors related to positive and negative outlooks on appearance, the third extracted factor stands on neutral ground, titled weight perception.

The third factor extracted from body image was entitled weight perception and included statements such as: "I am satisfied with my weight," "I feel I weigh the right amount for my height," and "I really like what I weigh." Weight perception proved to share a significant relationship with self-worth but not self-respect. These findings indicate that one's perception of weight may lead to a negative self-image, lowering their self-worth. An example illustrating this concept is the research by Mendelson et al. (2010) who demonstrated that weight perceptions can be separated from feelings about one's overall appearance.

In order to test the relationships between each extracted factor from body image confidence in body image, anxiety in body image, and weight perception with self-respect and then self-worth, multiple regression was used. After running multiple regression, the results indicated that confidence in body image shared a significant relationship with self-respect while 
anxiety in body image and weight perception did not. This means if an individual had good feelings based on their appearance, they were motivated to fulfill their intentions. While Golan et al. (2014) justified this relationship, they also found that gender and peer influence shared strong relationships with declining self-worth among children.

In regards to self-worth, each factor proved to have a statically significant relationship indicating the importance of overall body image with self-worth. Crocker and Wolfe (2001) confirmed the relationship body image shares with self-worth, as they justified that thoughts on appearance reflected an individual's self and a summarization of their worth.

After substantiating relationships between body image and self-esteem, the variable online visual media literacy was tested since the nature of the study involved online fashion advertising photographs. The second hypotheses tested relationships between online visual media literacy, self-respect and self-worth. Online visual media literacy proved to share significant relationships with both self-respect and self-worth. Using online visual media literacy statements ("Computer software is commonly used to alter the images of women in online fashion advertisements") to test respondents' knowledge of digital manipulation indicated that when an individual possessed the knowledge that a photo had been digitally manipulated, their self-respect was higher. When one possessed online visual media literacy, they did not have a strong sense of self-worth. Both of these results corroborate the importance of online visual media literacy. Chona, Foster, and Radford (2007), Davidson, and O’Dea (2003), and Tirlea, Truby, and Haines (2013) each support this finding as they uncovered that by educating females about the media, increasing their media literacy resulted in raised levels of self-esteem.

Analyzing the relationships that body image and online visual media literacy have with self-esteem, have allowed for better familiarization with the respondents perceptions on 
themselves and on digitally manipulated media. In order to ultimately test respondents' opinions of Victoria's Secret and Aerie, other factors such as brand image and self-congruence were analyzed.

Brand image and self-congruence were measured for both brands - Victoria's Secret and Aerie. Sung and Choi (2010) postulated that the theory of self-congruence is based on the notion that consumers use brands to illustrate their self-concepts and to make assumptions about others.

For each brand, statements measuring brand image perception ("Aerie comes to mind immediately when I want to purchase a fashion product") and self-congruence ("Wearing Victoria's Secret underwear is consistent with how I see myself") were presented to the respondents. The results concluded that Victoria's Secret brand image shared a relationship with self-congruence and Aerie brand image also shared a connection with self-congruence. These findings supported that of Mulyanegara and Tsarenko (2009) and Cho, Fiore, and Russell (2015) supporting a consumer's views of a brand will reflect their own personality, values, and prestige.

Using online advertising fashion photographs as a tool for this study, respondents were shown statements (I don't like looking at this online fashion advertisement, The model shown in this online fashion advertisement is attractive) about their opinions of two images. The regression results indicated that there was a significant relationship between self-congruence, Victoria's Secret image preference, and Aerie image preference. These results align with D'Alessandro and Chitty (2011) who found that when female participants were exposed to a relatable model in a fashion ad, who was a similar size and ethnicity to the participant, reacted positively toward the brand. These findings indicate that respondents who demonstrate an advertising image preference will be more likely to identify with the brand. 
Using self-respect and self-worth to predict brand preference among Victoria's Secret and Aerie, an interesting conclusion was drawn through multiple regression analysis. Victoria's Secret brand preference and self-respect presented a strong relationship, while self-worth and Victoria's Secret brand preference did not. This may be explained through Social Comparison Theory as respondents who demonstrated high levels of self-respect could identify with the Victoria's Secret advertising images as they did not feel the models were a threat to their own self-image. In Social Comparison Theory, when one is exposed to an unrealistic image, they may feel poorly about their own appearance, disregard the image, or relate to the image if they have a high opinion of their physical appearance. These results may indicate that the respondents think highly of their physical appearance so they embrace the Victoria's Secret brand completely. However, since Victoria's Secret brand preference and self-worth shared no relationship, this may indicate that respondents think less of themselves as successful, goal achieving individuals. Self-respect and brand preference have been researched by Mulyanegara and Tsarenko (2009) who found that individuals who exhibited self-respect, accomplishment, and self-fulfillment are more prone to prestige sensitivity affecting brand preferences. This notion of respondents exhibiting high self-respect and low self-worth support Malar, Krohmer, Hoyer, and Nyffenegger (2011) who suggested that high levels of self-respect and self-worth strengthens the relationship between self-congruence with a brand. Explained by the self-verification process, consumers with high self-esteem are attracted to a brand that matches their ideal self. Identifying with a brand that one images embodies their sense of self boosts consumer's feelings about themselves and creates a stronger association.

For Aerie, the results indicated a strong relationship with self-worth and no relationship with self-respect. These results could be influence by Aerie's brand image as the brand projects a 
body positive and 'girl next door' theme (American Eagle, 2016). Respondents who may not identify with Victoria's Secret's luxurious fantasy (Hume \& Mills, 2013) may lean toward Aerie out of brand image perception and style preference. Brand image perception may be an important factor in determining brand preference. Since Aerie proudly boasts that they do not digitally manipulate their models (Beer, 2014), respondents may admire this tactic and their efforts to represent a more diverse spectrum of women's bodies in their advertisements. The relationship between self-worth and Aerie demonstrates that respondents are aware of their physical imperfections and are accepting of Aerie in order to help maintain a positive self-image. Social Comparison Theory states that when an individual sees an image as a non-threat, like the models featured in Aerie advertising campaigns, the social comparisons are likely to inspire self-worth raising overall self-image (Knobloch-Westerwick \& Romero, 2011). Consumers will then compare their self-image with the brand image and use the brand to validate how they are representing themselves (Sirgy, 1982).

During the last multiple regression analysis, self-congruence and brand preference were tested with each brand. The results demonstrated that respondents who displayed strong selfcongruence with Victoria's Secret ultimately had a brand preference for Victoria's Secret. Respondents who identified having self-congruence with Aerie had a brand preference for Aerie. Previous research (Dolich, 1969; Piacentini \& Mailer, 2004; Sirgy, Grewal, Mangleburg, Park, Chon, Clairborne, \& Berkman, 1997) align with these results as findings preferred brands were ranked as similar to their own self-concepts and brands that were labeled as least preferred did not coincide with their self-image. For example, Sirgy, Grewal, Mangleburg, Park, Chon, Claiborne, \& Berkman (1997) surveyed individuals on their concepts of brand image and self- 
congruence with athletic footwear brands. The results showed that the participants' self-image matched the brand image of their preferred brand.

\section{Implications}

Based on the above interpretation of the study results, there are a multitude of components that led up to predicting brand preference. The study suggests that self-congruence and self-respect have a positive influences on Victoria's Secret brand preference, and selfcongruence and self-worth with Aerie brand preference. These findings coincide with Social Comparison Theory, stating that individuals will compare themselves to images and utilize these comparisons for self-evaluation or self- enhancement. Social Comparison Theory is vital to this study because often consumers compare their lives to the fantasy based illustrations in advertisements and this could result in negative self-worth (Bissell, 2006). Body image is often researched within Social Comparison Theory as audiences make comparisons between their physical appearance and that of models in advertisements. Understanding Social Comparison Theory gives researchers a better idea toward understanding the thoughts of consumers and how they identify with fashion brands when the advertisements are Photoshopped and another that is not digitally altered. Consumers may often utilize upward comparison with Victoria's Secret advertisements, comparing their lives to the glamorous concepts illustrated in the advertisements (Bissell, 2006). As these upward comparisons are being made, consumers' standards for attractiveness increases and satisfaction with one's own attractiveness decreases resulting in inferior evaluations of their own self-worth (Richins, 1991). In order to combat these negative comparisons, Victoria's Secret could feature more diverse models to appeal to a wider market, all while maintaining its brand image of fantasy and luxury (Hume \& Mills, 2013), based on the finding of this study that confidence in body image led to self-respect, which shared a 
relationship with Victoria's Secret brand preference. When consumers have a positive sense of body image, they enjoy shopping more (Yu \& Damhorst, 2015), therefore if an emphasis in body acceptance was projected through Victoria's Secret's advertisements, a more broad audience could be reached.

Aerie can continue to promote their non-Photoshop policy and feature a wide variety of models that carry the brand's positive message. Promoting the brand through online visual media literacy tactics will allow Aerie to stand out among competitors for shedding light on the topic of digital alteration. Since those who preferred Aerie demonstrated low self-worth, Aerie should continue to promote self-acceptance. Aerie may find that partnering with a respected media figure to promote acceptance and healthy living could embody their brand's message and give consumers a relatable connection. This plan of action relates back to Social Comparison Theory, for when consumers are faced with an advertisement featuring a model who seems relatable, they are labeled a 'non-competitor'. An individual may then view the non-competitor as inspiring, resulting in an upward comparison driven by self-improvement (Knobloch-Westerwick \& Romero, 2011). Based on the above premise of the Social Comparison Theory, Aerie, by promoting the real image of relatable models, it can still create a desirable brand image through consumers' upward social comparison, which may lead to an increase of product demand due to consumer aspiration.

Both brand image and image preference were linked to brand specific self-congruence. Victoria's Secret and Aerie can continue to embrace what their brands represent and release promotions to inspire their audiences. Victoria's Secret may consider focusing on their brand image by continuing to market attainable luxury items with more size options. While Victoria's Secret's current marketing embodies a luxurious fantasy, having expanded size options will give 
women who like the brand image a chance to partake in using the product. Because Aerie's target audience ranges from 15-25 (Mintel, 2011), online visual media literacy education is vital to spreading their message and ensuring their demographic knows the difference between Aerie's advertisements and those of competitors, thus strengthening consumers' self-congruence. Since Aerie is already partnered with the National Eating Disorder Association (NewsRX LLC, 2015), they could reach out to other partnering organizations to help spread the notion of non-digitally altered, realistic advertising. Aerie may consider hosting panels or body positive workshops in high schools and colleges as well.

Future research with Victoria's Secret and Aerie could analyze consumer self-congruence and specific adjectives used to describe each brand. Using those adjectives could better know the consumer and help formulate a more refined brand image within their marketing. For example, users who hold congruence with Aerie may use words like: positive, authentic, and empowering to describe the brand. Aerie should then use these terms to shape their next marketing strategy, such as showcasing their athletic wear or creating a more versatile product for the active consumer. If Aerie were to partner with a yoga enthusiast, this would create a connection between Aerie's message and its product offering for yoga wear. Victoria's Secret users may associate the brand with adjectives such as: feminine, luxurious, and high fashion (Hume \& Mills, 2013). Victoria's Secret offers a line of body fragrances and cosmetics, these product offerings may tie in with consumers' brand image perception so Victoria's Secret may want to increase the marketing of paired items such as body fragrances and lingerie to appeal to this market. 


\section{Limitations}

An important limitation of this study was that there was only two brands being represented. For a future study, a more thorough representation of competing brands could be analyzed in order to represent brand preference for a more broad pool of respondents. Using a quantitative method was effective to explore the consumer behaviors related to online fashion advertisement. However, it was limited in that there was a lack of reasons as to why participants chose what they chose in the survey. Future research could utilize qualitative research using focus group or interviews. Another factor to consider was the respondents' demographic. While college aged females seem to make up the majority of Victoria's Secret and Aerie's target demographic (Mintel, 2011), it would be insightful to study high school aged females and older adult females and their perceptions on the brands.

\section{Conclusions}

As acknowledged in the literature review, body image, self-esteem, and brand preference are all complex concepts which are influenced by a wide scope of factors. This study has uncovered that there are multiple aspects of body image: confidence in body image, anxiety in body image, and weight perception, as well as self-esteem: self-respect and self-worth. Using these variables in addition to online visual media literacy, brand image, and image preference, this research solidifies previous studies connecting self-congruence to brand preference and online visual media literacy to self-respect. This newly innovated study is set apart from others within the field of fashion advertising due to a focus on online fashion advertising photos rather advertisements within magazines. As we live in a digital age, the research must reflect that. The current study also sheds light on digital alteration, a newly explored topic, offering respondents an online visual media literacy statement within the instrument. As a newly formed brand, there 
is not an extensive amount of literature available on Aerie as it has not been analyzed as thoroughly over the years as Victoria's Secret. Brands can benefit from this study by embracing their brand image and taking time to show more acceptance, diversity, and honesty within their advertisements. These are the things consumers remember, forming lasting relationships with a brand. 


\section{REFERENCES}

Aagerup, U. (2011).The influence of real women in advertising on mass market fashion brand perception. Journal of Fashion Marketing and Management, 15(4), 486-502.

Adamczyk, A. (2014, August 14). ModCloth is first retailer to sign anti-photoshop pledge. Forbes, Retrieved from http://www.forbes.com/sites/aliciaadamczyk/2014/08/14/modcloth-is-first-retailer-tosign-anti-Photoshop-pledge

Alexander, M., Connell, L. J., Presley, A. B. (2005). Clothing fit preferences of young female adult consumers. International Journal of Clothing Science and Technology, 17(1), 5264.

American Eagle (2014, January 17). Aerie for American Eagle. Retrieved from http://www.ae.com/aerie/guides/aeriereal

American Eagle (2015) 2015 10-K form. Retrieved from www.mergentonline.com

American Eagle (2016, February 15). Katie hi low lightly lined bra. Retrieved from https://www.ae.com/aerie/browse/product_details.jsp?productId=4442_7656_460

Avalos, L., Tylka, T.L., \& Wood-Barcalow, N. (2005). The Body Appreciation Scale: Development and psychometric evaluation. Body Image, 2, 285-297.

Bahadur, N. (2014, November 6). Victoria's Secret 'Perfect Body' campaign changes slogan after backlash. Huffington Post, Retrieved from 
http://www.huffingtonpost.com/2014/11/06/victorias-secret-perfect-bodycampaign_n_6115728.html

Balcetis, E., Cole, S., Chelberg, M., \& Alicke, M. (2013). Searching out the ideal: Awareness of ideal body standards predicts lower global self-esteem in women. Self and Identity, 12(1), $1-15$.

Balogun J.A. (1986). Reliability and construct validity of the Body Cathexis Scale. Perceptual and Motor Skills, 62, 927-933.

Bardone-Cone, A.M., Brownstone, L.M., Higgins, M.K., Fitzsimmons-Craft, E.E., \& Harney, M.B. (2013). Anxiety, appearance contingent self-worth, and appearance conversations with friends in relation to disordered eating: examining moderator models. Cognitive, Therapy, and Research, 37(5), 953-963.

Beer, J. (2014, January 24). "This is who we are now:" Why Aerie stopped retouching the models in its ads. Retrieved from http://www.fastcocreate.com/3025443/this-is-who-we-are-nowwhy-aerie-stopped-retouching-the-models-in-its-ads

Bessenoff, G. R. (2006). Can the media affect us? Social comparison, self-discrepancy, and the thin ideal. Psychology of Women Quarterly, 30, 239-251.

Bissell, K. (2004). The virtual model: College women's knowledge of digital manipulation of fashion photographs and body image distortion. Proceedings of Visual Communication Interest Group, ICA Annual Meeting, New Orleans. May 2004.

Bissell, K. (2006). Skinny like you: Visual literacy, digital manipulation and young women's drive to be thin. Studies in Media \& Information Literacy Education, 1(6), 1-14.

Bosnjak, M. \& Rudolph, N. (2008). Undesired self-image congruence in a low-involvement product context. European Journal of Marketing, 42(5/6), 702-712. 
Botta, R.A. (1999), Television images and adolescent girls' body image disturbance. Journal of Communication, 49, 22-41.

Botta, R. A. (2000). The mirror of television: A comparison of black and white adolescents' body image. Journal of Communication, 50(3), 144-159.

Brave Girls Alliance. (2014, June 12). Advertisers pledge form. Retrieved from http://www.bravegirlswant.com/advertisers-pledge-form.html

Broderick, R. (2014, January 21). Lingerie brand Aerie isn't retouching its models with Photoshop for its new ad campaign. Buzzfeed, Retrieved from http://www.buzzfeed.com/ryanhatesthis/lingerie-brand-aerie-isnt-retouching-theirmodels-with-photo\#.jojVo45mR

Buckingham, D. (2003). Media education: Literacy, learning, and contemporary culture. Cambridge, UK: Polity Press.

Cash, T. F., Cash, D. W., \& Butters, J. W. (1983). "Mirror, mirror, on the wall...?" Contrast effects and self-evaluations of physical attractiveness. Personality and Social Psychology Bulletin, 9(3), 351-358.

Cash, T.F., \& Pruzinsky, T. (2002). Body image: A handbook of theory, research, and clinical practice. New York, NY: Guilford Press.

Chang, P.-L., \& Chieng, M.-H. (2006). Building consumer-brand relationship: A cross-cultural experiential view. Psychology \& Marketing, 23, 927-959.

Cho, E., Fiore, A. M., \& Russell, D. W. (2015). Validation of a fashion brand image scale capturing cognitive, sensory, and affective associations: Testing its role in an extended brand equity model. Psychology \& Marketing, 32(1), 28-48. 
Choi, T., Liu, N., Liu, S., Mak, J., \& To, Y. (2010). Fast fashion brand extensions: An empirical study of consumer preferences. The Journal of Brand Management, 17(7), 472-487.

Choma, B., Foster, M., \& Radford, E. (2007). Use of objectification theory to examine the effects of a media literacy intervention on women. Sex Roles, 56, 581-590.

Coleman, R. (2008). The becoming of bodies. Feminist Media Studies, 8(2), 163-179.

Collins, R. L. (1996). For better or worse: The impact of upward social comparison on selfevaluations. Psychological Bulletin, 119(1), 51-69.

Cooley, C. H. (1920). Human nature and the social order. New York: Scribner's.

Covington, M.V. 1992. Making the Grade: A Self-Worth Perspective on Motivation and School Reform. New York: Cambridge Univ. Press.

Crocker, J., \& Schwartz, I. (1985). Prejudice and in-group favoritism in a minimal intergroup situation: Effects of self-esteem. Personality and Social Psychology Bulletin, 11, 379386.

Crocker, J., \& Wolfe, C. T. (2001). Contingencies of self-worth. Psychological Review, 108, 593-623. doi:10.1037/0033-295X.108.3.593

Cunningham, M. R., Roberts, A., Barbee, A., \& Druen, P. B. (1989). Their ideas of beauty are, on the whole, the same as ours: Consistency and variability in the cross-cultural perception of female physical attractiveness. Journal of Personality and Social Psychology, 68, 261-279.

Cusumano, D., \& Thompson, K. (1997). Body image and body shape ideals in magazines: Exposure, awareness, and internalization. Sex Roles, 701-721.

D'Alessandro, S. \& Chitty, W. (2011) "Real or Relevant Beauty? Body Shape and Endorser Effects on Brand Attitude and Body Image",Psychology and Marketing, 28(8), 843-878. 
Dittmar, H., \& Howard, S. (2004). Thin-ideal internalization and social comparison tendency as moderators of media models' impact on women's body-focused anxiety. Journal of Social and Clinical Psychology. 23(6), 768-791.

Dolich, I.J. (1969), Congruence relationships between self-images and product brands. Journal of Marketing Research, 6, 80-84.

Elmore, M. (2013). The Effect of Repeated Exposure to Advertising over Time. Retrieved from https://www.insightexpress.com/docs/default-source/white-papers/the-effect-offrequency-over-time.pdf?sfvrsn=2

Elmore, M. (2013). InsightExpress implements new approach to measuring the impact of frequency in digital campaigns. Retrieved from https://www.insightexpress.com/blog/post/molly-elmore/2013/11/20/insightexpressimplements-new-approach-to-measuring-the-impact-of-frequency-in-digital-campaigns

Ford, J. B., LaTour, M. S., \& Lundstrom, W. J. (1991). Contemporary women's evaluation of female role portrayals in advertising. Journal of Consumer Marketing, 8, 15-28.

Festinger, L (1954). A theory of social comparison processes. Human Relations. 7, 117-40

Gillen, M.M. \& Lefkowitz, E.S. (2011). Body size perceptions in racially/ethnically diverse men and women: implications for body image and self-esteem. North American Journal of Psychology, 13(3) 447-467.

Golan, M., Hagay, N., \& Tamir, S. (2014). Gender related differences in response to "in favor of myself" wellness program to enhance positive self \& body image among adolescents. Plos One, 9(3), e91778. doi:10.1371. 
Gonzales, A., \& Hancock, J. (2011). Mirror, mirror on my facebook wall: Effects of exposure to Facebook on self-esteem. Cyberpsychology, Behavior, and Social Networking, 14(1/2), 79-83.

Greene, S. (2011). Body image perceptions, interpretations and attitudes. New York: Nova Science.

Groesz, L. M., Levine, M. P., \& Murnen, S. K. (2002). The effect of experimental presentation of thin media images on body satisfaction: A meta-analytic review. International Journal of Eating Disorders, 31, 1-16.

Grogan, S. (1999). Body image: Understanding body dissatisfaction in men, women and children. London: Routledge.

Guindon, M. H. (2002). Toward accountability in the use of the self-esteem construct. Journal of Counseling and Development, 80(2), 204-214.

Harrison, K., \& Cantor, J. (1997). The relationship between media consumption and eating disorders. Journal of Communication, 47, 40-66.

Henderson-King, E., \& Henderson-King, D. (1997). Media effects on women's body esteem: Social and individual difference factors. Journal of Applied Social Psychology, 27, 399417.

Hosany, S., \& Martin, D. (2012). Self-image congruence in consumer behavior. Journal of Business Research, 65, 685-691.

Hu, J., Liu, X., Wang, S., Yang, Z. (2012). The Role of brand image congruity in Chinese consumers' brand preference. Journal of Product \& Brand Management, 21(1), 26-34.

Hume, M, \& Mills, M. (2013),"Uncovering Victoria's Secret", Journal of Fashion Marketing and Management: An International Journal, 17(4), 460 - 485. 
Ilieva, J., Baron, S., \& Healey, N. M. (2002). Online surveys in marketing research: Pros and cons. International Journal of Market Research, 44(3), 361-376.

Irving, L. M., \& Berel, S. R. (2001). Comparison of media literacy programs to strengthen college women's resistance to media images. Psychology of Women Quarterly, 25, 103111.

James, W. (1890). Principles of psychology (Vol. 1). New York: Henry Holt.

Johar, J. S., \& Sirgy, M. J. (1999). Value-expressive versus utilitarian advertising appeals: When and why to use which appeal, Journal of Advertising, 20, 23-35.

Kahle, L., \& Homer, P. (1985). Physical attractiveness of the celebrity endorser. Journal of Consumer Research, 11, 954-961.

Kamysheva, E., Wertheim, E., Skouteris, H., Paxton, S., \& Milgrom, J. (2009). Frequency, severity, and effect on life of physical symptoms experienced during pregnancy. Journal of Midwifery \& Women's Health, 54, 43-49.

Kang, J., \& Park-Poaps, H. (2011). Motivational antecedents of social shopping for fashion and its contribution to shopping satisfaction. Clothing and Textiles Research Journal, 29(4), $331-347$.

Keller, K. L. (1993). Conceptualizing, measuring, and managing customer-based brand equity. Journal of Marketing Research, 29, 1-22.

Knobloch-Westerwick, S., \& Romero, J. P. (2011). Body ideals in the media: Perceived attainability and social comparison choices. Media Psychology, 14(1), 27-48.

Kretz, V.E. (2011). Perceived reality of women in magazines (Unpublished Master's thesis). Marquette University, Milwaukee, Wisconsin. 
Kwak, D.H., \& Kang, J.H. (2009). Symbolic purchase in sport: the roles of self-image congruence and perceived quality. Management Decision, 47(1), 85-99.

Lennon, S. J., \& Rudd, N. A. (1994). Linkages between attitudes toward gender roles, body satisfaction, self-esteem and appearance-management behaviors in women. Family and Consumer Sciences Research Journal, 2(3), 94-117.

Lennon, S. J., Rudd, N. A., Sloan, B., \& Kim, J. S. (1999). Attitudes toward gender roles, selfesteem, and body image: Application of a model. Clothing and Textiles Research Journal, 17(4), 191-202.

Lin, C.L. (2008). Sexual Issues: The Analysis of female role portrayal preferences in Taiwanese print ads. Journal of Business Ethics, 83(3), 409-418.

Lucas, R. E., Diener, E., \& Suh, E. (1996). Discriminant validity of well-being measures. Journal of Personality and Social Psychology, 71, 616-628.

Lyubomirsky, S., Tkach, C., \& DiMatteo, M. R. (2006). What are the differences between happiness and self-esteem? Social Indicators Research, 78, 363-404.

Mahoney, E.R., \& Finch, M.D. (1976). The Dimensionality of Body-Cathexis. Journal of Psychology: Interdisciplinary and Applied, 92(2), 227-229.

Major, B., Testa, M., \& Bylsma, W. H. (1991). Responses to upward and downward social comparisons: The impact of esteem-relevance and perceived control. Social Comparison: Contemporary Theory and Research (pp. 237-260). Hillsdale, NJ: Erlbaum.

Malär, L., Krohmer, H., Hoyer, W. D., \& Nyffenegger, B. (2011). Emotional brand attachment and brand personality: The relative importance of the actual and the ideal self. Journal of Marketing, 75(4), 35-52. 
Malhotra, N. K. (1993). Marketing research: An applied orientation. Englewood Cliffs, NJ: Prentice-Hall.

Mander, J. (2014). Digital vs. traditional media consumption summary. Retrieved from http://insight.globalwebindex.net/hs-fs/hub/304927/file-1414878665pdf/Reports/GWI_Media_Consumption_Summary_Q3_2014.pdf

Mason, J.B., \& Mayer, M.L. (1970). The problem of the self-concept in store image studies. Journal of Marketing, 34(2), 67-69.

Maslow, A. H. (1954). Motivation and personality. New York, NY: Harper \& Row.

Mazur, A. (1986). US trends in feminine beauty and overadaption. Journal of Sex Research, 22, 281-303.

McCrae. R. R., \& Costa, P. T. Jr. (1990). Personality in adulthood. New York: Guilford.

McGuire, William J. (1985) Attitudes and Attitude changes. In Linzey, G., \& Aronson, E., (Eds.), Handbook of Social Psychology (Vol. 2), (pp. 233-346). NY: Random House.

Mead, G. H. (1934). Mind, self, and society. Chicago: University of Chicago Press.

Media Dynamics Incorporated (2014). Media Usage Trends. Retrieved from http://www.mediadynamicsinc.com/userfiles/files/adults_spend_almost_10_hours_per_d ay_with_media_note_150_ads.pdf

Mehrabian, A. (1971). Silent messages. Belmont, CA: Wadsworth.

Mendelson, B.K., Mendelson, M.J., \& White, D.R. (2001) Body-Esteem Scale for Adolescents and Adults, Journal of Personality Assessment, 76(1), 90-106. 
Mintel. (2011). Women's Sleepwear - US - December 2011. Retrieved from Mintel Oxygen database.

Mulyanegara, R.C. \& Tsarenko,Y. (2009). Predicting brand preferences: An examination of the predictive power of consumer personality and values in the Australian fashion market. Journal of Fashion Marketing and Management: An International Journal, 13(3), 358 371.

Myers P.N., \& Biocca, F.A. (1992). The elastic body image: The effect of television advertising and programming on body image distortions in young women, Journal of Communication 42, 108-33.

NewsRX LLC (2015). Aerie takes a stance \& leads fashion industry by supporting the national eating disorders association. Fitness \& Wellness Business Week, 20.

Nunnaly, J. (1978). Psychometric theory. New York: McGraw-Hill.

Odell, A. (2012, July 20). Career Confidential: The Photo Retoucher Who Usually Doesn't Have To Distort Bodies. Retrieved from http://www.buzzfeed.com/buzzfeedshift/careerconfidential-the-photo-retoucher-who-usual

Ohanian, R. (1990). Construction and validation of a scale to measure celebrity endorser's perceived expertise, trustworthiness, and attractiveness. Journal of Advertising, 19(3), 3952.

One Poll. (2013). Women Need Further Education Into Extent of Digital Manipulation of Models in Mags, New Look Survey Finds. Retrieved from http://www.prweb.com/releases/2013/11/prweb11361783.htm 
Orbach, S. (1993). Anorexia and adolescence. In M. Lawrence (Ed.) Fed up and hungry: women, oppression and food (pp. 74-85). London: The Women's Press.

Park, J., Nam, Y., Choi, K., Lee, Y., \& Lee, K. (2009). Apparel consumers' body type and their shopping characteristics. Journal of Fashion Marketing and Management, 3(13), 372393.

Pérez Tornero, J. M., \& Varis, T. (2010). Media literacy and new humanism. Moscow: UNESCO Institute for Information Technologies in Education. Retrieved January 28, 2015 from http://iite.unesco.org/pics/publications/en/files/3214678.pdf.

Piacentini, M., \& Mailer, G. (2004). Symbolic consumption in teenagers' clothing choices. Journal of Consumer Behavior, 3(3), 251-262.

Pidgeon, A. \& Harker, R. A. (2013). Body-focused Anxiety in Women: Associations with Internalization of the Thin-ideal, Dieting Frequency, Body Mass Index and Media Effects. Open Journal of Medical Psychology, 2, 17-24.

Preference [Def. 1]. (n.d.). Oxford Dictionaries. Oxford University Press. Retrieved from http://www.oxforddictionaries.com/us/definition/american_english/preference

Posavac, H. D., Posavac, S. S., \& Posavac, E. J. (1998). Exposure to media images of female attractiveness and concern with body weight among young women. Sex Roles, 38(3-4), $187-201$.

Poulter, S. (2011, July 27). Because Julia Roberts wasn't beautiful enough: Star among celebs whose ads were banned over airbrushing. Retrieved from 
http://www.dailymail.co.uk/femail/article-2019162/Julia-Roberts-Christy-Turlington-LOreal-adverts-banned-airbrushing.html\#ixzz1TJuuDmVB

Powell, A.D., \& Kahn, A.S. (1995). Racial differences in women's desires to be thin. International Journal of Eating Disorders, 17, 191-195.

Pyle, R.L., Neuman, P.A. Halvorson, P.A. \& Mitchell, J.E. (1990). An ongoing cross-sectional study of the prevalence eating disorders in freshman college students. International Journal of Eating Disorders, 10(6), 667-677.

Pyszczynski, T., Greenberg, J., Solomon, S., Arndt, J., \& Schimel, J. (2004). Why do people need self-esteem? A theoretical and empirical review. Psychological Bulletin, 130(3), $435-468$.

Rawls, John. 1999. A Theory of Justice. Cambridge, MA: Harvard University Press.

Reaves, S. (2005). A survey of reactions to photographic manipulation. In Smith, K, Moriarty, S., Barbatsis, G, Kenney, K. (Ed.), Handbook of Visual Communication: Theory, Methods, and Media, (p. Part X, Section II). Lawrence Erlbaum Associates: Mahwah, NJ.

Reaves, S. (2011). Rethinking visual ethics: Evolution, social comparison and the media's monobody in the global rise of eating disorders. Journal of Mass Media Ethics, 26(2), 114-134.

Reaves, S., Hitchon, J. B., Park, S., \& Yun, G. W. (2004a). If looks could kill: Digital manipulation of fashion models. Journal of Mass Media Ethics, 19(1), 56-71. 
Reaves, S., Hitchon, J. B., Park, S., \& Yun, G. W. (2004b). You can never be too thin" - or can you?: A pilot study on the effects of digital manipulation of fashion models" body size, leg length and skin color. Race, Gender \& Class, 11(2), 140-155.

Rhee, J., \& Johnson, K. K.P. (2012). Predicting adolescents' apparel brand preferences. Journal of Product \& Brand Management, 21(4), 255-264.

Richins, M.L. (1991). Social Comparison and the Idealized Images of Advertising, Journal of Consumer Research, 18, 71-83.

Rideout, V. J., Foehr, U. G., \& Roberts, D. F. (2010). Generation M2: Media in the lives of 8- to 18 year olds. Retrieved from http://www.kff.org/entmedia/upload/8010.pdf.

Roberts, K. (2005). Lovemarks: The future beyond brands (2nd ed.). New York: Powerhouse Books.

Rosenberg, M. (1965). Society and the adolescent self-image. Princeton, NJ: Princeton University Press.

Secord, P. F., \& Jourard, S. M. (1953). The appraisal of body-cathexis: Body-cathexis and the self. Journal of Consulting Psychology, 17(5), 343-347.

Seock, Y., \& Merritt, L. R. (2013). Influence of body mass index, perceived media pressure, and peer Criticism/Teasing on adolescent girls' body Satisfaction/Dissatisfaction and clothing-related behaviors. Clothing and Textiles Research Journal, 31(4), 244-258.

Sheldon, P. (2010). Pressure To Be Perfect: Influences on College Students' Body Esteem. Southern Communication Journal, 75(3), 277-298.Shin, E., \& Baytar, F. (2014). Apparel 
fit and size concerns and intentions to use virtual try-on: Impacts of body satisfaction and images of models' bodies. Clothing and Textiles Research Journal, 32(1), 20-33.

Sirgy, M. J. (1986). Self-Congruity: Toward a Theory of Personality and Cybernetics. New York: Praeger Publishers.

Sirgy, J.M. and Johar, J.S. (1999). Toward an Integrated Model of Self-Congruity and Functional Congruity, in (Ed.), European Advances in Consumer Research Volume 4, (pp. 252-256). Association for Consumer Research.

Sirgy, M. J., Grewal, D., Mangleburg, T. F., Park, J., Chon, K., Claiborne, C. B., \& Berkman, H. (1997). Assessing the predictive validity of two methods of measuring self-image congruence. Journal of the Academy of Marketing Science, 25(3), 229-241.

Sohn, M., \& Bye, E. (2015). Pregnancy and Body Image: Analysis of Clothing Functions of Maternity Wear. Clothing and Textiles Research Journal, 33(1), 64-78.

Stephen, I.D., \& Perera, A. (2014). Judging the Difference between Attractiveness and Health: Does Exposure to Model Images Influence the Judgments Made by Men and Women? PLoS ONE, E86302-E86302. Retrieved from http://www.plosone.org/article/authors/info:doi/10.1371/journal.pone.0086302

Sung, Y., \& Choi, S.M. (2010), The influence of self-construal on self-brand congruity in the United States and Korea. Journal of Cross-cultural Psychology, 10, 1-16.

Thompson, J., \& Heinberg, L. (1999). The Media's Influence on Body Image Disturbance and Eating Disorders: We've Reviled Them, Now Can We Rehabilitate Them? Journal of Social Issues, 55, 339-353. 
Tirlea, L., Truby, H., \& Haines, T.P. (2013). Investigation of the effectiveness of the "Girls on the Go!" program for building self-esteem in young women: trial protocol. SpringerPlus, 2,683 .

Trampe, D., Stapel, D. A., \& Siero, F. W. (2007). On models and vases: Body dissatisfaction and proneness to social comparison effects. Journal of Personality and Social Psychology, 92(1), 106-118.

Tsai, W. S. (2013). There are no ugly women, only lazy ones": Taiwanese women's social comparison with mediated beauty images. Advertising \& Society Review 13(4), Advertising Educational Foundation. Retrieved October 29, 2014, from Project MUSE database.

Voojis, M. W., \& Van der Voort, T.H.A. (1993). Learning about television violence: The impact of a critical viewing curriculum on children's attitudinal judgments of crime series. Journal of Research and Development in Education 26(3): 133-142.

Wade, T. D., Davidson, S., \& O'Dea, J. A. (2003). A preliminary controlled evaluation of a school-based media literacy program and self-esteem program for reducing eating disorder risk factors. International Journal of Eating Disorders, 33(4), 371.

Wasilenko, K. A., Kulik, J. A., \& Wanic, R. A. (2007). Effects of social comparisons with peers on women's body image. International Journal of Eating Disorders, 40, 740-745.

Wasylkiw, L., Emms, A.A., Meuse, R., \& Poirier, K.F. (2009). Are all models created equal? A content analysis of women in advertisements of fitness versus fashion magazines, Body Image, 6(2), 137-140. 
Wertime, K., \& Fenwick, I. (2008). DigiMarketing: The New Imperative. In DigiMarketing: The essential guide to new media \& digital marketing (p. 30). Singapore: John Wiley \& Sons (Asia).

Wills, T. A. (1981). Downward comparison principles in social psychology. Psychological Bulletin, 90(2), 245-271.

Wilson, E. (2009, May 28). Smile and Say 'No Photoshop'. The New York Times, p. E1.

Yu, U. (2014). Deconstructing college students' perceptions of thin-idealized versus nonidealized media images on body dissatisfaction and advertising effectiveness. Clothing and Textiles Research Journal, 32(3), 153-169.

Yu, U.-J. \& M. L. Damhorst (2015). Body satisfaction as antecedent to virtual product experience in an online apparel shopping context. Clothing and Textiles Research Journal, 33(1), 3-18.

Zajonc, R.B. and Markus, H. (1982), Affective and cognitive factors in preferences. Journal of Consumer Research, 9, 123. 


\section{APPENDIX A}

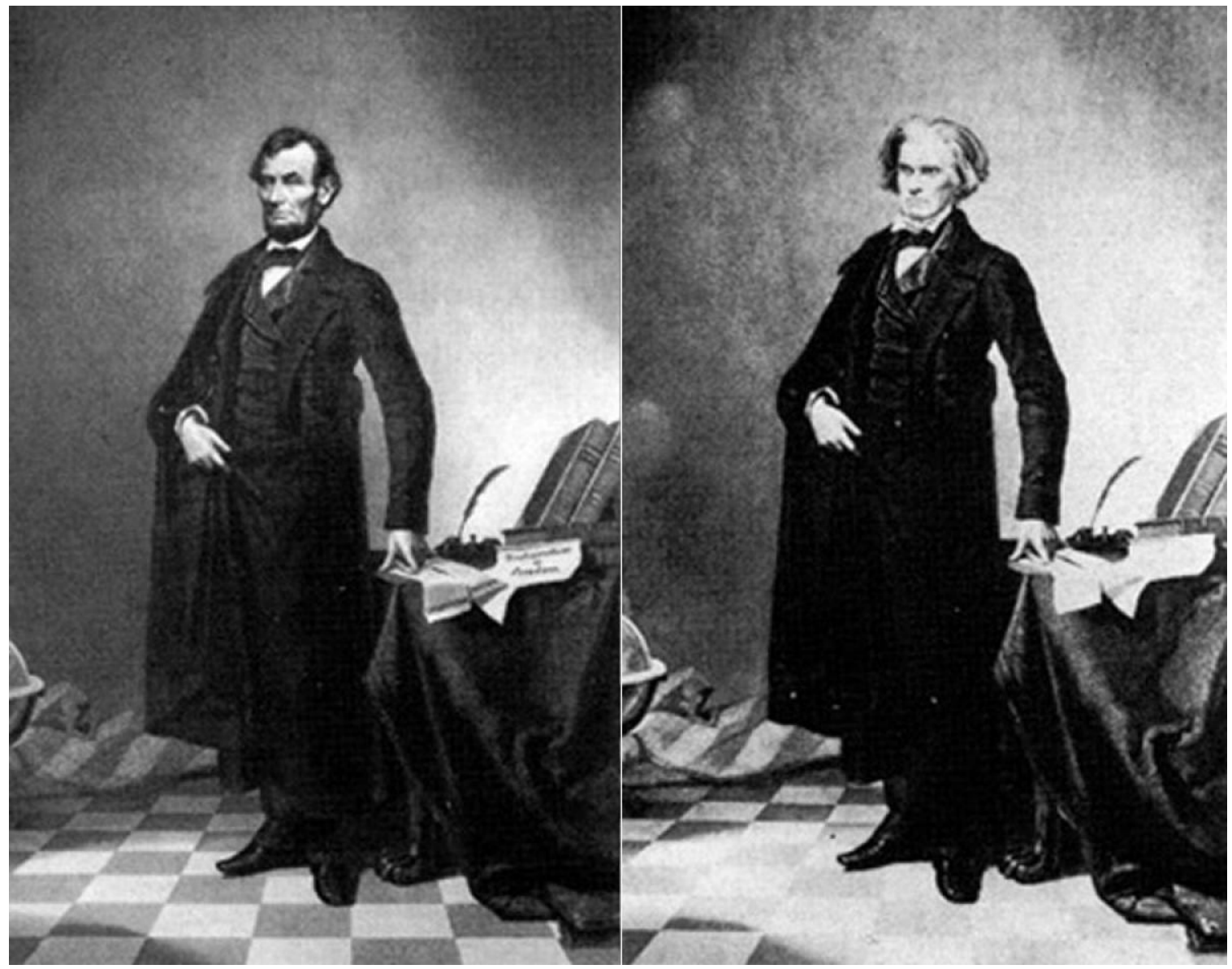

Figure 1.1. Abraham Lincoln

Abraham Lincoln Portrait [Online image]. (1860). Retrieved November 11, 2014 from

http://www.dailymail.co.uk/news/article-2107109/Iconic-Abraham-Lincoln-portraitrevealed-TWO-pictures-stitched-together.html 


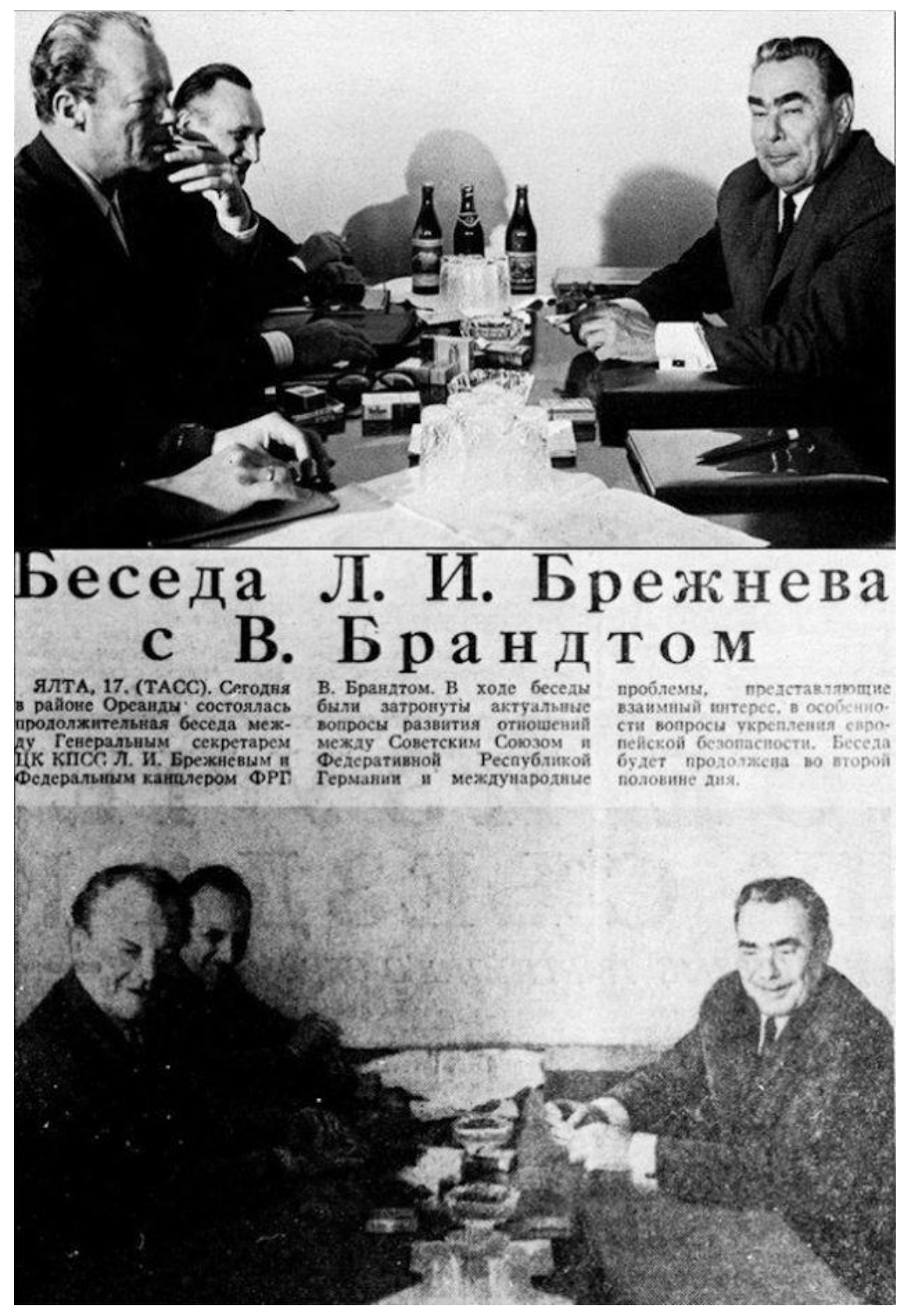

Figure 1.2. German Chancellor

German Chancellor Meeting [Online image]. (1971). Retrieved November 11, 2014 from http://www.fourandsix.com/photo-tampering-history/?currentPage=2 


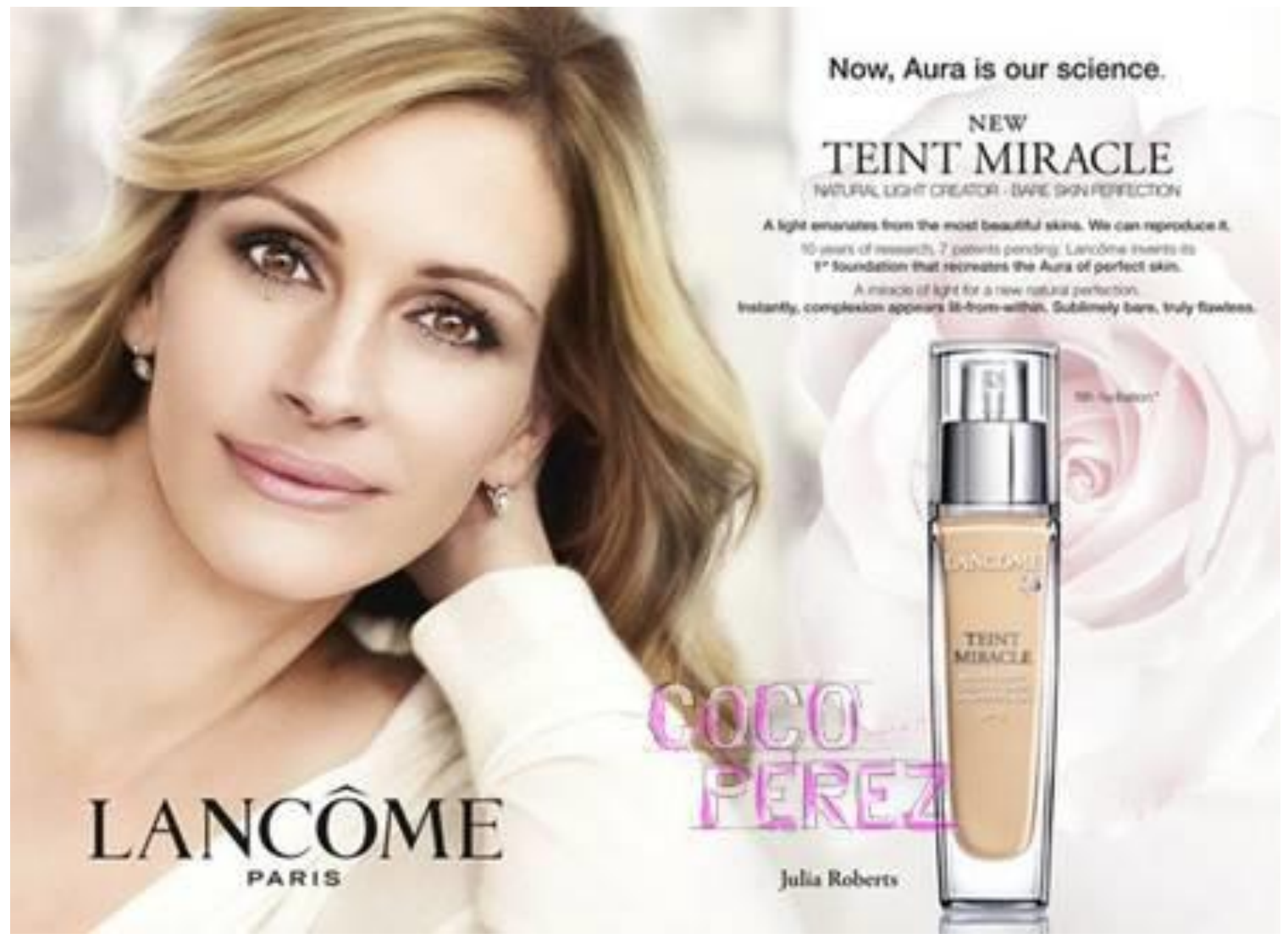

Figure 1.3. Julia Roberts in Lancôme advertisement

Lancôme (2011). [Advertisement for Lancôme]. Retrieved from

http://www.dailymail.co.uk/femail/article-2019162/Julia-Roberts-Christy-Turlington-L-

Oreal-adverts-banned-airbrushing.html\#ixzz1TJuuDmVB 


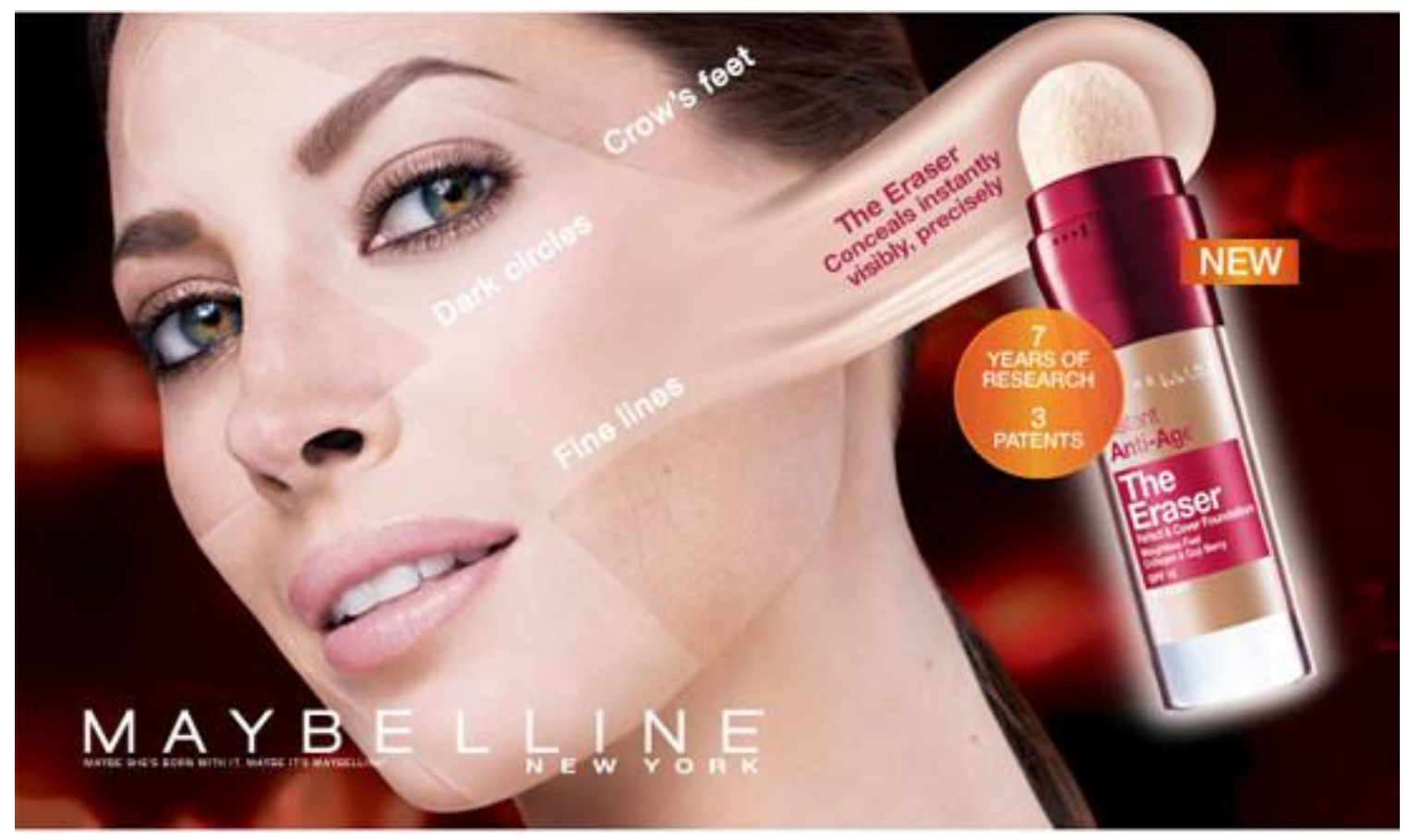

Figure 1.4. Christy Turlington in Maybelline advertisement

Maybelline (2011). [Advertisement for Maybelline]. Retrieved from

http://www.dailymail.co.uk/femail/article-2019162/Julia-Roberts-Christy-Turlington-LOreal-adverts-banned-airbrushing.html\#ixzz1TJuuDmVB 


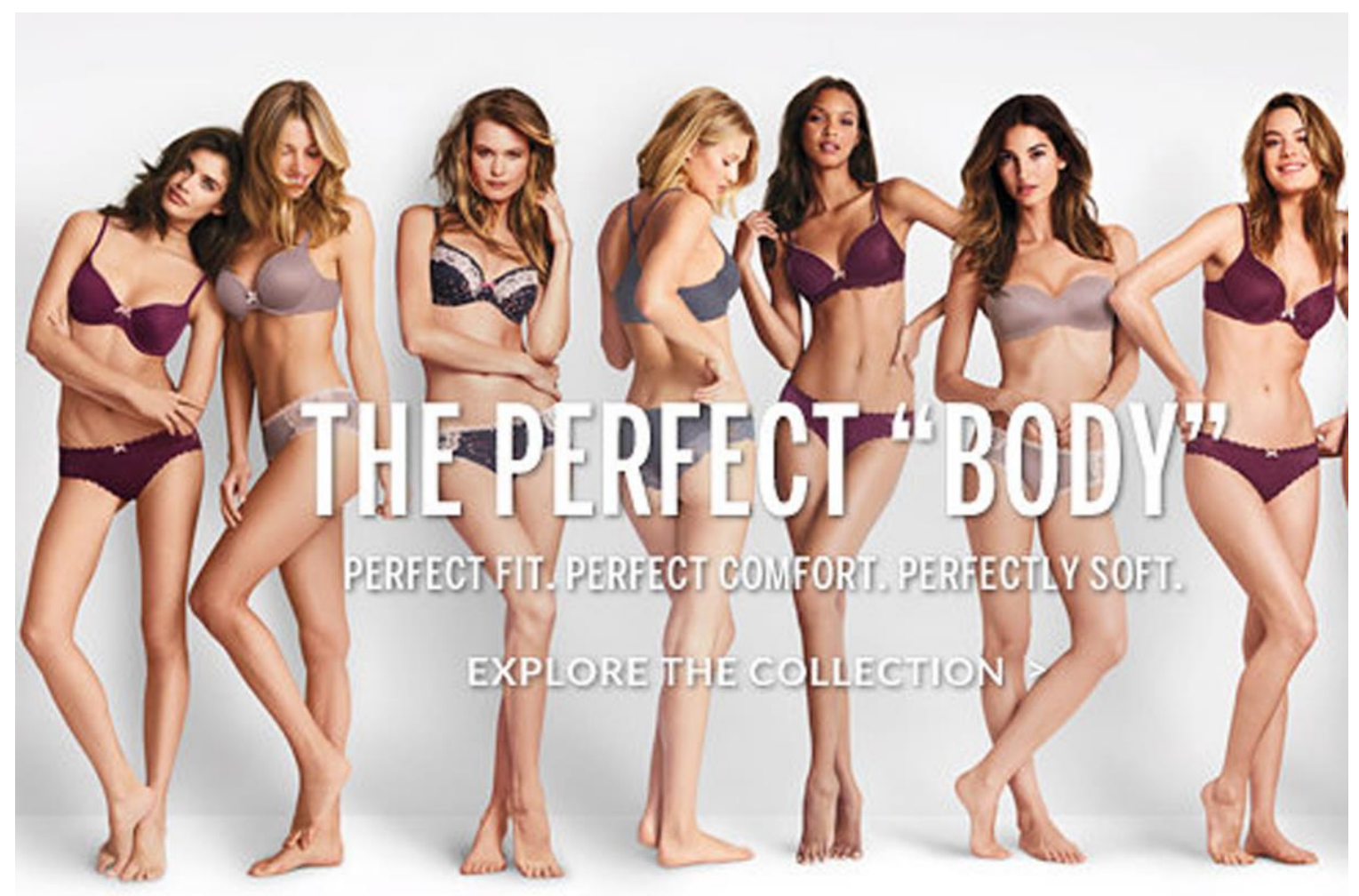

Figure 1.5. Perfect Body advertisement by Victoria's Secret

Victoria's Secret. (2014, November 6). [Advertisement for Victoria's Secret]. Retrieved from http://www.huffingtonpost.com/2014/11/06/victorias-secret-perfect-bodycampaign_n_6115728.html 


\section{APPENDIX B}

Online Survey Questionnaire

Indicate how much you agree with the following statements $(1=$ strongly disagree, $6=$ strongly agree)

1. I am familiar with the brand Victoria's Secret

2. I am familiar with the brand Aerie

Use the image below to answer the following questions.

Aerie Non-Photoshopped Advertisement

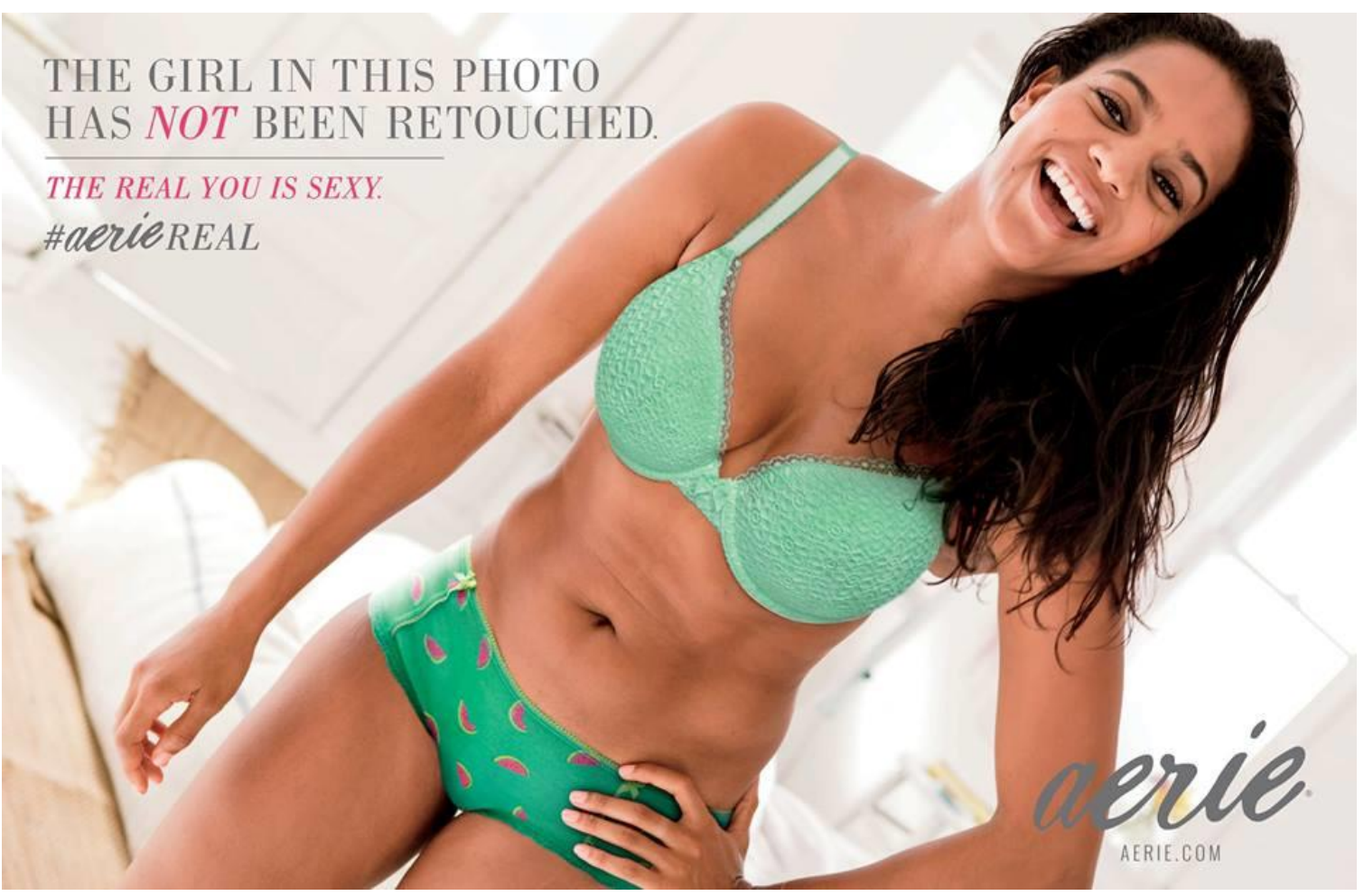

https://www.facebook.com/Aerie/photos_stream

Regarding the image above: Indicate how much you agree with the following statements ranging from strongly disagree to strongly agree. $(1=$ strongly disagree, $6=$ strongly agree $)$

3. Looking at this image makes me feel happy. 
4. The model shown in this online fashion advertisement is attractive.

5. I don't like looking at this online fashion advertisement.

Use the image below to answer the following questions.

Victoria's Secret Photoshopped Advertisement

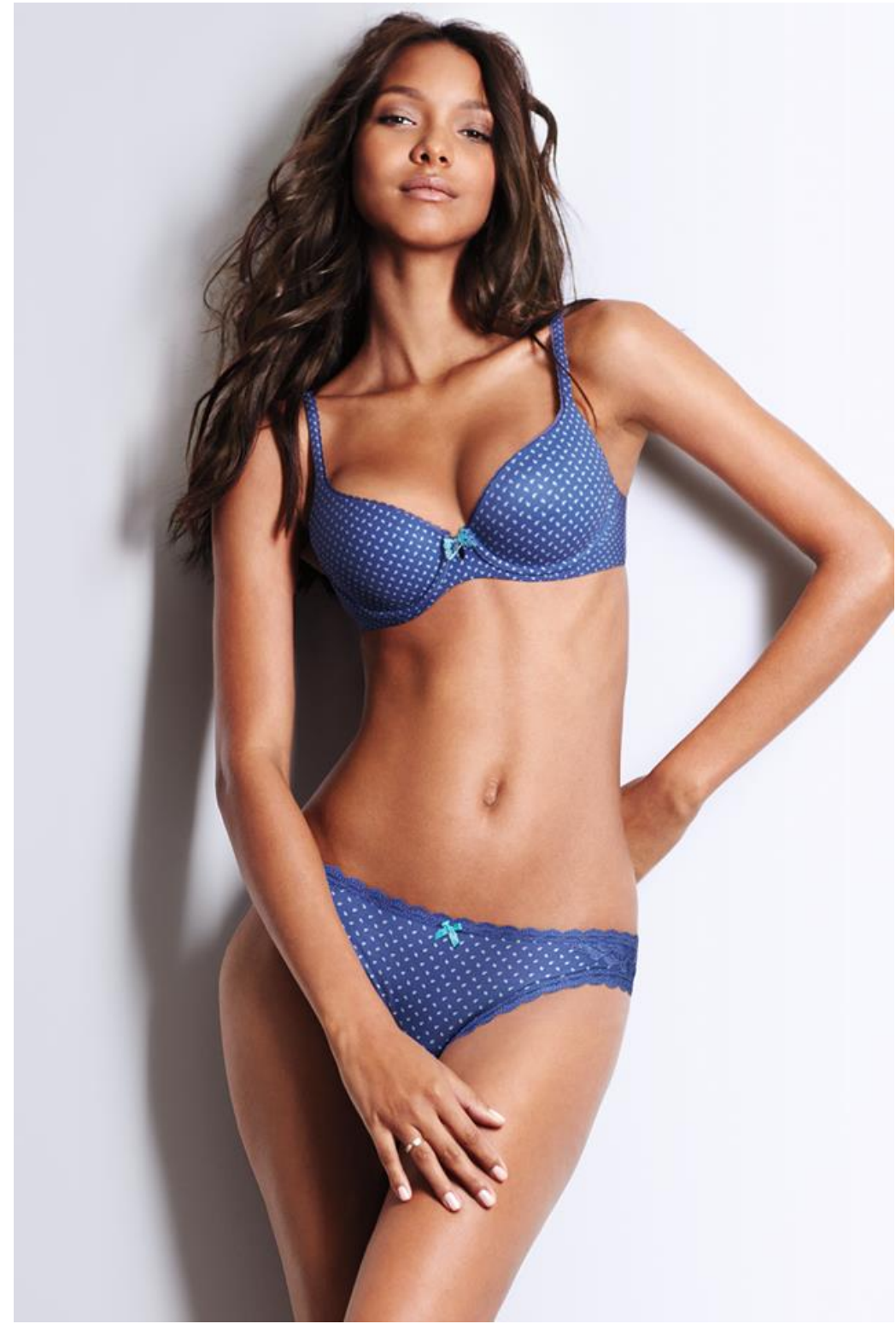

https://www.facebook.com/victoriassecret/photos_stream

Regarding the image above: Indicate how much you agree with the following statements ranging from strongly disagree to strongly agree. $(1=$ strongly disagree, $6=$ strongly agree $)$

6. Looking at this image makes me feel happy.

6. The model shown in this online fashion advertisement is attractive.

7. I don't like looking at this online fashion advertisement. 
Use the image below to answer the following questions.

Aerie Non-Photoshopped Advertisement

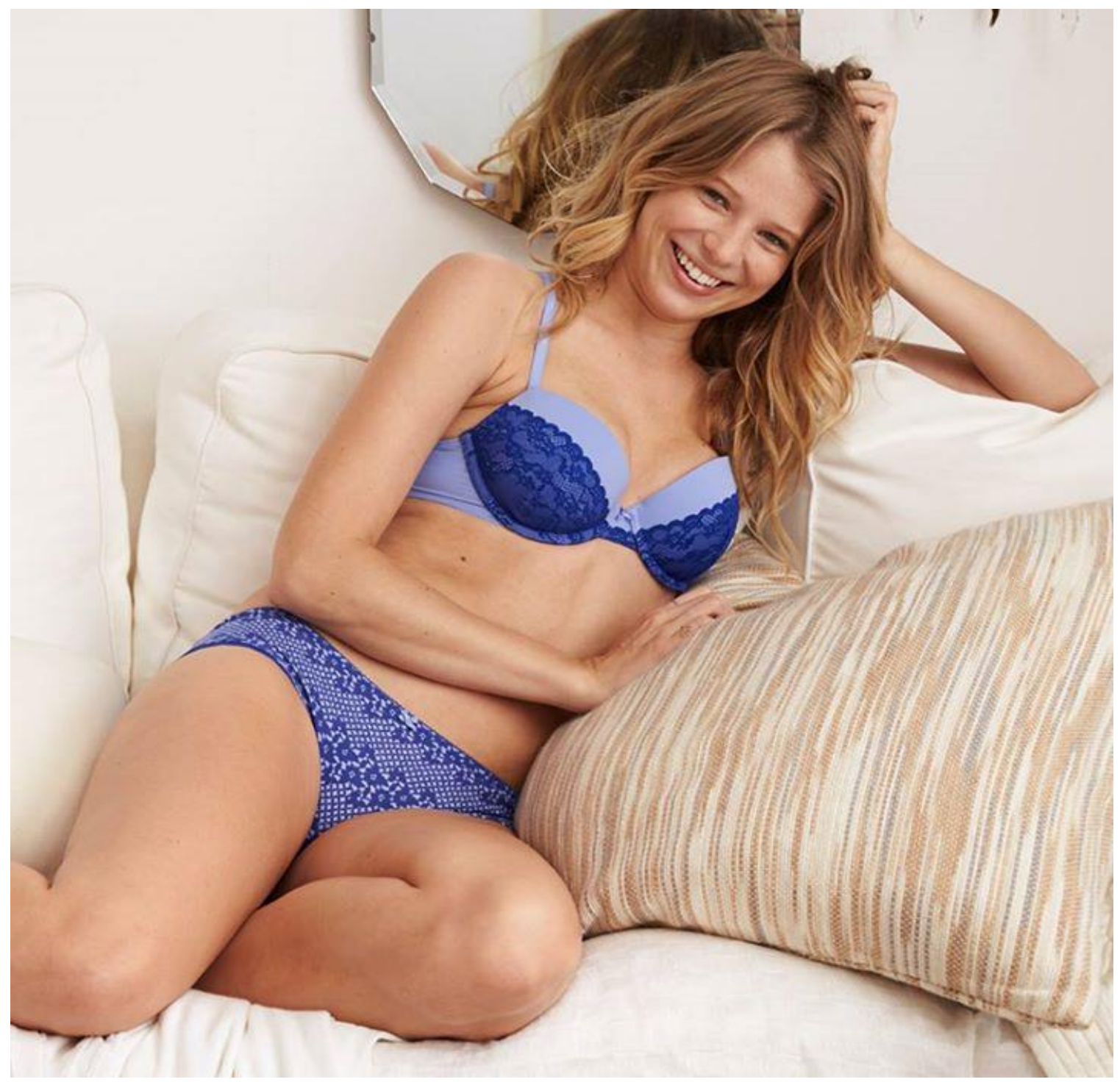

https://www.facebook.com/Aerie/photos_stream

Regarding the image above: Indicate how much you agree with the following statements ranging from strongly disagree to strongly agree. $(1=$ strongly disagree, $6=$ strongly agree $)$

9. Looking at this image makes me feel happy.

8. The model shown in this online fashion advertisement is attractive.

9. I don't like looking at this online fashion advertisement. 
Use the image below to answer the following questions.

Victoria's Secret Photoshopped Advertisement

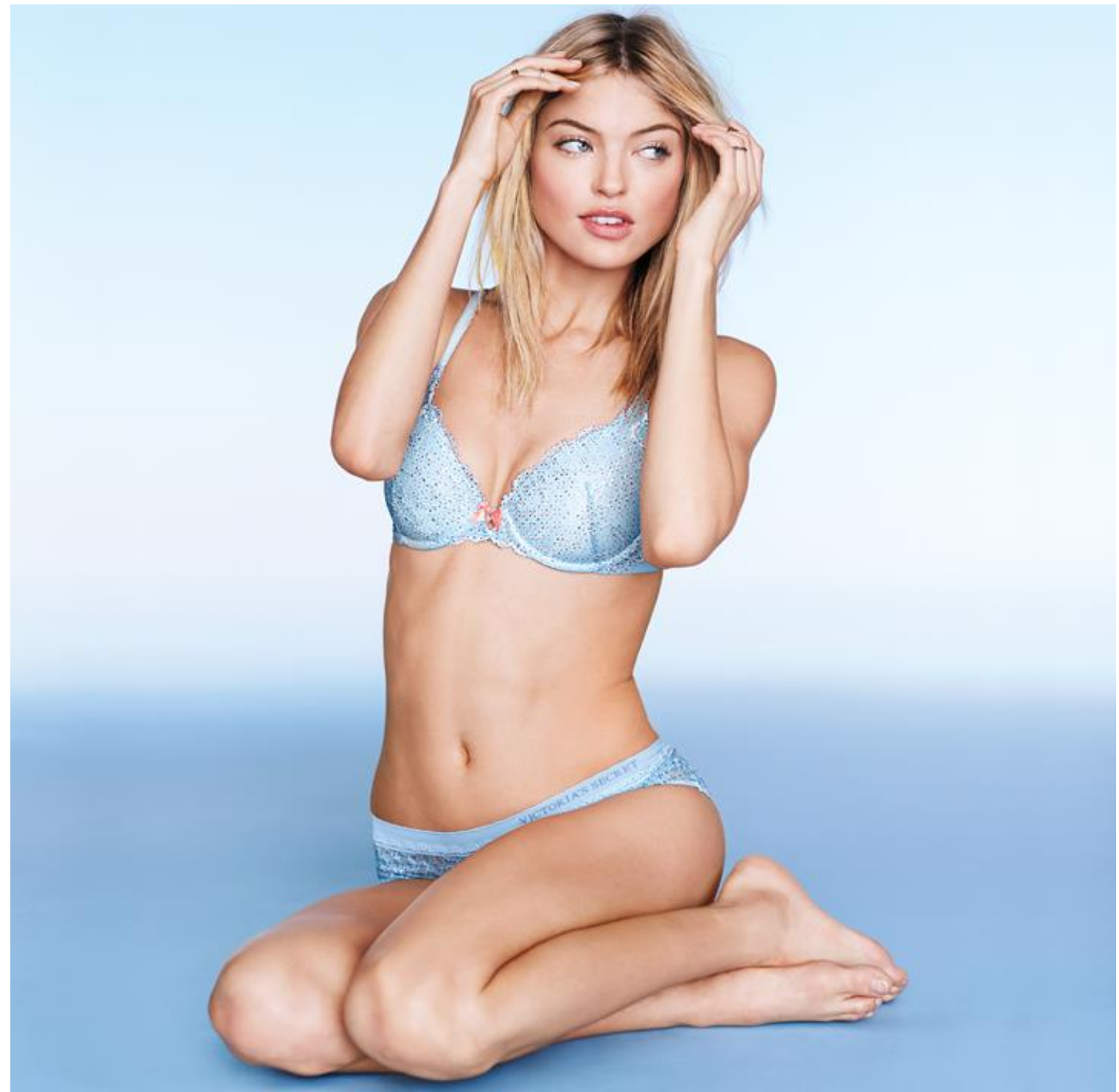

https://www.facebook.com/victoriassecret/photos_stream

Regarding the image above: Indicate how much you agree with the following statements ranging from strongly disagree to strongly agree. $(1=$ strongly disagree, $6=$ strongly agree $)$

12. Looking at this image makes me feel happy.

11. The model shown in this online fashion advertisement is attractive.

12. I don't like looking at this online fashion advertisement. 
Regarding Aerie: Indicate how much you agree with the following statements ranging from strongly disagree to strongly agree. $(1=$ strongly disagree, $6=$ strongly agree $)$

15. I approve of Aerie's performance

14. Aerie leads fashion trend season to season

15. Aerie is honest to me

16. I respect Aerie

17. Aerie has a beautiful color scheme

18. The design of Aerie's ads is really well done

19. Aerie captures the times

20. Aerie comes to mind immediately when I want to purchase a fashion product

Regarding Victoria's Secret: Indicate how much you agree with the following statements ranging from strongly disagree to strongly agree. $(1=$ strongly disagree, $6=$ strongly agree).

21. I approve of Victoria's Secret performance

22. Victoria's Secret leads fashion trend season to season

23. Victoria's Secret is honest to me

24. I respect Victoria's Secret

25. Victoria's Secret has a beautiful color scheme

26. The design of Victoria's Secret ads is really well done

27. Victoria's Secret captures the times

28. Victoria's Secret comes to mind immediately when I want to purchase a fashion product

Regarding Aerie: Indicate how much you agree with the following statements ranging from strongly disagree to strongly agree. $(1=$ strongly disagree, $6=$ strongly agree $)$.

29. I would be inclined to buy Aerie over Victoria's Secret.

30. Aerie is my preferred brand over Victoria's Secret.

31. I would use Aerie more than I would use Victoria's Secret.

32. I like Aerie better than Victoria's Secret.

Regarding Victoria's Secret: Indicate how much you agree with the following statements ranging from strongly disagree to strongly agree. $(1=$ strongly disagree, $6=$ strongly agree).

33. I would be inclined to buy Victoria's Secret over Aerie.

34. Victoria's Secret is my preferred brand over Aerie.

35. I would use Victoria's Secret more than I would use Aerie.

36. I like Victoria's Secret better than Aerie.

Indicate how much you agree with the following statements about the brand Victoria's Secret and yourself. $(1=$ strongly disagree, $6=$ strongly agree $)$

37. Wearing Victoria's Secret underwear reflects who I am

38. Wearing Victoria's Secret underwear is consistent with how I see myself 
Indicate how much you agree with the following statements about the brand Aerie and yourself. $(1=$ strongly disagree, $6=$ strongly agree $)$

39. Wearing Aerie underwear is consistent with how I see myself

40. Wearing Aerie underwear reflects who I am

The following questions are to understand your perceptions of your body.

Indicate how much you are satisfied with the following physical features ranging from very dissatisfied to very satisfied $(1=$ very dissatisfied, $6=$ very satisfied $)$

41. Facial features

42. Complexion

43. Hair

44. Hips

45. Thighs

46. Buttocks

47. Legs

48. Waist

49. Stomach or abdomen

50. Bust or breasts

51. Shoulders

52. Arms

53. Muscle tone

54. Weight

55. Height

56. Overall appearance

To understand your perceptions on appearance, indicate how much you agree with the following statements. $(1=$ strongly disagree, $6=$ strongly agree $)$

57. I'm looking as nice as I'd like to.

58. I think I have a good body.

59. I worry about the way I look.

60. My looks help me get dates.

61. My weight makes me unhappy.

62. Weighing myself depresses me.

63. I feel ashamed of how I look.

64. I feel I weigh the right amount for my height.

65. I'm pretty happy about the way I look.

66. I'm as nice looking as most people.

67. My looks upset me.

68. People my own age like my looks. 
69. I wish I looked like someone else.

70. I really like what I weigh.

71. I wish I looked better.

72. I am satisfied with my weight.

73. There are lots of things I'd change about my looks if I could.

74. I like what I see when I look in the mirror.

75. I think my appearance would help me get a job.

76. I am preoccupied with trying to change my body weight.

77. I'm proud of my body.

78. Other people consider me good looking.

79. I like what I look like in pictures.

The following questions are to understand your perceptions on your self.

Indicate how much you agree with the following statements ranging from strongly disagree to strongly agree. $(1=$ strongly disagree, $6=$ strongly agree $)$

80. I feel that I have a number of good qualities.

81. I feel that I am a person of worth, at least on an equal plane with others.

82. All in all, I am inclined to feel that I am a failure.

83. I am able to do things as well as most other people.

84. I feel I do not have much to be proud of.

85. I take a positive attitude toward myself.

86. On the whole, I am satisfied with myself.

87. I wish I could have more respect for myself.

88. I certainly feel useless at times.

89. At times I think I am no good at all.

To understand your perceptions of the media, indicate how much you agree with the following statements.

Indicate how much you agree with the following statements ranging from strongly disagree to strongly agree. $(1=$ strongly disagree, $6=$ strongly agree $)$

90. Computer software is commonly used to alter the images of women in online fashion advertisements

91. Computer software is used frequently to alter the images of women in online fashion advertisements

92. The use of computer software to alter the images of women in online fashion advertisements is a widespread practice 
Use the image below to answer the following questions

Aerie Non-Photoshopped Advertisement

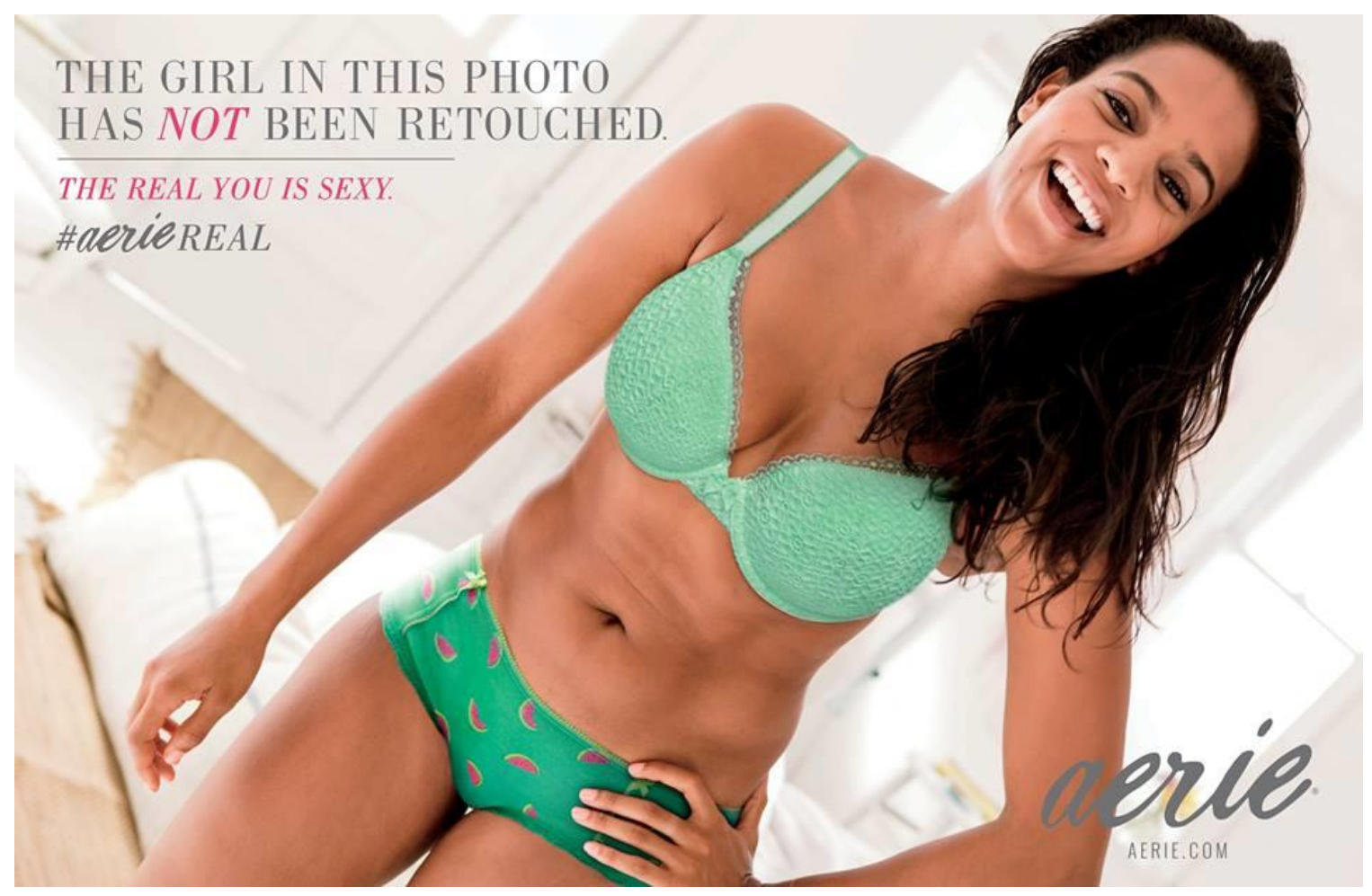

https://www.facebook.com/Aerie/photos_stream

Regarding the image above: Indicate how much you agree with the following statements ranging from strongly disagree to strongly agree. $(1=$ strongly disagree, $6=$ strongly agree $)$

95. The photo of the model in this image was airbrushed or altered on a computer.

94. This online fashion advertisement looks like it was created by a professional photographer, graphic designer, or photo retoucher.

95. A photo of the model shown here was taken for the online fashion advertisement and used exactly as it was taken.

96. It's not possible for a real woman to look like the model shown in this fashion advertisement. 
Use the image below to answer the following questions.

Victoria's Secret Photoshopped Advertisement

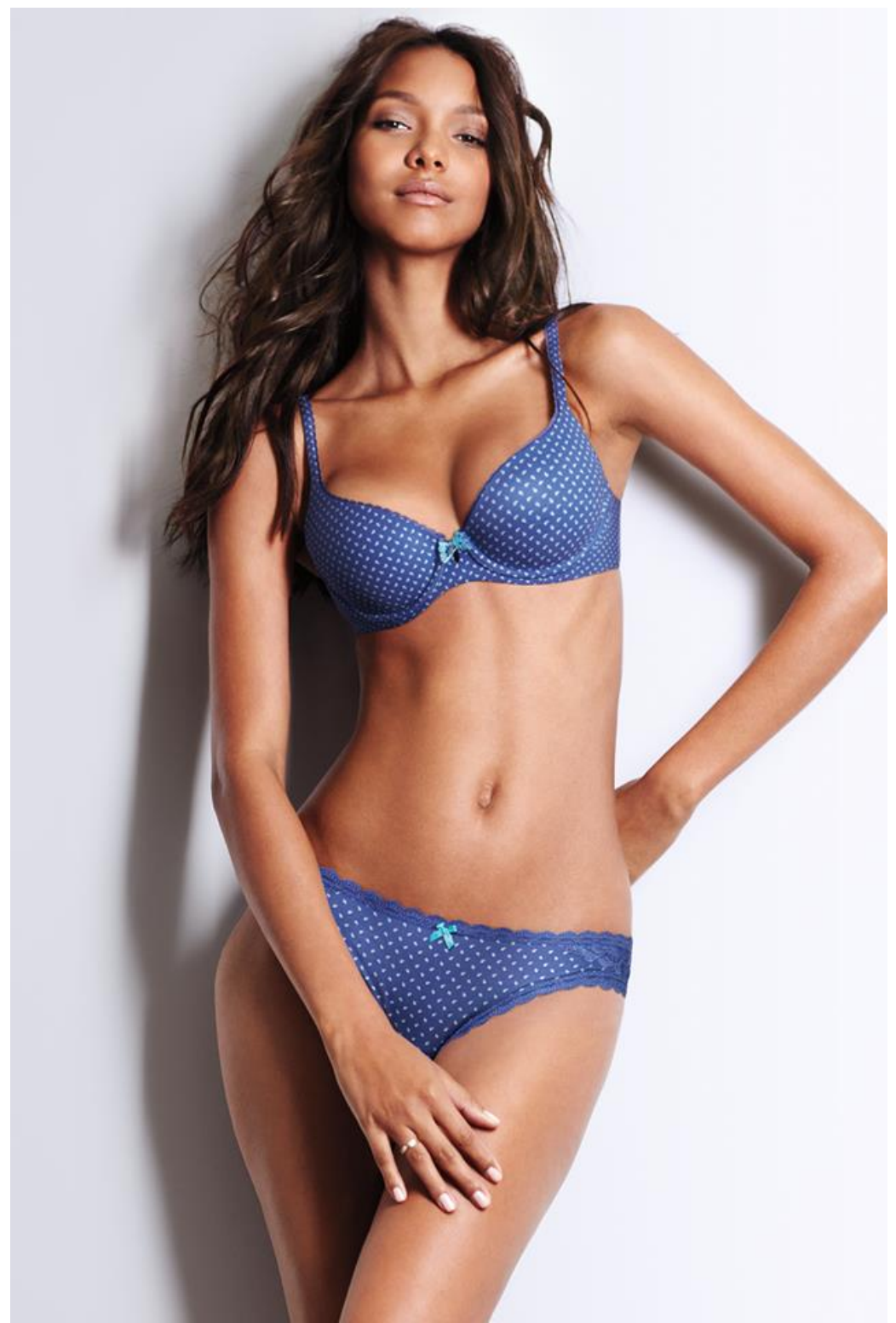

https://www.facebook.com/victoriassecret/photos_stream

Regarding the image above: Indicate how much you agree with the following statements ranging from strongly disagree to strongly agree. $(1=$ strongly disagree, $6=$ strongly agree $)$

99. The photo of the model in this image was airbrushed or altered on a computer.

98. This online fashion advertisement looks like it was created by a professional photographer, graphic designer, or photo retoucher.

99. A photo of the model shown here was taken for the online fashion advertisement and used exactly as it was taken. 
100. It's not possible for a real woman to look like the model shown in this fashion advertisement.

Use the image below to answer the following questions.

Aerie Non-Photoshopped Advertisement

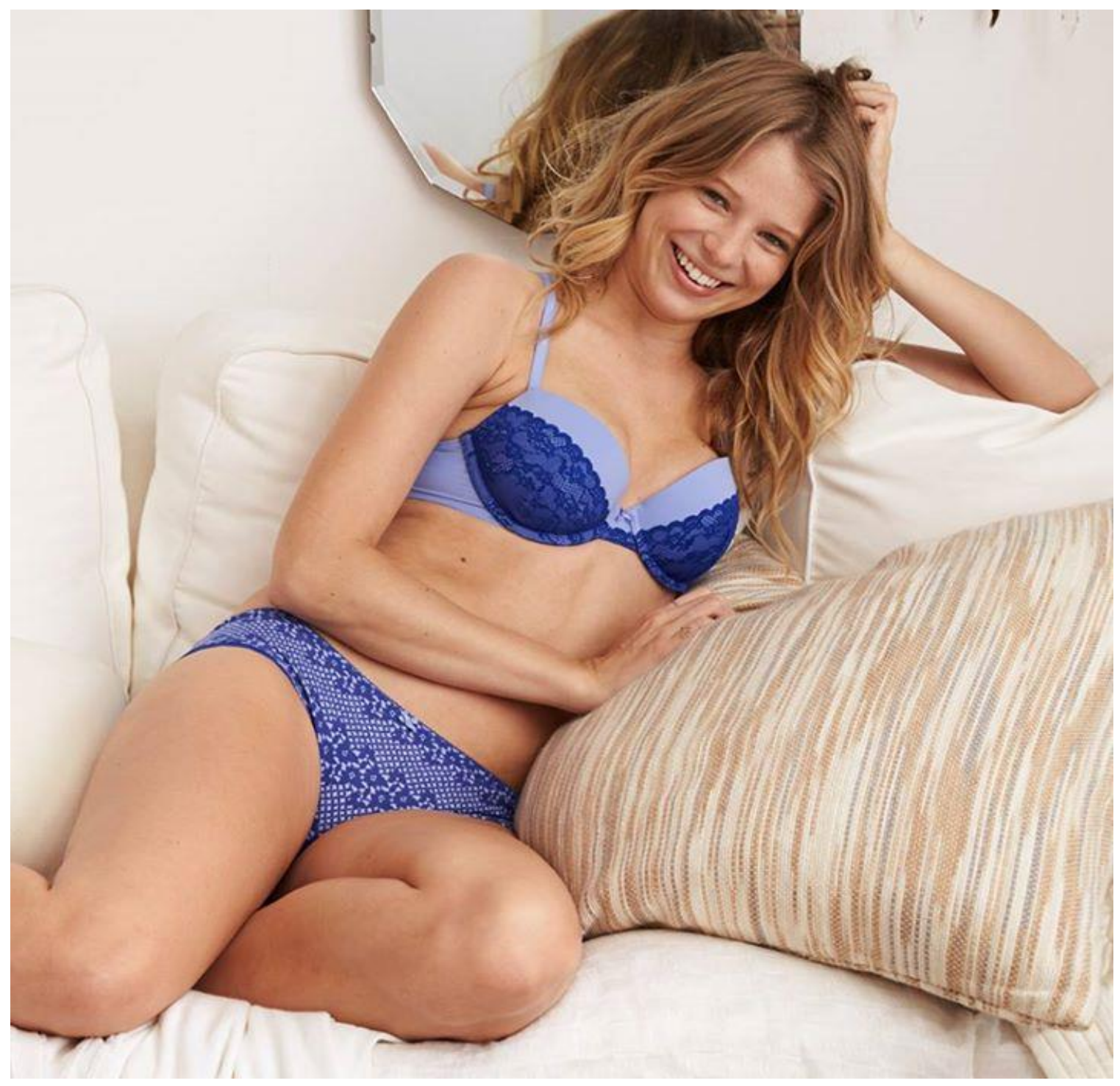

https://www.facebook.com/Aerie/photos_stream

Regarding the image above: Indicate how much you agree with the following statements ranging from strongly disagree to strongly agree. $(1=$ strongly disagree, $6=$ strongly agree $)$

101. The photo of the model in this image was airbrushed or altered on a computer.

102. This online fashion advertisement looks like it was created by a professional photographer, graphic designer, or photo retoucher. 
103. A photo of the model shown here was taken for the online fashion advertisement and used exactly as it was taken.

104. It's not possible for a real woman to look like the model shown in this fashion advertisement.

Use the image above to answer the following questions.

Victoria's Secret Photoshopped Advertisement

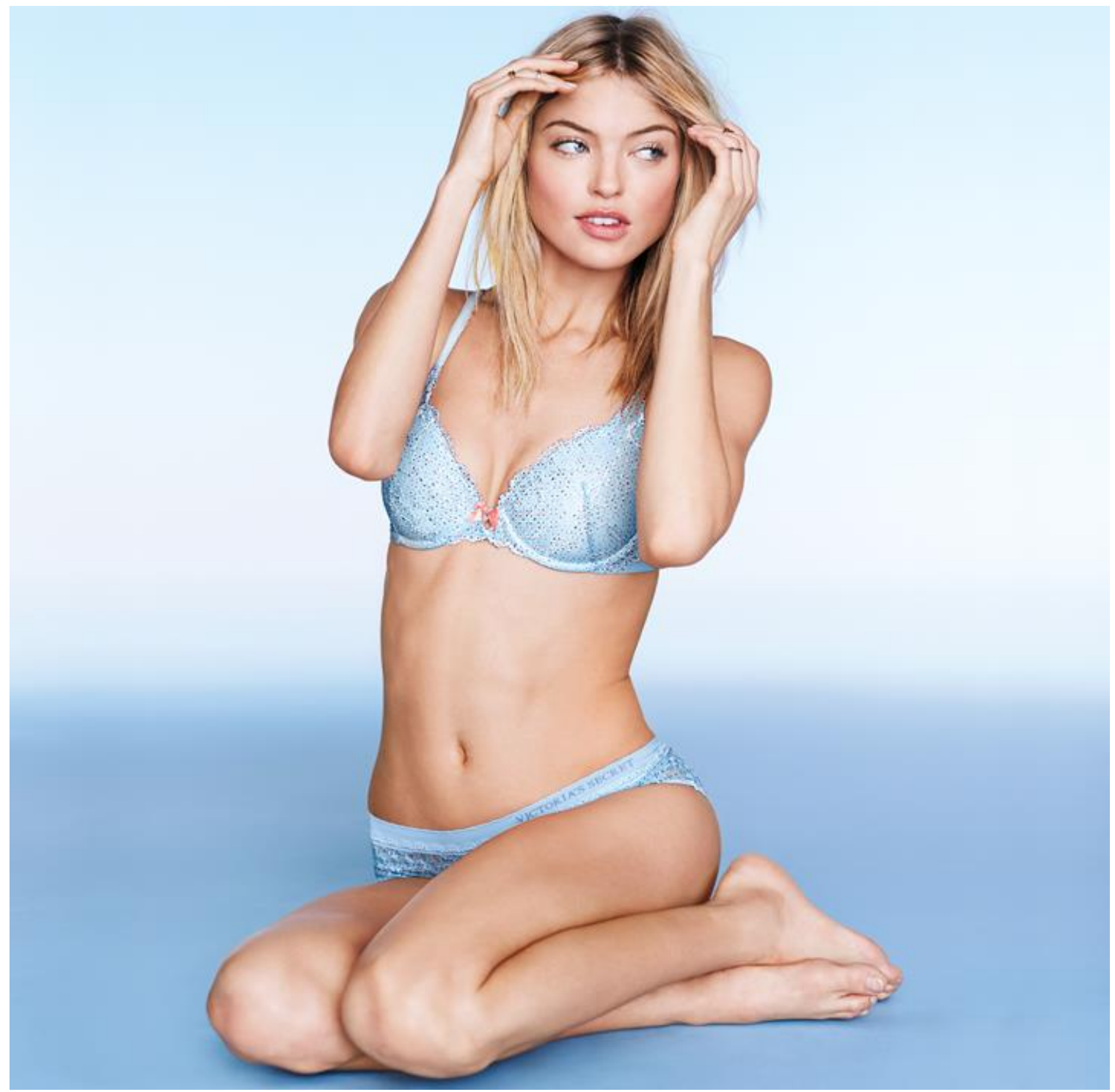

https://www.facebook.com/victoriassecret/photos_stream

Regarding the image above: Indicate how much you agree with the following statements ranging from strongly disagree to strongly agree. $(1=$ strongly disagree, 6 = strongly agree) 
105. The photo of the model in this image was airbrushed or altered on a computer.

106. This online fashion advertisement looks like it was created by a professional photographer, graphic designer, or photo retoucher.

107. A photo of the model shown here was taken for the online fashion advertisement and used exactly as it was taken.

108. It's not possible for a real woman to look like the model shown in this fashion advertisement.

109. What is your gender?
a. Male
b. Female
c. Prefer not to say

110. Indicate your age by selecting one of the following groups
a. $18-20$
b. $21-25$

111. What is your ethnicity?
a. White or European American
b. Black or African American
c. Hispanic or Latino
d. Asian
e. Native American or Alaskan Native
f. Native Hawaiian or Pacific Islander
g. A combination of one or more of these
h. None of these

112. What is your highest level of education?
a. High School
b. Some College
c. Associate's Degree
d. Bachelor's Degree
e. Doctoral Degree 